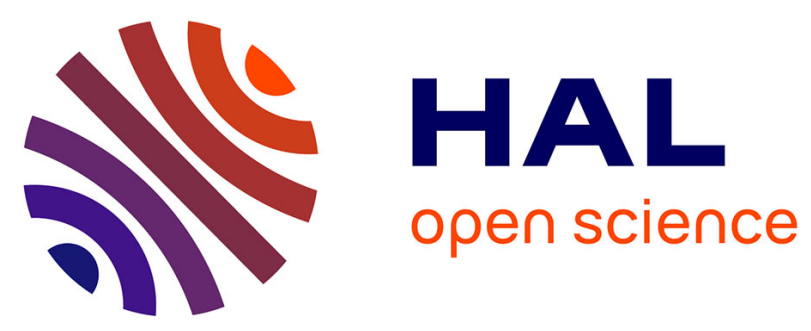

\title{
Joint Europa Mission (JEM) a multi-scale study of Europa to characterize its habitability and search for extant life
}

Michel Blanc, Nicolas André, Olga Prieto-Ballesteros, Javier Gómez-Elvira, Geraint D. Jones, Veerle Sterken, William Desprats, Leonid Gurvits, Krishan Khurana, Aljona Blöcker, et al.

\section{To cite this version:}

Michel Blanc, Nicolas André, Olga Prieto-Ballesteros, Javier Gómez-Elvira, Geraint D. Jones, et al.. Joint Europa Mission (JEM) a multi-scale study of Europa to characterize its habitability and search for extant life. Planetary and Space Science, 2020, 193, pp.104960. 10.1016/j.pss.2020.104960 . insu02883533

\section{HAL Id: insu-02883533}

https://hal-insu.archives-ouvertes.fr/insu-02883533

Submitted on 30 Jun 2020

HAL is a multi-disciplinary open access archive for the deposit and dissemination of scientific research documents, whether they are published or not. The documents may come from teaching and research institutions in France or abroad, or from public or private research centers.
L'archive ouverte pluridisciplinaire $\mathbf{H A L}$, est destinée au dépôt et à la diffusion de documents scientifiques de niveau recherche, publiés ou non, émanant des établissements d'enseignement et de recherche français ou étrangers, des laboratoires publics ou privés. 


\section{Journal Pre-proof}

Joint Europa Mission (JEM) a multi-scale study of Europa to characterize its habitability and search for extant life

Michel Blanc, Nicolas André, Olga Prieto-Ballesteros, Javier Gomez-Elvira, Geraint Jones, Veerle Sterken, William Desprats, Leonid I. Gurvits, Krishan Khurana, Aljona

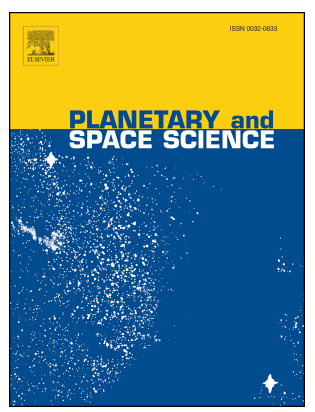
Blöcker, Renaud Broquet, Emma Bunce, Cyril Cavel, Gaël Choblet, Geoffrey Colins, Marcello Coradini, John Cooper, Dominic Dirkx, Philippe Garnier, David Gaudin, Paul Hartogh, Luciano less, Adrian Jäggi, Sascha Kempf, Norbert Krupp, Luisa Lara, Jérémie Lasue, Valéry Lainey, François Leblanc, Jean-Pierre Lebreton, Andrea Longobardo, Ralph Lorenz, Philippe Martins, Zita Martins, Adam Masters, David Mimoun, Ernesto Palumba, Pascal Regnier, Joachim Saur, Adriaan Schutte, Edward C. Sittler, Tilman Spohn, Katrin Stephan, Károly Szegő, Federico Tosi, Steve Vance, Roland Wagner, Tim Van Hoolst, Martin Volwerk, Frances Westall

PII: S0032-0633(19)30501-X

DOI: https://doi.org/10.1016/j.pss.2020.104960

Reference: $\quad$ PSS 104960

To appear in: Planetary and Space Science

Received Date: 1 December 2019

Revised Date: 15 April 2020

Accepted Date: 25 April 2020

Please cite this article as: Blanc, M., André, N., Prieto-Ballesteros, O., Gomez-Elvira, J., Jones, G., Sterken, V., Desprats, W., Gurvits, L.I., Khurana, K., Blöcker, A., Broquet, R., Bunce, E., Cavel, C., Choblet, Gaë., Colins, G., Coradini, M., Cooper, J., Dirkx, D., Garnier, P., Gaudin, D., Hartogh, P., less, L., Jäggi, A., Kempf, S., Krupp, N., Lara, L., Lasue, Jéé., Lainey, Valé., Leblanc, Franç., Lebreton, J.P., Longobardo, A., Lorenz, R., Martins, P., Martins, Z., Masters, A., Mimoun, D., Palumba, E., Regnier, P., Saur, J., Schutte, A., Sittler, E.C., Spohn, T., Stephan, K., Szegő, Ká., Tosi, F., Vance, S., Wagner, R., Van Hoolst, T., Volwerk, M., Westall, F., Joint Europa Mission (JEM) a multi-scale study of Europa to characterize its habitability and search for extant life, Planetary and Space Science (2020), doi: https:// doi.org/10.1016/j.pss.2020.104960. 
This is a PDF file of an article that has undergone enhancements after acceptance, such as the addition of a cover page and metadata, and formatting for readability, but it is not yet the definitive version of record. This version will undergo additional copyediting, typesetting and review before it is published in its final form, but we are providing this version to give early visibility of the article. Please note that, during the production process, errors may be discovered which could affect the content, and all legal disclaimers that apply to the journal pertain.

(C) 2020 Published by Elsevier Ltd. 


\section{Credit to authors}

The objective of the research described in this paper is to share with the planetary science community and mission designers a preliminary concept study for a joint USA-Europe mission to search for life. The overall coordination of this research was done by Michel Blanc, Olga Prieto-Ballesteros, Nicolas André and Javier Gomez-Elvira. The different authors all contributed to the elaborated contents on the basis of their specific expertise: scientific data analysis, modelling, instrument development, spacecraft architecture design, mission analysis, planetary protection, navigation, data downlink and radio astronomy. All coauthors equally contributed to the draft, which is the product of the collective expertise of the JEM team. 


\section{A multi-scale study of Europa to Characterize its Habitability}

\section{and Search for extant life}

4

Michel Blanc ${ }^{(1)}$, Nicolas André( ${ }^{(1)}$, Olga Prieto-Ballesteros ${ }^{(2)}$, Javier Gomez-Elvira ${ }^{(2)}$, Geraint Jones $^{(3)}$, Veerle Sterken ${ }^{(4,5)}$, William Desprats ${ }^{(1,6)}$, Leonid I. Gurvits ${ }^{(7,16,38)}$, Krishan Khurana ${ }^{(8)}$, Aljona Blöcker ${ }^{(9)}$, Renaud Broquet ${ }^{(10)}$, Emma Bunce ${ }^{(11)}$, Cyril Cavel ${ }^{(10)}$, Gaël Choblet ${ }^{(12)}$, Geoffrey Colins $^{(13)}$, Marcello Coradini ${ }^{(14)}$, John Cooper ${ }^{(15)}$, Dominic Dirkx ${ }^{(16)}$, Philippe Garnier ${ }^{(1)}$, David Gaudin $^{(6)}$, Paul Hartogh ${ }^{(17)}$, Luciano Iess ${ }^{(18)}$, Adrian Jäggi ${ }^{(4)}$, Sascha Kempf ${ }^{(19)}$, Norbert Krupp $^{(17)}$, Luisa Lara ${ }^{(20)}$, Jérémie Lasue ${ }^{(1)}$, Valéry Lainey ${ }^{(21)}$, François Leblanc ${ }^{(22)}$, Jean-Pierre Lebreton $^{(23)}$, Andrea Longobardo ${ }^{(24)}$, Ralph Lorenz ${ }^{(25)}$, Philippe Martins ${ }^{(26)}$, Zita Martins ${ }^{(27)}$, Adam Masters $^{(28)}$, David Mimoun ${ }^{(6)}$, Ernesto Palumba ${ }^{(33)}$, Pascal Regnier ${ }^{(10)}$, Joachim Saur ${ }^{(29)}$, Adriaan Schutte ${ }^{(30)}$, Edward C. Sittler ${ }^{(15)}$, Tilman Spohn ${ }^{(31)}$, Katrin Stephan ${ }^{(31)}$, Károly Szegö ${ }^{(32)}$, Federico Tosi ${ }^{(33)}$, Steve Vance ${ }^{(34)}$, Roland Wagner ${ }^{(31)}$, Tim Van Hoolst ${ }^{(35)}$, Martin Volwerk ${ }^{(36)}$, Frances Westall ${ }^{(37)}$.

Affiliations: ${ }^{(1)}$ IRAP, France ; ${ }^{(2)}$ INTA-CAB, Spain; ${ }^{(3)}$ MSSL/UCL, UK ; ${ }^{(4)}$ University of Bern, Switzerland; ${ }^{(5)}$ ETH Zürich, Switzerland; ${ }^{(6)}$ ISAE, France; ${ }^{(7)}$ Joint Institute for VLBI ERIC, Dwingeloo, The Netherlands; ${ }^{(8)}$ UCLA, USA ; ${ }^{(9)}$ Royal Institute of Technology KTH, Sweden, ${ }^{(10)}$ Airbus D\&S, France, ${ }^{(11)}$ Univ. Leicester, UK; ${ }^{(12)}$ LPG, Univ. Nantes, France; ${ }^{(13)}$ Wheaton College, USA; ${ }^{(14)} \mathrm{CSEO}$, USA; ${ }^{(15)} \mathrm{GSFC}$, USA; ${ }^{(16)} \mathrm{TU}$ Delft, The Netherlands; ${ }^{(17)}$ MPS, Germany; ${ }^{(18)}$ Univ. Roma La Sapienza, Italy; ${ }^{(19)}$ LASP, Univ. Colorado, USA; ${ }^{(20)}$ IAA, Spain; ${ }^{(21)}$ IMCCE, France; ${ }^{(22)}$ LATMOS, France; ${ }^{(23)}$ LPC2E, France; ${ }^{(24)}$ IAPS, Italy; ${ }^{(25)}$ APL/JHU, USA ; ${ }^{(26)}$ Télécom ParisTech, France ; ${ }^{(27)}$ CQE, IST, Portugal ; ${ }^{(28)}$ Imperial College, UK; CBM, France; ${ }^{(29)}$ University of Cologne, Germany; ${ }^{(30)} \mathrm{SKA}$ Organisation, UK; ${ }^{(31)}$ DLR, Germany; ${ }^{(32)}$ WIGNER Institute, Hungary; ${ }^{\left({ }^{33}\right.}$ IAPS, Italy; ${ }^{(34)}$ Jet Propulsion Laboratory, USA; ${ }^{(35)} \mathrm{ROB}$, Belgium; ${ }^{(36)} \mathrm{IWF}$, Austria; ${ }^{(37)} \mathrm{CBM}-\mathrm{CNRS}$, France; ${ }^{(38)}$ CSIRO Astronomy and Space Science, Marsfield, NSW, Australia. 


\section{ABSTRACT}

Europa is the closest and probably the most promising target to search for extant life in the Solar System, based on complementary evidence that it may fulfil the key criteria for habitability: the Galileo discovery of a sub-surface ocean; the many indications that the ice shell is active and may be partly permeable to transfer of chemical species, biomolecules and elementary forms of life; the identification of candidate thermal and chemical energy sources necessary to drive a metabolic activity near the ocean floor.

In this article we are proposing that ESA collaborates with NASA to design and fly jointly an ambitious and exciting planetary mission, which we call the Joint Europa Mission (JEM), to reach two objectives: perform a full characterization of Europa's habitability with the capabilities of a Europa orbiter, and search for bio-signatures in the environment of Europa (surface, subsurface and exosphere) by the combination of an orbiter and a lander. JEM can build on the advanced understanding of this system which the missions preceding JEM will provide: Juno, JUICE and Europa Clipper, and on the Europa lander concept currently designed by NASA (Maize, report to OPAG, 2019).

We propose the following overarching goals for our proposed Joint Europa Mission (JEM): Understand Europa as a complex system responding to Jupiter system forcing, characterise the habitability of its potential biosphere, and search for life at its surface and in its subsurface and exosphere. We address these goals by a combination of five Priority Scientific Objectives, each with focused measurement objectives providing detailed constraints on the science payloads and on the platforms used by the mission. The JEM observation strategy will combine three types of scientific measurement sequences: measurements on a high-latitude, lowaltitude Europan orbit; in-situ measurements to be performed at the surface, using a soft lander; and measurements during the final descent to Europa's surface.

The implementation of these three observation sequences will rest on the combination of two science platforms: a soft lander to perform all scientific measurements at the surface and subsurface at a selected landing site, and an orbiter to perform the orbital survey and descent sequences. We describe a science payload for the lander and orbiter that will meet our science objectives. 
We propose an innovative distribution of roles for NASA and ESA; while NASA would provide an SLS launcher, the lander stack and most of the mission operations, ESA would provide the carrier-orbiter-relay platform and a stand-alone astrobiology module for the characterization of life at Europa's surface: the Astrobiology Wet Laboratory (AWL). Following this approach, JEM will be a major exciting joint venture to the outer Solar System of NASA and ESA, working together toward one of the most exciting scientific endeavours of the 21 st century: to search for life beyond our own planet.

Key words: outer planets exploration; search for life; Jupiter system; ocean moon; habitability.

\section{Scientific goals of JEM}

\subsection{Searching for extraterrestrial life in the Solar System.}

Astrobiologists agree today that the conditions for habitability are directly related to the definition of life we can formulate on the basis of the only model of life we know, namely terrestrial life. From this standpoint, habitable environments must meet three basic requirements symbolically represented by the "Triangle of Habitability" (cf. Westall and Brack, 2018): 1) The presence of liquid water, which is the best solvent known for inorganic and many small organic substances. The $\mathrm{H}_{2} \mathrm{O}$ molecule has unique properties that are specifically useful for life, e.g. latent heat due to the chemical bonds, potential for high salt content due to its density, broad range of temperature and pressure stability, etc. 2) The availability of life-essential chemical elements, such as $\mathrm{H}, \mathrm{N}, \mathrm{C}, \mathrm{O}, \mathrm{S}, \mathrm{P}$, as well as transition metals that help provide structure to the biomolecules and provide nutrients to the organisms. Transition metals are made available through the dissolution of the minerals. 3) Energy sources available for life to maintain metabolism. In the absence of light, energy accessible for life is usually provided by chemical disequilibria sourced either by radiation, reactions activated by temperature, or redox reactions. An additional key dimension to planetary habitability is time. We do not know how quickly life appeared on Earth. The process must have been sufficiently fast at the beginning to impede backward reaction, but the emergence of forms of increasing complexity likely needed longer time scales, thus, implying the maintenance of habitability conditions over very long times. 
Based on these considerations, Lammer et al. (2009) explored the variety of known configurations of planets and satellites to derive four classes of "habitable worlds", or Habitats, as being the ones that meet partly the habitability conditions. Classes I and II relate to our terrestrial planets (Earth, Mars, Venus), and to the past or present existence of liquid water at their surface. Classes III and IV correspond to objects where liquid water can be found, not at the surface, but in sub-surface oceans, which are found among the icy satellites of Jupiter and Saturn: they are the "Ocean worlds". Among them, Europa stands out as one of the most promising destinations, and certainly the most promising one in the Jupiter System. To understand why, let us first examine how the coupling of Europa to the Jupiter system may have maintained it "inside the triangle of habitability".

\subsection{Searching for life in the Jupiter system.}

\section{The Galilean satellites.}

In our search for life in the Jupiter System, the four Galilean satellites, sketched in figure 1, immediately capture our attention. What we know of these moons today is essentially the legacy of the exploration of the Jupiter System by the Galileo mission. First, we recognize three likely "ocean worlds": Europa, Ganymede and Callisto, whose sub-surface oceans, if confirmed, meet the first and most important condition for habitability. If we then turn to their internal structure, the two innermost moons, Io and Europa, are essentially "rocky moons". Thus, Europa's possible ocean must be in direct contact with the thick silicate mantle which occupies most of its volume. A third important characteristics is that Io, Europa and Ganymede are trapped in a 4:2:1 mean motion resonance, the so-called "Laplace resonance", which provides them with a continuous source of internal heating due to the dissipation of tidal motions. Finally, both Io and Europa are recognized as "active moons". While this is straightforward for volcanic Io, the permanent resurfacing processes of Europa's terrains places it as well in this category. Even more importantly, a few repeated though still tentative observations by the Hubble Space Telescope (Roth et al. 2014) of plumes rising hundreds of kilometers above Europa's surface indicate that Europa might be the subject of geyser-like activity like Enceladus, though less intense. Evidence of plumes of water by these marginal detections has been recently reinforced by two new observations, one from space and one from the ground: first, a re-examination of in situ low Europan altitude magnetic field and plasma wave data from Galileo, provided strong evidence 
that at least on one occasion this spacecraft flew through a dense plume rising to at least $200 \mathrm{~km}$ above the surface (Jia et al., 2018); and secondly, direct searches for water vapor on Europa spanning dates from February 2016 to May 2017 with the Keck Observatory resulted in nondetections on 16 out of 17 dates, with upper limits below the water abundances inferred from previous estimates. But on one date (26 April 2016) water vapor corresponding to a total amount of about 2000 tons was clearly detected on Europa's leading hemisphere (Paganini, 2019). Taken together, available observations support the idea that Europa plumes are real, though sporadic and perhaps rare events.

Examined altogether, these four macroscopic properties point to Europa as the unique Galilean moon likely bearing a subsurface ocean in direct contact with the silicate mantle (the very definition of a Class III habitat), subject to tidal heating, and displaying signs of activity at its surface. Liquid water, a permanent energy source, and access to heavy elements at the sea-floor: even a very superficial inspection of the "triangle of habitability", to be refined in detail later, provides a strong indication that Europa likely stands "within the triangle". For all these reasons we are now going to focus on a "systemic" understanding of how this "Ocean world" is coupled to the Jupiter System, and on how the dynamics of the coupled Europa/Jupiter-System may maintain habitability conditions at Europa.

\section{Europa as a "Complex System" responding to Jupiter system forcing.}

One can describe Europa as a system of concentric and coupled layers, from the core to the exosphere and the plasma envelope, responding globally to Jupiter system forcing. This forcing is essentially of two types: gravitational (tidal) forcing, exerted mainly on the solid layers of Europa, and the electrodynamic interaction of Jupiter's corotating plasma, magnetic field and energetic particles with Europa's exosphere/ionosphere, surface and subsurface ocean.

\section{Tidal forcing.}

With a typical radius of $1500-2500 \mathrm{~km}$, the four Galilean moons are large bodies inducing strong gravitational perturbation to their environments throughout their orbital motions. Figure 2 illustrates the Laplace resonance linking the mean motions of Io, Europa and Ganymede and shows the temporal spectrum of the gravitational perturbations exerted on Europa (derived from 
Lainey et al., 2006). Because of this orbital resonance, a dynamical equilibrium and continuous energy exchange are maintained between the three innermost Galilean moons.

Tides are a major actor for heating the interior of the moons, with a heat flow up to 70 times the radiogenic heating at Io (Hussmann et al. 2010). They affect both Jupiter and its moons. Because the moons are synchronous, orbital eccentricity is the most evident way to allow for tidal forcing inside the moons. Without the Laplace resonance, the eccentricity of the orbits would have been lost for long. But the Laplace resonance forces the eccentricities of Io and Europa to substantial values while the orbits are secularly evolving under tides.

In addition to the eccentricity of their orbits, the existence of an obliquity and large physical librations may allow for tidal friction inside the moons too. For the Galilean system, the obliquities are believed to be small, even though never measured so far (Bills \& Ray 2000). The magnitude of physical librations depends on the moment of inertia of the moons. The presence of an internal ocean may allow a decoupling between the interior and the crust. Like for the obliquities, the physical librations of the Galilean moons remain unmeasured. A clear measurement of the obliquities and physical librations will allow a more accurate estimation of heating inside the bodies (Wisdom 2004).

On long time scales, the evolution of the Galilean system links the moons internal evolution with their orbital one. While the moons are heating up (cooling down) their viscosity may decrease (increase), allowing for significant feedback on the orbits. Studying such coupling, periodic solutions for Io's heating were pointed out by Ojakangas \& Stevenson (1986) and Hussmann \& Spohn (2004). More generally, the origin of friction inside the moons remains to be discriminated. In icy bodies, significant tidal dissipation may arise inside the silicate core, the ocean and the icy crust. While strong dissipation within the ocean remains unlikely (Tyler 2008; Chen et al. 2014), tidal heating may play an important role within the mantle (Moore (2003), Hussmann and Spohn (2004), Tobie et al. (2005)) and the icy crust (Cassen et al. (1979), Tobie et al. (2005), Nimmo et al. (2002)).

This resonant coupling mechanism has important consequences for all moons. In the case of Europa, it provides a permanent source of heating to the ice shell and mantle. But the temporal variation of total tidal heating and its vertical distribution between mantle and ice shell are 
poorly constrained by observations. Figure 3 shows a simulation result from Tobie et al. (2003) predicting that most of the tidal heating goes into the ice shell, but this prediction has to be validated by adequate observations.

\section{Magnetospheric forcing.}

At the Jovicentric radial distance of Europa, the dynamics of the magnetosphere is dominated by three phenomena: (a) Jupiter's field lines host the strongest radiation belts in the Solar System, whose harshest region extends slightly beyond Europa's orbit ; (b) Jupiter's magnetic field lines corotate with the planet; (c) the dominant source of plasma is Io's volcanic activity, which results in the injection of about one ton/s of fresh Iogenic ions into the corotating magnetic flux tubes. The centrifugal force acting on these flux tubes drives an outward diffusion of this Iogenic plasma, which dominates all other plasma sources throughout the inner and middle magnetosphere. At its radial distance, Europa is still imbedded inside the Jovian radiation belts, and it opposes two types of obstacles to the Jovian corotating magnetic flux tubes and plasma (Figure 4).

The first obstacle is the Europan surface. While the thermal plasma flow is deviated around this obstacle, energetic particles bombard the surface, producing space weathering, particle absorption and desorption, induced chemical reactions, and desorption of surface molecules. Some neutral exospheric particles experience charge exchange with the incident magnetospheric flow. Charged particles freshly implanted into the flow via pick-up are accelerated to tens of keV energies by Jupiter's strong corotation electric field. In this way the Europan interaction adds ions of Europan origin coming from its exosphere or from its surface, including ions of astrobiological interest, to the Jovian ion population.

In the sub-Alfvenic regime of this interaction, magnetic field lines first bend around this obstacle and pile up, before being diverted around it. The velocity difference between this magnetized flow and the Europan conductor induces a large potential drop, on the order of $200 \mathrm{kV}$, between the Jupiter-looking side of Europa and the opposite side. This potential drop in turn drives a current system which flows inside the tenuous ionosphere of Europa, before closing partly within the far-field Alfven wings generated by the obstacle, and partly through Jupiter's upper atmosphere. To understand the exchange of angular momentum and of energy between Europa 
and the surrounding magnetospheric flow produced by this interaction, one must be able to characterize the different components of this electrical circuit.

The second obstacle is the conducting ocean, which opposes the penetration of time-varying magnetic field. The depth to which a signal is able to penetrate the conductor is given by the parameter:

$\mathrm{S}=\left(\omega_{\mathrm{is}} \mu \sigma_{\mathrm{is}} / 2\right)^{-1 / 2}$

called the skin depth where $\mathrm{w}_{\text {is }}$ is the frequency of the signal and $\mathrm{s}_{\text {is }}$ the conductivity of the obstacle. Galileo magnetometer data using Jupiter's rotating field as an 11-hour periodic signal unambiguously confirmed the presence of a liquid water ocean but were not robust enough to place reliable constraints on ice thickness, ocean thickness and ocean salinity. With its multiple flybys, the Europa Clipper mission should be able to provide estimates of the inductive response of Europa's ocean at both the 11-hr and 85-hour periods, and even of ocean thickness and conductivity within a certain domain of these parameters. But a Europa Orbiter can provide estimates of signal strength and response over the much broader range of frequencies of magnetic fluctuations experienced in the Europan environment (see fig. 4, insert) and thus provide unique and accurate estimates of ice thickness, ocean thickness and ocean conductivity, as will be shown in section 2.1 .

\section{Europa as a potential habitat}

In the context of a combined Europa orbiter-lander mission, we propose to re-examine now the relationship of Europa to the "triangle of habitability" in the light of the coupling mechanisms of Europa to the Jupiter system, which a Europa orbiter will be able to examine in unprecedented detail.

Based on the above reflections, there are several converging reasons for identifying the system formed by the ice shell and internal ocean of Europa and their interfaces above (with the exosphere and Jovian magnetosphere) and below (with the sea floor and silicate mantle), illustrated in Figure 5, as a potential habitable world:

- Tidal interaction with Jupiter and the other Galilean satellites produces heat dissipation inside the solid components of Europa, mantle and ice sheet, with a still unclear 
distribution between these two sinks. This energy complements radiogenic heating and may play an important controlling role in the maintenance of a liquid ocean, the activity of the rocky mantle and in the thickness of the ice shell. The huge amount of energy available is manifested as geological features that deform the icy crust around the globe. Some of them apparently are linked to aqueous reservoirs or the ocean. The geological interpretation of these features indicates the possible presence of giant shallow lakes in the subsurface, recent plume activity and diapirism, showing that the ice shell can mix vigorously:

- Europa's subsurface ocean is likely in direct contact with a silicate seafloor, possibly similar in composition to the terrestrial ocean crust. It is an open question whether the rocky mantle is geologically active, but if it is it may release essential elements for life: we know from terrestrial analogues that catalytic reactions associated with hydrothermalism at the seafloor alter rocks, making them porous, by favouring oxidation of minerals; they also produce oxidized and reduced fluids, as well as organic compounds and hydrogen. $\mathrm{Mg}$ sulfates that are observed on the icy surface could be abundant in the ocean, forming from the oxidation of sulfides. Carbon species such as carbonates, methane or other hydrocarbons can form from carbon dioxide or primordial organics depending on the hydrogen fugacity or decomposition temperature.

Apart from those produced during hydrothermal alteration of the rocks, other chemical gradients are produced on the surface. The moon orbits well inside the Jovian radiation belts, whose particles have direct access to its surface where they induce a host of radiolytic processes on the surface material, including the synthesis of oxidizers, again a source of free energy. Europa thus has the potential of displaying a redox couple between its sea floor and its surface, which can be a source of chemical energy if the oxidized species can be transported through the ice shell by endogenous processes, such as subduction as proposed by Kattenhorn and Prockter (2014). Galileo/NIMS first detected distortions in the water ice absorption bands occurring between 1 and $3 \mu \mathrm{m}$ reveal the existence of non-ice material mixed with water ice at specific locations on the surface of Europa. They have been identified as hydrated salt minerals like $\mathrm{Mg}-, \mathrm{Na}-, \mathrm{Ca}-$ sulphates, chlorides, perchlorates and carbonates (endogenous), hydrated sulphuric acid and hydrogen 
peroxide $\left(\mathrm{H}_{2} \mathrm{O}_{2} \cdot 2 \mathrm{H}_{2} \mathrm{O}\right)$ (exogenous), or a combination of these three classes of compounds in varying proportions across the surface (McCord et al., 1999; Dalton et al., 2005; Dalton et al., 2010; Carlson et al., 2005; Loeffler and Baragiola, 2005; Brown and Hand 2013; Hanley et al., 2014). Many of these chemical elements may be related to catalysis of prebiotic molecules. In particular, magnesium may play a major role in stabilizing prebiotic molecules and catalysing more complex molecules (Russell et al. 2014). On the other hand, other compounds would also have an exogenous origin, such as silicates from impact materials (Zahnle et al. 2008) and sulphur species from Io and elsewhere that take part in a radiolytic S cycle on the surface (Carlson et al., 1999).

Provided that the ice shell is "partly permeable" to the transfer of chemical species between the liquid ocean and the icy surface, two key cycling processes may co-exist there:

- a net transport of radiolytically produced oxidizing species from surface to the liquid mass of the ocean;

- conversely, the possibility of transfer of biomolecules and even of specific forms of life from the deep ocean to the surface (more likely, to the sub-surface because of the radiation conditions there), or even to erupting plumes, as will be discussed later.

Under these assumptions, the sub-system of Europa extending from the ocean silicate floor to the ice shell surface, which corresponds exactly to the region of overlap between the domains of influence of tidal and magnetospheric forcing, constitutes a candidate "Europan biosphere" worth characterizing by means of quantitative measurements.

\section{The potential dark biosphere of Europa.}

How could life possibly emerge in this putative Europan biosphere? Of all existing scenarios, abiogenesis at hydrothermal vents, with their highly reactive surfaces and protective porous niches, is favored by many (e.g. Baross and Hofmann 1985; Russell and Hall, 1997). In terrestrial hydrothermal vents, the building blocks of life were concentrated in the pores of the rocks, stabilized and assembled with the aid of mineral surfaces. The process had to be kinetically fast and in one direction with estimates of the time necessary ranging from some tens/hundreds of thousands to a few million years (Westall and Brack, 2018). The living cells 
that emerged from this process were very simple, even compared to the simplest of living cells today. They consisted of hydrophilic molecules (long chain lipids) forming membranes that separated the molecules (proteins) undertaking the process of living reactions (metabolism), i.e. obtaining nutrients from the external environment and transforming them into energy and other molecular components of cells, as well as molecules capable of encoding and transmitting information (e.g. RNA, DNA and their as yet unknown predecessors). These first cells were fuelled on Earth by ingredients provided by simple organic molecules, as well as hydrogen, produced by Fischer-Tropsch alteration of the hot crust by circulating seawater and hydrothermal fluids, or released from organic rich fluid inclusions in ultramafic rocks. Their carbon source was either inorganic $\mathrm{CO}_{2}$ dissolved in the seawater (degassed by differentiation and dissolved from the early $\mathrm{CO}_{2}$ atmospheres), or the simple organic molecules provided by hydrothermal activity or dissolved from the relatively abundant organic matter raining down on the various bodies in the early Solar System in the form of carbonaceous meteorites, and comets. Such chemotrophic cells would have formed colonies, possibly even biofilms on the surfaces of rocks and minerals bathed in the hydrothermal fluids. Their abundance and distribution would have been strictly controlled by access to nutrients, as was the case on the early Earth.

If there is continued hydrothermal activity on the seafloor of Europa, the most likely forms of life to have lived possibly in the past and at present would be chemotrophs. These are surface specific life forms whose biomass development and distribution is controlled by access to hydrothermal fluids and chemical gradients. For possible traces of life on Europa to be detected today, either extant or extinct, it will be necessary for the traces to be transported up to the base of the ice shell and through it towards the surface. Under this restricting assumption, how can we design a "winning strategy" for our quest for life there?

\subsection{Searching for life at Europa.}

An efficient strategy to search for life at Europa must encompass three main types of contexts: the biological, the chemical, and the geological/geophysical contexts. Traces of extant or extinct life could be found potentially at the surface and near-surface environment of the ice, incorporated through reworking (impact gardening, mass wasting and internal dynamics) of material brought up from aqueous reservoirs, or in plumes of oceanic water spewed up into the exosphere: those are the places to look for. But bio-signatures, if they exist, will be strongly 
influenced by the extreme environmental conditions reigning on the surface of the ice and in the exosphere - high radiation, production of corrosive oxidizing species and radicals, tenuous atmosphere and low water activity. This would lead to rapid death of living cells and rapid degradation of the organic components of life. The remnant organic molecules are likely to be refractory, particularly if they have been exposed to the surface for long periods of time. Therefore, the search for signs of life needs access to fresh endogenic materials, which should be coming from the habitable environment in the case of extant life, and must be performed with a specific instrumentation and in the appropriate layers:

- Subsurface sampling, a must in our strategy, must search for better protected samples that could be analysed in different physical states (solid/liquid). Analysis of samples in the aqueous phase will be obtained by melting near-surface ice samples, while chemical disequilibria will be simultaneously characterized during the search for biosignatures. The choice of performing our biomolecule characterization measurements in liquid rather that in solid phase depends on the type of biosignature and on the analytical procedure of identification, as will be explained in section 2.3.

- Capturing compounds in a plume, if and when it occurs, is another indirect way to access to material emerging from the sub-surface. Evidences of water plumes erupting from the surface up to $200 \mathrm{~km}$ around the southern hemisphere have been reported by Hubble Space Telescope images (Roth et al. 2014, NASA report 26/09/2016). Ejecting materials would be coming from the interior of Europa, potentially from liquid layers, so they could include important information about the habitable environments or even evidences of life, as will be discussed further in section 2.2 and 2.3. This discovery offers a unique opportunity to access the interior materials. Details of how this phenomenon occurs in Europa are still unknown. Several mechanisms of plume production have been proposed for Enceladus, and the same might work on Europa (Porco et al., 2006; Kiefer et al., 2006; Schmidt et al., 2008). Not all of them involve liquid water: some of them are based on pressure changes in ice layers. The example of Enceladus shows that an oceanic origin can be considered if salt or other specific mineral grains are detected by future observations. 
The design and planning of JEM will be able to rest on the unique asset of several missions to the Jupiter System to be flown by ESA and NASA in the coming decade: Juno (NASA), JUIICE (ESA) and most importantly Europa Clipper. The host of data on Europa this mission will return from its 45 fly-bys will provide the necessary basis for the design of a lander mission, which is already under study by NASA. The overarching goal of JEM, complementary to its predecessors at Jupiter, can be formulated as follows:

\section{Understand Europa as a complex system responding to Jupiter system forcing,} characterize the habitability of its potential biosphere and search for life at its surface and in its sub-surface and exosphere.

To address this goal, the science plan of JEM, schematically represented in figure 6 , will study Europa as a system of coupled layers at three scales: the global scale (Europan radius), a medium scale (the thickness of Europa's potential biosphere), on the basis of five priority science objectives.

\section{Detailed scientific objectives and measurement requirements.}

For each of our five science objectives, we describe now the corresponding measurement requirements and constraints on the mission profile, which are summarized in the Science Traceability Matrix of JEM (Annex I).

2.1. Global scale science investigations: Understand Europa as a system of coupled layers responding to Jupiter System forcing.

PSO\#1: Determine the global structure of the Europan magnetic field and plasma environment including potential plume characterization, and the associated response of Europa, including its ocean, to Jupiter System magnetospheric forcing.

The interaction of Europa with the Jovian magnetospheric field and flow results in the complex distribution of plasmas, energetic particles, magnetic fields and electric currents illustrated in Figure 4. The resulting charged particle population is a complex mixture of ions of different origins: to the primary population of Iogenic ions, dominant in the Jovian plasma sheet, the Europan interaction adds ions of Europan origin coming from its exosphere, or even directly from its surface, or from its subsurface through potential plumes, into the magnetospheric flow. 
Measuring its chemical composition bears a high astrobiological potential, since biomolecules present in Europa's surface layer may have made their way to the Europan charged particle environment as ionospheric and pick-up ions. JEM composition measurements must be able to find endogenic materials amidst the background of magnetospheric species constantly raining down on the surface. JEM magnetic field measurements will have to retrieve the 3-D picture of the four contributions to magnetic field configuration produced by the Europan magnetospheric interaction: (1) the background undisturbed Jovian magnetic field, which is on the order of 450 $\mathrm{nT}$; (2) a never detected hypothetical intrinsic Europan magnetic field generated by a core dynamo mechanism, of which we know only an upper limit (Schilling et al., 2004). Continuous low-altitude measurements by JEM will decrease its detection threshold by at least an order or magnitude; (3) the magnetic fields produced in the Europan environment by the Europan magnetospheric interactions; (4) the magnetic effects of the electric currents induced into Europa's conducting ocean by the varying Jovian magnetic field, on the order of 50-100 nT, which constitute a natural magnetic sounding of the ocean. To achieve a good accuracy in this magnetic sounding of Europa's ocean, one must separate the Jovian source (1) and the oceanic response to its variations (4) from the other two components. This goal can be achieved using models of various levels of complexity, such as the MHD model by Blöcker et al. (2016), illustrated in Figure 7. For the analysis of JEM magnetic field and plasma data, a comprehensive model separating the four contributions and simultaneously constraining ocean thickness, conductivity, and atmospheric densities will be developed, based on the data assimilation techniques currently used in meteorology and related research areas. This inversion process will take advantage of the two-point magnetic field measurements, on the orbiter and during the 22 days of operation of the lander at the surface.

Figure 7, which shows the current systems, the global distribution of ionospheric densities around Europa, and the corresponding ionospheric currents, suggests that an orbit around 100 to $200 \mathrm{~km}$ altitude will provide a good access to the current system near its intensity maximum.

Finally, the JEM orbiter would collect more useful data in two days of operation than what will be obtained from Europa Clipper in 40 flybys spread over three years. If a continuous time series is available from an orbiter for a period of 3 months or longer, one can use not only the main prime frequencies with large amplitudes, but also the broadband spectrum of much weaker lower 
frequencies to sound the ocean under the ice sheet. As shown in Figure 8, adapted from Khurana et al. (2009), these frequencies, materialized by pink, green and yellow curves, allow a much better coverage of the (ocean thickness vs. amplitude of the magnetic response) parameter space than the sole dominant frequencies at the $11.1 \mathrm{hr}$ (Jovian synodic) and Europan orbital ( $85.2 \mathrm{hrs}$ ) periods.

In addition, if the lander carries a magnetometer, simultaneous measurements with the orbiter will facilitate the decomposition of the internal and external fields directly in time domain. The decomposed internal and external field time series can then be Fourier decomposed into the primary field and Europa's response at not only the two prime frequencies but also the weaker non-harmonic frequencies. A strong advantage of two-point measurements is that even relatively short time series can be inverted into their constituent primary and secondary fields.

In conclusion, JEM will perform the following investigations to address the PSO\#1:

- Determine the global structure of magnetic fields, electric currents, plasma and energetic populations in the Europan environment;

- Separate the four contributions to Europan magnetic fields and current systems;

- Use the natural fluctuations of the Jovian magnetic field to perform a broad-band magnetic sounding of the Europan sub-surface ocean;

- Determine the composition/flux of plume material to characterize the properties of any subsurface water.

PSO\#2: Determine the global structure of the solid body and potential biosphere of Europa, and their response to Jupiter System tidal forcing.

To achieve the measurement objectives of PSO\#2, JEM will combine altimetry, gravimetry, the characterization of rotation and magnetic measurements, using the geophysical investigations available on the orbiter and on the lander geophysical station, with the additional support of astrometry measurements. The following parameters will be determined in priority: (1) the harmonic expansion of the static gravity field and of the topography up to degree 30-40, (2) the amplitude (precision $<10^{-2}$ ) and phase (precision $<1^{\circ}$ ) of the gravity variations $\left(\mathrm{k}_{2}\right.$ Love 
number) and topographic deformation ( $\mathrm{h}_{2}$ Love number) of the Europan tides, from which an accurate estimator of the ice shell can be derived, (3) the libration and rotation properties of Europa, from radio science (gravity field), altimeter data and surface lander positioning, (4) the instantaneous orbital characteristics of Europa and its long-term evolution, using the PRIDE-E astrometry experiment analyzed in the context of previous astrometry measurements of the orbital dynamics of the Galilean satellites (space and ground-based).

By combining these measurements, a rich set of integrated information on Europa's internal structure, dynamics and energy budget will be produced, including: (1) detailed radial profiles of the key geophysical quantities, (2) an assessment of the assumed hydrostatic equilibrium, (3) a global description of the undulations of the critical interfaces: ice shell/ocean, ocean/rock mantle, rock mantle/core (if the latter is precisely defined); (4) an accurate description of tidal deformation and heating, possibly including constraints on its distribution between the different layers.

Figure 9 shows results of simulations we performed of the use of the gravity science investigation of JEM. These results show that the gravity field can be retrieved up to a degree 1 of 30 and possibly 40 for the orbital parameters and mission duration foreseen for JEM (compared to $1<20$ for the 45 fly-bys of Europa Clipper). Furthermore, the expected uncertainty on the measurement of Love number k2 would be about 20 times smaller: while Europa Clipper will do an excellent job to go beyond Galileo, significantly augmented information about the interior of Europa will be provided by JEM.

Furthermore, the combination of the measured gravity and topography tidal waves will provide a direct evaluation of the total ice shell thickness at the $5-\mathrm{km}$ precision and of some of its mechanical properties at the resolution necessary to provide key constraints for dynamic models of the ice shell, for instance to decide about its conductive or convective nature. The combination of gravity and surface deformation phase lags will further allow to discriminate between predominant tidal dissipation in the ice shell or in the rock mantle, an important ingredient to investigate the coupling between the orbital dynamics and the thermal evolution of Europa and better constrain the chemical coupling and mass transfer processes at work between ocean, silicate floor, ice shell and surface. 
PSO's 1 and 2 combined will provide unique information on the internal structure, layering and dynamics of Europa, using the synergies between measurement techniques deployed on the orbiter and on the lander. Figure 10 illustrates this complementarity of techniques (rotation monitoring, electromagnetic sounding, gravimetry, seismic or acoustic sounding...) and shows how their combination will provide a comprehensive description of key characteristics of the different layers of Europa's interior.

2.2. Medium scale study: Determine the characteristics of the potential habitable zone of Europa.

PSO\#3: Understand the exchange and transformation processes at the interface between the ice-shell surface/subsurface and the exosphere/ionosphere including potential plume characterization

Europa's surface and exosphere. Europa's surface is composed of an icy porous regolith (50 to $100 \mu \mathrm{m}$ grains) permanently bombarded by Jovian magnetospheric energetic ions (essentially $\mathrm{keV}$ to $\mathrm{MeV} \mathrm{S}^{\mathrm{n}+}$ and $\mathrm{O}^{\mathrm{n}+}$ coming from Io's torus) and electrons (equivalent of 100 to 1000 times the dose rate at the Moon) and by photons (Cooper et al. 2001). The radiolysis and photolysis induced by this bombardment alter the optical layer of the surface, from microns up to meter depth, on a time scale between 10 and $10^{9}$ years. The typical yield of $\mathrm{S}^{+}$and $\mathrm{O}^{+}$at $\mathrm{keV}$ to $\mathrm{MeV}$ energy is around 1000, so that the ice resurfacing rate induced by sputtering should be of $\sim 0.1$ microns / year (or $100 \mathrm{~m} / \mathrm{Gyr}$ ), significantly lower than the resurfacing rate due to meteoroid. As a consequence, the regolith can be a substantial trap for radiation-altered material.

The incident magnetospheric particles and photons decompose Europa's icy surface into $\mathrm{H}_{2}, \mathrm{O}_{2}$ and $\mathrm{H}_{2} \mathrm{O}_{2}$. Preferential loss of the volatile $\mathrm{H}_{2}$ leaves an oxidized surface, a gravitationally bound $\mathrm{O}_{2}$ atmosphere and peroxide trapped in ice (see the right-hand side of figure 11 from Shematovich et al. 2005). This processing also determines the state of trace species such as S, C, $\mathrm{Na}, \mathrm{K}$ and $\mathrm{Mg}$. Sources and sinks of trace species in Europa's icy surface are: implantation from Io plasma torus, upwelling or venting from interior sources, and meteorite impacts. As a result of sputtering, Europa's exosphere is expected to display a composition closely related to the surface composition, thus providing a probe to understand how the surface composition is processed by radiolysis/photolysis, enriched by exogenic sources and eroded by sputtering. The ultimate goal 
494

495

496

497

498

499

500

501

502

503

504

505

506

507

508

509

510

511

512

513

514

515

516

517

518

519

520

521

for JEM will be to estimate the respective role of these processes and their spatial and temporal variations, using three signatures for each of these processes: compositional, energetic and spatial.

Europan plumes. Based on Enceladus studies, Europan plumes might be stratified according to the density of materials, with dust grains of salt, silicate materials or heavy organics remaining in the lower parts of the plume, while light volatiles would reach higher altitudes. Thus, the compounds that could be analysed at different altitudes could provide information about the formation history and habitability of the moon.

In summary, JEM will perform the following investigations in the context of PSO\#3:

- Determine the composition and spatial distribution of major and trace species of Europa's exosphere;

- Ascertain the roles of the surface/subsurface, magnetosphere, dust and possibly plumes as drivers of exosphere formation.

PSO\#4: Understand the exchange processes between the ice-shell surface/subsurface and the potential habitable zone.

Exchange processes between the ice-shell surface/subsurface and deep aqueous layers constrain the possibility of finding signatures of the non-accessible habitable zone with JEM observations of surface and subsurface chemistry and geological features. The extreme diversity of these surface features is illustrated in Figure 12. In order to recognize which features are young and have endogenous origin, JEM will benefit from: a) Europa Clipper and JUICE mission measurements of remote imaging, spectroscopy and radar scanning of Europa, which will provide for the first time detailed information on geological features, activity and history at regional resolution; b) JEM global accurate geophysical measurements, particularly topography; c) JEM novel information at the local scale of the landing site.

Resurfacing by cryovolcanism, geyserism or tectonism could have effects on transportation of materials and cycling of the elements in the moon. In this regard, the study of the local geological features (e.g. morphology, grain sizes of surface materials, presence of boulders, presence of small craters, stratigraphic relationship between materials), the distribution of 
materials, and the subsurface structure at the landing site will help to characterize the nearest aqueous layer at the lander spot. A relation between surface and subsurface features can reveal the depth of liquid reservoirs and their putative links to the surface.

Due to the extreme conditions on the surface, the relative abundances of key materials for habitability, such as organics, minerals and volatiles containing bio-essential chemical elements might differ according to their stratigraphy position, chemical state (redox state, degradation rate) and phase (e.g. water ice/clathrate hydrate). Deposition of radiation energy into materials is controlled by the chemical and physical properties of the regolith at the landing site (e.g. grain size, porosity mineral, crystallinity). These parameters determine the so-called "biosignature preservation potential" (BPP) at the surface/subsurface, which is especially significant for the search for biosignatures (see 2.3). Magnetic field intensity and radiation dose measurements at the landing site will be needed to determine the BPP. Selection of the landing site is critical to maximize the probability of finding fresh endogenous materials, which seems to be more frequent in the leading hemisphere according to previous studies (see Figure 13).

Availability of chemical elements that life needs depends on the physical and chemical properties of the solvent. This novel investigation can be performed by JEM by characterizing the melt endogenous materials in the liquid state: a) $\mathrm{pH}$, since it influences the stability, reactivity and mobility of elements, inorganic and polar organic compounds; b) Redox potential, which affects the behavior of many elements and chemical constituents in aqueous media and in the living organisms and is the main energy source for chemotroph organisms; c) conductivity, which is affected by salinity. Dissolved inorganic ions such as $\mathrm{Mg}^{2+}, \mathrm{Ca}^{2+}, \mathrm{K}^{+}, \mathrm{Na}^{+}, \mathrm{Cl}^{-}, \mathrm{SO}_{4}{ }^{2-}$, $\mathrm{HCO}_{3}{ }^{-}$and $\mathrm{CO}_{3}{ }^{2-}$ can constitute redox couples that could provide energy for chemosynthetic life; d) volatiles (e.g. $\mathrm{CH}_{4}, \mathrm{NH}_{3}, \mathrm{O}_{2}, \mathrm{H}_{2}$ ) that are sources of nutrients and potential biosignatures.

\section{In summary, the investigations that JEM will perform to address PSO \#4 are:}

- Detect any geological feature which involves exchange processes between surface/interior at the landing site and determine whether any activity exists today;

- Determine the proximity to liquid water reservoirs in the landing site area; 
549

550

551

552

553

554

555

556

557

558

559

560

561

562

563

564

565

566

567

568

569

570

571

572

573

- Characterize the biosignature preservation potential of accessible surface materials at the landing site;

- Characterize the physical properties at the landing site;

- Characterize the key compounds associated with habitability near the surface;

- Characterize the wet context of surface materials.

\subsection{Local scale study:}

PSO\#5. Search for bio-signatures at the surface / subsurface.

At present, space exploration considers distinct categories of biosignatures requiring different analytical techniques with different detection limits:

1) General biomarkers (molecular bio-signatures) are indisputable evidence of life. They are biological polymers like polysaccharides, lipids, proteins or some form of informationtransmitting molecule similar to DNA. Of particular interest are conservative biomolecules that are deeply and ubiquitously rooted in the tree of life, proteins that are involved in deeply rooted and widespread metabolic pathways, structural components of cell walls of broad prokaryotic groups, and phylogenetically conserved structural proteins and storage compounds of broad prokaryotic groups conserved under stress, e.g. with limited water availability. These different groups are presented in Figure 14.

2) Organic indicators of past or present life. Since high radiation conditions on the Europan surface may degrade any material if it is exposed for any length of time, biomolecules will likely break up and react, producing degraded organic compounds that can also be symptomatic of the presence of life. It is critical to validate the biological origin of those degraded compounds.

3) Inorganic indicators of past and present life: biogenic stable isotope patterns in minerals and organic compounds, biogenic minerals, or certain atmospheric gases produced by metabolism.

4) Morphological and textural indicators of life, e.g. any object or pattern indicating bio-organic molecular structures, cellular and extracellular morphologies, or biogenic fabric on rocks. 
574 Discerning the origin of the bio-signatures is mandatory, specifically for the simpler organics since they may as well come from meteorites or from ejecta produced by plume activity. Organics may form by interaction of surface materials with the radiation environment if $\mathrm{CO}_{2}$ is originally present in the ice matrix (Hand et al., 2007). Detection of formamide $\left(\mathrm{CH}_{3} \mathrm{NO}\right)$ is particularly crucial, since it is a key compound for the formation of nucleic acids. However, an exogenous origin of some organics (e.g. PAH) cannot be ruled out.

The JEM search for biosignatures will primarily focus on local scale studies on a landing site where fresh and young material will be expected, coming from the near surface or even from putative plumes. In near-surface investigations, direct sampling and contact analysis instruments are absolutely necessary since the concentration of bio-signatures is assumed to be very low. Sampling materials at depths below $5-10 \mathrm{~cm}$ from the leading hemisphere is required for access to unaltered molecules. Measurements may require the sample to be in the solid or liquid phase for analysis, depending on the biosignature typology and the technique used for its recognition. Simple molecules of categories 2 and 3 can be detected and identified directly by vibrational spectroscopy if they are present in the solid matrix of ice. For isotopic ratios and some more complex organics (e.g. amino acids, lipids), their unambiguous identification can be performed by mass spectrometry after sample volatilization, which is a step of the GC/MS procedure. To unambiguously identify macromolecules of category 1 (e.g. polysaccharides, proteins or DNA/RNA) a biochemical analytical technique is necessary, such as antibody microarrays immunoassays. This technique can identify macromolecules because they bind to their particular $3 \mathrm{D}$ structures in a liquid medium, which is needed to transport the antibodies and to allow binding to the specific antigens/target molecules. In JEM, the liquid medium will be obtained by melting the ice sample of the near surface. Antibodies can also recognize and identify small but still complex molecules such as aromatic amino acids (Phe, Tyr, Trp) and PAHs such as benzoa-pyrene.

Besides near-surface science, JEM will also search for bio-signatures of extant life in the exosphere and in plumes if their existence is confirmed. Traces of life there could include organic and inorganic biosignatures expelled from the habitable zone, even cells, cellular material, or biomolecules. Closer to the "vent" exit points, deposits containing rock fragments 
603

604

605

606

607

608

609

610

611

612

hosting either extant (or recently dead) life forms or the fossilized remains of life might be found.

In conclusion, PSO \#5 will include a set of investigations which are unique in the Solar System exploration, such as:

- identifying general biomarkers;

- detecting and characterizing any organic indicator of past or present life;

- identifying morphological and textural indicators of life;

- detecting and characterizing any inorganic indicator of past and present life;

- determining the origin of sampled material;

- determining if living organisms persist in sampled materials.

\section{Proposed scientific instruments:}

The implementation of the JEM science plan is based on the joint operation of scientific investigations on two complementary platforms: a lander (currently under study by NASA) and a carrier/orbiter, each including a baseline main element and an optional small detachable platform. We describe now the instrument suite required on each of these platforms to meet our measurement requirements.

\subsection{The Orbiter instrument suite.}

To meet our measurements requirements, we propose that the Orbiter carries the instruments listed in Table 1, some of them to be operated during a minimum of 22 days simultaneously with lander data relay, then all of them during the subsequent 3 months of nominal orbital science, and again some of them during the final descent to Europa's surface. The added complexity of the extreme radiation environment at Jupiter drives the orbiter instrument architecture. We make the choice of decoupling the sensor heads from their part of their electronics. This allows flexibility in their accommodation, easier radiation mitigation, full integration of the scientific capabilities of each of them and ensures optimum science return while keeping the total resources low. 
The gravity field, the tidal deformations (both gravitational and physical) and the rotational state (obliquity and physical librations in longitude) will be determined by means of Doppler and range measurements carried out both on the orbiter-to-ground, two-way, coherent link, and on the orbiter-to-lander proximity link. The two-way link to ground, enabled by an onboard transponder (Integrated Deep Space Transponder or IDST) operating at X or Ka-band, will provide radiometric observables to estimate a > 20×20 gravity field, k2 Love number, and global obliquity and physical librations of the moon.

The magnetometer (MAG) instrument will measure the magnetic field in the vicinity of the spacecraft. This is crucial for a) resolving the interaction of Europa with Jupiter's magnetosphere with multipoint measurements, b) constraining the extent of Europa's intrinsic magnetization, and c) searching for evidence of induced electric currents in Europa's subsurface ocean. The typical range, resolution, and noise-level of this instrument are $\pm 10 \mu \mathrm{T}$, up to $50 \mathrm{pT}$ (dependent on range), and $<100 \mathrm{pT} / \sqrt{\mathrm{Hz}}$ (at $1 \mathrm{~Hz}$ ) respectively. The range is more than adequate to measure expected magnetic fields at Europa.

The Laser Altimeter (LA) will investigate the surface and interior of Europa. By measuring the time-of-flight of a laser pulse transmitted from the instrument, backscattered at the moon's surface and detected in the instrument's receiver telescope, height profiles can be obtained in along-track direction. Combining many of these tracks, the local, regional, and global topography of Europa can be obtained. From the pulse-spreading of the returned pulse the surface roughness on the scale of the laser footprint (order of a few tens of meters) can be measured. Information on the albedo at the laser wavelength $(1064 \mathrm{~nm})$ can be gained from the intensities of the transmitted and returned pulses. By obtaining not only good spatial coverage but also temporal coverage with laser ground-tracks, the tidal deformation of Europa's ice shell along its orbit around Jupiter will be measured. From the tidal signal (expressed in terms of the radial tidal Love number $h_{2}$ ), the extension of Europa's ice shell can be constrained, especially when combined with measurements of the tidal potential by the radio science experiment. By measuring the phase-lag of tidal deformation LA will provide constraints on the internal heat production of Europa. Combined with phase-lag measurements of the tidal potential a highly dissipative silicate interior could be detected. The instrument is composed of a transceiver unit 
and two electronic units. The transceiver unit contains the complete laser subsystem and the optical chain of the receiver.

The Ion Mass Spectrometer and Electron Spectrometer (IMS/ELS) suite will provide the most comprehensive and critically needed thermal and suprathermal plasma measurements to achieve the following science objectives: (1) reliably characterize plasma ion and electron currents constituting major backgrounds for magnetometer detection of the oceanic source of induced magnetic field; (2) characterize Europa's environment, its composition, structure and dynamics and Europa's interaction with the Jovian magnetosphere; and (3) unveil and quantify the key processes of erosion and exchange of elements at Europa surface, including presence of expelled minor/trace elements, possibly representative of sub-surface layers.

The ELS sensor is an electrostatic analyzer that will provide fast 3D measurements in the energy range $1 \mathrm{eV}-30 \mathrm{keV}$ and will be customized for the energy range as well as the dynamic range encompassing magnetospheric suprathermal and thermal plasma originating from Io, cold ionospheric species including photoelectrons and ram negative ions from Europa, as well as pick-up negative ions likely to be observed around Europa.

The Ion Mass Spectrometer (IMS) sensor is a 3D mass spectrometer that will measure positive ion fluxes and provide detailed composition measurements at Europa. A major feature of IMS is its Time Of Flight (TOF) section. which includes two MCP detectors, one with high-count measurements to ensure a good time resolution, and a second one, based on the reflectron technique, to provide an enhanced mass resolution. This double detection allows a detailed composition analysis capable of measuring multiply charged ions and separating ions of the same mass / charge ratio (e.g. S++ and O+).

The Ion and Neutral Mass Spectrometer (INMS) is a time-of-flight mass spectrometer using an ion mirror (reflectron) for performance optimization. A TOF mass spectrometer has inherent advantages with respect to other mass spectrometer concepts since it allows recording of a complete mass spectrum at once without the necessity of scanning over the mass range of interest. INMS is a time of flight (TOF) mass spectrometer with $M / \Delta M \approx 1100$ resolution over a mass range of $M / q=1-1000 \mathrm{u} / \mathrm{e}$. 
The Dust Analyzer (DA) is a TOF impact mass spectrometer that uses the technology of the successful Cosmic Dust Analyzer (CDA) operating on Cassini and employs advanced reflectrontype ion optics optimized for the combination of high mass resolution, large target area, and large Field-of-View (FOV). For unambiguous recognition of valid dust impacts, a coincident detection method will be implemented with all analog signals being continuously monitored with threshold detection.

The additional Langmuir Probe (LP) (if resources allow it) will consist of one boom with a spherical sensor at the tip. The LP will monitor the cold plasma parameters (electron and ion number densities, the electron temperature and the plasma drift velocity), as well as signals from micrometeorite impacts on the S/C. The derived LP parameters will provide the basis to a) characterize the Europan ionosphere and its dynamics; b) characterize the plume dust and plasma properties; c) characterize the ambient size/mass distribution of mm-sized dust around Europa and in the Europa torus; and d) monitor the spacecraft potential for use by the particle spectrometers and for the determination of the integrated EUV flux.

In addition, the Planetary Radio Interferometry and Doppler Experiment for JEM (PRIDE-E) is an instrument with zero demand on the science payload mass, and only ad hoc demand on other S/C resources (the onboard power, commands, telemetry). This experiment is designed as an enhancement of the science output of the mission using the JEM radio links and the extensive infrastructure of Earthbased radio astronomy facilities. PRIDE-E is a repetition of PRIDE-JUICE, one of the experiments of the JUICE mission (Witasse et al. 2015). PRIDE is based on the use of Very Long Baseline Interferometry (VLBI) instrumentation available and operational on more than 40 Earth-based radio telescopes. The applicability of the VLBI technique for ad hoc experiments with planetary probes has been demonstrated for the Huygens probe (Pogrebenko et al. 2004, Lebreton et al. 2005, Bird et al. 2005), Venus Express (Duev et al. 2012., Bocanegra Bahamón et al. 2018) and Mars Express (Duev et al. 2016, Bocanegra Bahamón et al. 2019) missions. The prime scientific objective of PRIDE-E is to provide inputs into improvement of the ephemerides of the Jovian system. PRIDE-E will also provide complementary measurements of the S/C lateral coordinates and radial velocity in the interests of other science applications. Various applications of PRIDE-E measurements for improvements of Jovian system ephemerides and related parameters are discussed in detail by Dirkx et al. (2016, 2017, 2018).

To accommodate and operate this instrument suite on the Orbiter Science Platform will take the estimated resources shown in Table 2. 
3.2. The Lander instrument suite.

On the NASA side the instrumentation for the lander will be selected based on a future AO to which European institutes may contribute under the umbrella of their national funding agencies. In this section we focus on the sensors to be delivered by ESA to the lander through the proposed standalone Astrobiological Wet Laboratory (described in section 4.3.3) augmented by two geophysical sensors. To meet our measurements requirements, the Lander should carry the instrument suite presented in Table 3 , to be operated during a minimum of 22 days.

Multi-probe immunoassay-based (MPAS) instruments have been proposed for planetary exploration: the Life Marker Chip (LMC) (Sims et al, 2012) and the Signs Of Life Detector (SOLID) (Parro et al., 2005; 2008; 2011), but neither LMC nor SOLID can be implemented in the AWL because of mass and volume restrictions. We are therefore proposing a different approach adapted to AWL constraints.

The MPAS instrument must be based on simplicity and robustness. It minimizes the use of electronic devices, mechanical actuators and power consumption. The most promising concept is something well known on biomedical laboratories: the lateral flow assay (LFA) or immunocapillary test, as it is also called. The first immunoassay based on lateral flow was reported in 1978 and it has been extensively used on pregnancy tests (Mark, 2010). In the LFA

734 developed for MPAS, the Sample Pad is in contact with the fluid deposit and it is flooded with 735 the water sample coming from the ice fusion. The sample moves forward by capillarity to the Conjugate Pad, preloaded with a set of antibodies (Ab) labeled with colloidal gold or colored latex spheres. At this step the target molecules (organics, biomarkers, or antigen-Ag) bind to their corresponding Ab's and the sample movement continues through the Detection Pad. Once the labeled sample gets the multi-probe Detection Array, the couple Ag-Ab binds again to the immobilized Ag-conjugate (in a competitive immunoassay) or immobilized capturing $\mathrm{Ab}$

741 (sandwich assay), and dark spots corresponding to the trimeric complexes Ag-AuAb-ConAg or $742 \mathrm{Ag}-\mathrm{AuAb}-\mathrm{capAb}$ are visualized by illuminating (visible) the array and image capturing with a 743 small camera.

744 The Multiparametric probe (MPP) will have heritage from the MECA package onboard the 745 Phoenix mission which was the unique probe with capability to perform chemical analysis of a 
water sample. The MECA package (Kounaves, 2003) was a wet chemistry lab with sensors to measure: $\mathrm{H}+$, dissolved $\mathrm{O} 2$, redox potential, oxidants and reductants, and several ions and cations. The MECA package was designed as a multi-sample instrument with a mass, volume and power consumption out of the scope of the instrumentation for this mission. From the different alternatives available in the environmental monitoring market, the most attractive by its miniaturization capabilities are those sensors based on ChemFET technology (Jimenez-Jorquera, 2010). Oxygen dissolved, $\mathrm{pH}$, conductivity, $\mathrm{NH}^{++}, \mathrm{NO}^{3}, \mathrm{Ca}^{2+} \mathrm{K}+\mathrm{Cl}, \mathrm{NO}^{3}$ are parameter with sensors developed to measure it.

The VISTA (Volatiles In Situ Thermogravimetric Analyzer) sensor is a miniaturized thermogravimetry analyzer that will perform measurements of the Europa volatile compounds (Palomba et al. 2016). The instrument is based on thermogravimetric analysis (TGA) and its core is a Quartz Crystal Microbalance (QCM), oscillating at a resonant frequency linearly related to the mass deposited on its sensible area. The technique measures the change in mass of a sample as a function of temperature and time. VISTA measurement goals are: a) to discriminate between water ice and clathrate hydrates, by heating the QCM up to the decomposition temperature of clathrate hydrates at 120-160 K (Lunine and Shevchenko 1985) and to the sublimation temperature of water ice (200 K at a depth of 3 meters, Handbook of Chemistry and Physics 1980), and by recording the temperature at which mass loss due to heating occurs; b) to measure the composition of non-ice materials, by heating the PCM up to the dehydration temperatures of possible Europa components, ranging in the interval 220-320 K (McCord et al. 2001), by recording the temperature where mass loss due to heating occurs and by measuring the volatile/refractory abundance ratio (this measurement which is fundamental to characterize the non-ice material is not performed by other instrumentation onboard the lander); c) to detect and measure the relative abundance of organics, by heating the PCM up to organics desorption at about $230 \mathrm{~K}$ and measuring the mass difference before and after desorption.

The magnetometer can provide magnetic field measurements at a rate of up to $128 \mathrm{~Hz}$ and an accuracy of $0.1 \mathrm{nT}$. One on the lander itself, and one on a short $(0.5 \mathrm{~m})$ boom will ideally be needed. The laser retroreflector has the property to reflect light back to its source with a minimum of scattering. A laser onboard the orbiter could target the device from a distance of tens to hundreds of thousands of $\mathrm{km}$ (for instance from the halo orbit). Attached to the lander it would allow to determine the exact landing site with a precision of a few meters and the 
measurement of tides and of the rotational state already during the relay phase (like a control point). The device is fully passive (no power or data consumption). A good example is the ExoMars 2016 Schiaparelli retroreflector (http://exploration.esa.int/mars/57466- $\square$ retroreflector-$\square$ for- $\square$ exomars- $\square$ schiaparelli/). It has a size of $54 \mathrm{~mm}$ in diameter and a total mass of $25 \mathrm{~g}$.

Our estimate of the resources needed to operate this instrument suite on the Surface Science Platform is shown in Table 4.

\section{Proposed mission configuration and profile}

\subsection{JEM orbits and science operations.}

The implementation of the science plan of JEM will rest upon instruments deployed synergistically on two space platforms: a carrier/relay/orbiter platform (hereafter referred to as orbiter), and a soft lander platform, both described in section 4.2. These 2 platforms will be used to perform the 3 sequences of scientific observations, or science sequences, illustrated in Figure 15 :

A. A surface science sequence involving the lander instruments, planned to last about 22 days on a selected site;

B. An orbital science sequence involving the orbiter instruments. This sequence will first overlap in time with the surface science sequence, while the orbiter platform will reside on a halo orbit of the Jupiter-Europa system to relay the orbiter data to Earth, before continuing in low Europan orbit for a planned duration of three months;

C. A descent science sequence will correspond to an additional period, after the end of sequence $\mathrm{B}$, during which the orbiter will explore regions of the exosphere/ionosphere very close to the surface, below the lowest altitude to be covered by Europa Clipper, to search for biomolecules in the lowest layers of the exosphere.

Our astrometry experiment PRIDE-E (section 3.4), will support and complement these three sequences from Earth using the world-wide VLBI network of radio telescopes. 
802

803

804

805

806

807

808

809

810

811

812

813

814

815

816

817

818

819

820

821

822

823

824

825

826

827

828

The determination of the landing site (sequence $\mathrm{A}$ ) and of the $\mathrm{B}$ and $\mathrm{C}$ orbits must be the result of a detailed optimization aimed at fulfilling our measurement requirements. For sequence B, we have chosen a scenario fulfilling different requirements on two different successive orbits. For sequence $\mathrm{C}$, the requirement of measuring exospheric species in the near-surface exosphere could be implemented by de-orbiting the orbiter platform and taking data from its initial orbit until final impact, or by letting the working orbit of sequence B evolve naturally until final impact. A detailed mission analysis will be needed to identify the most promising approach.

The spatial/temporal coverage provided by our JEM orbiter will nicely complement the coverage and the scientific information to be provided by Europa Clipper, which will have flown 45 times by Europa a few years before JEM, providing data both much closer to the surface, and at much larger distances from it, than the high-inclination orbits of JEM will allow. JEM will provide a three-months continuous coverage of Europan planetary fields and plasma populations on a highinclination orbit, after an initial sequence on a halo orbit which will provide a detailed insight into the structure of the Europan Alfven wings. To reach these orbits, starting from Earth with a SLS launch, the JEM flight complement will have to go through a succession of mission sequences (S-1 to S-9) listed in Table 5, first on heliocentric orbits and then on Jovicentric orbits before reaching its first Europan orbit.

The choice of the sequence of orbits will be the result of a trade-off in a 3D parameter space described by:

- the Total Ionizing Dose (TID) accumulated along the spacecraft trajectory, which gives the maximum operation time our platforms will be able to live through;

- the shielding thickness used to protect the equipment and mitigate radiation dose effects, which has a direct incidence on the weight of the platform and instruments;

- the total Delta V provided by the propulsion system, with direct impact on spacecraft total wet mass.

The JEM spacecraft will first cruise on a DV-EGA trajectory to Jupiter (Figure 16, sequence S1). We choose this trajectory to bring the maximum mass possible into Jovian orbit and 
829

830

831

832

833

834

835

836

837

838

839

840

841

842

843

844

845

846

847

848

849

850

851

852

853

854

855

856

accommodate a significant science payload on each platform, at the expense of a larger travel time.

After a Jupiter Orbit Insertion (JOI) immediately followed by a Perijove Raise Manoeuver (PRM) to minimize exposition to the inner parts of the Jovian radiation belt (sequence S-2), the JEM spacecraft will execute a tour in Jovicentric orbits to reach Europa (sequence S-3 and figure 17). Here we choose the 12-L1 tour with only flybys of two Galilean satellites (Ganymede and Callisto) to reach Europa in a short time and minimize the dose accumulated (Campagnola et al, 2014), in order to enable a lifetime in Europan orbit significantly above 4 months, at the expense of a significant Delta V. At the end of sequence S-3, the JEM flight complement is injected on an eccentric Europan orbit from which the lander stack is released, de-orbits and executes its landing sequence.

Immediately after lander release, the JEM orbiter will be transferred to a halo orbit to fulfil its relay function. At that point, the lander and the orbiter will start their science operations.

The geometry of the science orbits has been the object of a mission analysis summarized in Annex III. It is shown in Figure 18. During the 35-day surface science sequence, the orbiter is primarily used to study the Alfven wings produced by the Europan magnetospheric interaction (sequence S-5). At the end of surface science operations, it is transferred to a low altitude 200$\mathrm{km}$ high-inclination orbit to perform a global mapping of gravity and magnetic fields and of the Europan plasma populations (sequence S-7). After 3 months of science operations, the orbiter leaves its $200-\mathrm{km}$ circular orbit to explore the very low latitude exosphere in the final descent sequence $(\mathrm{S}-8)$.

\subsection{Environmental constraints on the JEM mission}

\section{Planetary protection:}

As the interest in icy Solar System's bodies is increasing with exciting new findings, new missions are proposed and particularly towards Jupiter's moon Europa. On the basis of deliberations of the dedicated Task Working Group on the Forward Contamination of Europa (NRC, 2000) and of the studies of new international experts working groups such as the "Planetary Protection for the Outer Solar System" (PPOSS) working group commissioned by the 
European Science Foundation, a conservative approach has been defined to be required to protect the Europan environment: Indeed since Europa may have a global ocean possibly connected with the surface, viable extremophile microorganisms such as cold and radiation tolerant organisms may survive a migration to the sub-surface of the ocean and multiply there. According to the COSPAR Planetary Protection policy, a general requirement for every lander mission to Europa, categorized as IV, has to be applied in order to reduce the probability of inadvertent contamination of a subsurface ocean by viable terrestrial microorganisms or their spores to less than $\sim 10^{-4}$ per mission (1 viable microorganism / 10,000 missions).

COSPAR Planetary protection policy of Icy moons missions is under revision. In the context of future missions to these moons, some concepts require an updated definition such as: the environmental conditions potentially allowing terrestrial organisms to replicate; the specific problematic species that might easily adapt to such extreme environments; the period of biological exploration of 1000 years already discussed for Europa Clipper; and even a definition and characterization of "Enhanced Downward Transport zones" at the surface of icy moons that require special care (Coustenis et al., 2019).

In the case of the Europa lander, there is a consensus that planetary protection requirements must be even more stringent than for Mars. The NASA Europa Lander team, following the previous requirements defined for Europa Clipper, proposes changes in the entry parameters used to calculate the probability of contamination of the Europan surface/subsurface. As examples of this severity, all species in the bioburden should be included, not just bacterial spores, and the probability of contaminating a liquid reservoir with less than 1 living organism should be estimated. To achieve that, new approaches and technologies must be implemented, such as terminal sterilization systems and lethality modelling including bio-reduction due to spaceflight. In order to comply with these significantly more stringent International Regulations and to meet the maximum allowed bioburden levels, a strict planetary protection strategy will be set up for JEM. It will integrate the lessons learnt from the past, current and planned missions to the outer Solar System, including those regarding the limitation on crash probability for orbiters, the sterility requirements on landers, penetrators and orbiters that do not meet the non-crash probability, and an ultra-cleanliness level for all life detection instruments and those which are not exposed to the sterilising radiation during the spaceflight. 
The inner magnetosphere of Jupiter where Europa orbits is the most severe radiation

890

891

892

893

894

895

896

897

898

899

900

901

902

903

904

905

906

907

908

909

910

911

912 In its baseline configuration, illustrated in Figure 20, the JEM flight system is composed of two

913 platforms, possibly augmented by an additional CubeSat element (Gaudin, 2016), not described 914 in this article: environment in the Solar System. This presents significant challenges for operating a spacecraft and its science instruments at Europa. The phases when the mission elements are in orbit around Europa are by far the most constraining ones in terms of radiation doses. Low-altitudes orbits around Europa however have a clear advantage in terms of reduced radiation doses when one takes into account the complex trajectories traced by charged particles in the combined Jovian and Europan magnetic fields (Truscott et al., 2011). Figure 19 shows the results of our radiation analysis for these phases using SPENVIS, the JOSE model, as well as various assumptions described in the caption. The sensitive parts and electronics will need to be shielded to reduce the effects of the total ionizing dose (TID), which is equivalent to $50 \mathrm{kRad}$ inside a $22 \mathrm{~mm} \mathrm{Al}$ sphere. Table 6 presents the total ionizing doses received during the different phases of the Europa science mission as a function of the thickness of the aluminium shield. A number of mitigation measures in subsystems designs, shielding of critical elements, and use of radiation hardened parts are discussed in sections 3 and 4.3 .

Europa is within a hard radiation environment, with particle fluxes $>20$ times larger than at Ganymede. The instantaneous background flux due to radiation in low-altitude Europa orbits presents significant challenges for the science instruments but is slightly lower that the JUICE worst case. The flux is on the order of up to $10^{5}-10^{6} \mathrm{~cm}^{-2} \mathrm{sr}^{-1} \mathrm{~s}^{-1}$ behind 10-20 mm Al. This higher background may have a significant impact on the SNR of certain detectors. Sophisticated background suppression techniques will need to be implemented together with shielding optimizations in order to ensure maximal science return as discussed in section 3.

\subsection{The JEM flight system.}

\section{Global architecture.}

\section{- A soft lander platform:}


916 Given the heritage and expertise gained from previous studies, this platform, with $26 \mathrm{~kg}$ payload mass class (including a 32\% margin) operating 22 days on surface, should most likely be delivered by NASA with possible contributions of European national agencies at the investigation level. It will perform investigations in astrobiology, ice characterization and geophysics (Hand et al. 2017).

As an essential component of the JEM concept, we propose that ESA studies and discusses with NASA the procurement of a small sub-platform, the «Astrobiology Wet Laboratory » (AWL), to conduct original astrobiology investigations specialising in the analysis of wet samples (see 924 4.3.3).

\section{- A carrier/orbiter/relay platform:}

926

This platform will fulfil the key functions of injecting the lander stack into an Europan orbit just prior to

its de-orbitation, and of relaying the lander data to Earth. It will also carry a focused instrument suite

(section 3.1) to perform global high-resolution measurements of the gravity, magnetic field and topography fields and of the plasma/neutral environment along Europan orbits.

Optional augmentation: a mission that is likely to fly beyond 2030 should include a small platform that could be released from the main orbiter in Europan orbit to perform focused scientific measurements. Following an open call to the academic community for cubesat ideas, it could be selected on the basis of scientific merit, either as a science contribution to one of the JEM PSO's, or as an opening to a new research theme. One particularly appealing option has been studied by the authors of this article: using a cubesat for a targeted flyby through a Europa plume that would have been previously identified during the beginning of the Europa science orbits (Gaudin et al., 2016).

\subsubsection{The JEM Orbiter complement.}

\subsubsection{The carrier / orbiter / relay platform}


The JEM carrier/orbiter platform will serve two objectives: (1) deliver the NASA lander to an orbit around Europa, and relay its scientific data to Earth; (2) perform global high-resolution measurements of the gravity, magnetic field and topography fields and of the plasma/neutral environment. The proposed JEM orbiter concept, presented in Annex II, is inherited from two platforms currently developed by ESA:

1- the European Service Module (ESM) of the Orion Multi-Purpose Crew Vehicle (MPCV), from which the mechanical and propulsion bus is adapted for JEM. The ESM serves as primary power and propulsion component of the Orion spacecraft. It presents several advantages for the JEM mission: it can carry a very heavy payload (the Orion Crew Vehicle is in the 10 tons class), it can be launched on SLS, and it is developed in a NASA / ESA collaboration framework. Many key systems proposed to be reused for JEM will be flight-proven at the time of JEM mission adoption.

2- the Jupiter Icy Moons Explorer (JUICE) platform, which provides a relevant basis for the avionics of an interplanetary mission to Jupiter. The JUICE spacecraft, to be launched in May 2022, provides key assets for the other components of the JEM orbiter: a rad-hard avionics adapted to the specific constraints of an interplanetary mission and protected within a leadshielded vault, and a power subsystem designed for LILT (Low Intensity Low Temperature) conditions.

Figure 21 shows the general configuration of the carrier/orbiter and its interface with the lander stack, before deployment (left) and just after lander stack release (right).

\subsubsection{The JEM Lander complement.}

\subsubsection{The Soft Lander platform.}

For the purpose of this work we assumed that the soft lander platform will be delivered by NASA and benefit from the heritage of several previous studies of its concept. Figure 22 shows its architecture in the 2017 SDT report (Hand et al., 2017), a concept still under review. The soft lander will be the final element of the "lander stack" which also includes a propulsion stage and a sky crane following a concept similar to the Mars Science Laboratory sky-crane- A gimbaled high gain antenna, co-aligned with the panoramic camera and mounted on the same articulated mast, will be used for the communications with the carrier-orbiter. The lander will be equipped, in addition to the payload, with a robotic arm with collection tools. 
971

972

973

974

975

976

977

978

979

980

981

982

983

984

985

986

987

988

989

990

991

992

993

994

995

996

997

998

999

In line with the JEM science plan, we propose the functional structure presented in figure 23 for the surface science platform carried by this soft lander. The analysis of samples of astrobiological interest will be performed by two complementary sample analysis facilities, one devoted to the analysis of solid samples, and another one dealing with liquid samples. The interest in the wet chemistry measurements is testified by the recent selection in the ICEE-2 program for instrument development of two technologies incorporating microfluidic systems (MICA: Microfluidic Icy world Chemistry Analyzer ; MOAB: Microfluidic Organic Analyzer for Biosignatures). The two facilities will be served by a common articulated arm shown in figure 22. In addition to astrobiology investigations, the lander will also operate a geophysics station for the study of the planetary fields, the sounding of the sub-surface and the study of the properties of the surface ice.

We propose that the liquid sample analysis facility, called AWL for Astrobiology Wet Laboratory, be developed by ESA with sensor provided by its member states.

\subsubsection{The Astrobiology Wet Laboratory (AWL)}

We envisage two accommodation options for the AWL: on the lander (AWL/L), or deployable as a separate element at the surface (AWL/S). The latter option requires that the arm holds the instrument and deposits it on the surface. The reason for selecting one of other option could be based on the arm design constrains but also on the biochemical cleanliness conditions. AWL detects large organics molecules (proteins, lipids, etc.) and to avoid false positives the level of biochemical cleanliness of the arm solid sampler should be stricter than if it only supplies samples to an organic analyser or a vibrational spectrometer. If the AWL works at the surface it has its own sampler; if it is inside the lander it only has a module to liquefy the sample. From an engineering point of view, it is more efficient to have the AWL inside the lander. The AWL could also host the magnetometer with a small increase of mass (deployment boom, sensor head and electronic) and if it is on the lander it could also include the thermogravimeter. In this case, the ESA contribution is a totally independent package, with clear interfaces with the lander.

AWL/S description: the block diagram of the Astrobiology Wet Laboratory (AWL) is shown in Figure 24. In the AWL/S option it is composed of: i) a Sample Acquisition Module in charge of making a $10 \mathrm{~cm}$ hole to take a liquid sample, ii) the Data Processing Unit which controls the 
1000

1001

1002

1003

1004

1005

1006

1007

1008

1009

1010

1011

1012

1013

1014

1015

1016

1017

1018

1019

1020

1021

1022

1023

1024

1025

1026

1027

1028

instrumentation and the communication with the lander; iii) a Power Unit composed by the batteries and circuit to regulate the power and distribute it to the other units; iv) a Communication Unit to establish the connections with the lander via an umbilical cable. An external structure support allows one to deploy the AWL with the lander manipulator. For the Sample Acquisition Module (SAM), we have evaluated different alternatives for drilling (Ulamec 2007, Biele 2011, Weiss 2011, Sakurai 2016), taking into account the limitations on resources and trying to reduce as much as possible the use of any mechanism. The most promising option is the use of a drilling system based on laser. Sakurai (2016) has demonstrated the capabilities of this concept. Some of the characteristics of SAM are summarized in Table 7:

Figure 25 shows a sketch of the concept proposed. The water sample is taken in two steps: i) the first $5 \mathrm{~cm}$ of ice (degraded by the radiation) are sublimated by the laser and ii) the tube is moved down by a pneumatic actuator and once in contact penetrates by $5 \mathrm{~cm}$ in the ice. The tube is pressurized and heated to provide conditions in which the water is stable. At this moment the sample is sucked by a syringe (controlled by a spring) to fill the sample deposit. From this deposit the instruments are filled. A single pressurized deposit (nitrogen TBC) is used for tube movement and pressurization. The most critical components of the AWL/S are the batteries. They are the heaviest element and need to be controlled above a determined temperature to maintain their performances. For radiation protection, the Warm and Shielding Box has a thickness of $18 \mathrm{~mm} \mathrm{Al}$ to allow the use of space standard components. Figure 26 shows the AWL mechanical configuration. A warm and shielding box (WSB) is used to maintain the operational temperature and protect all the electronics for radiation. The WSB will guarantee by design bio-cleanliness after integration. The SAM will have an isolation lid that will be closed once at the end of the integration to maintain biological cleanliness. An opening protected with an EPA filter will help the decompression during launch. The external structure supports the magnetometer boom and allows hanging to the lander articulated arm.

This configuration allows ejection from the lander if for some scientific reason it was recommended to explore some site far from it. The AWL side could be equipped with small airbags following a similar concept implemented in the Pathfinder lander. A set of petals could guarantee its vertical orientation. 
1029

1030

1031

1032

1033

1034

1035

1036

1037

1038

1039

1040

1041

1042

1043

1044

1045

1046

1047

1048

1049

1050

1051

1052

1053

1054

1055

1056

1057

AWL/L description: The main difference with the AWL/S is the SAM, which in this case is reduced to a module to liquefy the sample and has no batteries, making the Power Unit much simpler. The process for obtaining the liquid sample is similar to the one proposed for the AWL/S.

\subsubsection{Exploring the potential of the Square Kilometre Array for enhanced data downlink} capabilities.

The Square Kilometre Array (SKA) ${ }^{1}$ is an international project aiming to eventual construction of the radio telescope with the collecting area of the order of one square kilometer. Its physical construction is to start in 2021 in two locations, in Western Australia and South Africa, with the full operational deployment well before the realistic launch date of the mission described in this paper. The SKA part located in South Africa, the so-called SKA-Mid, will cover the standard deep space communications radio bands at 2.3 and, importantly, $8.4 \mathrm{GHz}$, the latter being one of the main operational data downlink bands for the JEM mission. The SKA1-Mid, the first implementation part of the complete SKA project, is presented in detail in Annex IV.

The SKA's high sensitivity warranted by its unprecedented collecting area has been considered as an important asset for potential deep space communication applications early in the SKA project development stage (e.g., Bij de Vaate et al. 2004, Fridman et al. 2010). The use of SKA1Mid for deep space communication has also been considered during the detail design phase (Schutte 2016). A preliminary discussion between the JEM proposing team and the SKA Organization has identified a significant mutual interest in using the SKA to enhance the data downlink capability of JEM for short periods during each of the three generic science sequences: (Sequence B) SKA will be able to increase the data volume returned to Earth from the carrierorbiter by about an order of magnitude; (Sequence A) SKA might be able to receive data directly from the lander or from the JEM cubesat, without a relay by the orbiter; (Sequence C) finally, SKA could directly receive data from the orbiter during the critical descent science phase, thus solving the platform pointing conflicts between the high-gain antenna and the INMS instrument. An in-depth investigation of engineering and operational issues of the SKA use as a JEM science

\footnotetext{
${ }^{1}$ https://www.skatelescope.org, accessed 2020.03.23.
} 
1058

1059

1060

1061

1062

1063

1064

1065

1066

1067

1068

1069

1070

1071

1072

1073

1074

1075

1076

1077

1078

1079

1080

1081

1082

1083

1084

1085

data reception station will be addressed at the appropriate phases of the JEM project. Some preliminary engineering considerations are given in Annex IV. As it becomes clear from the estimates presented there, SKA-Mid could increase deep space telemetry rates by more than an order of magnitude for short communication sessions.

\section{Proposed international collaboration schemes:}

We propose the following share of responsibilities between ESA and NASA, to be discussed by the two agencies: (1) The two baseline platforms would be operated by NASA with the support of ESA; (2) NASA would build and operate the lander platform and study with ESA the possibility of deploying from that platform a small ESA-provided « Astrobiology Wet Laboratory (AWL)» as an option; (3) ESA would take a major responsibility in the delivery of the carrier/orbiter/relay platform, ranging from the delivery of the full platform to the delivery of an integrated «science investigation platform » and of critical subsystems; (4) The proposed selection of scientific investigations on the different flight elements would be validated by ESA for the carrier/orbiter and by NASA for the lander and will likely include contributions from the two corresponding scientific communities. ESA would support the developments required to reach TRL6 during the study phase for the AWL, the MPAS and the MPP sensors. ESA would initiate early in the project the planetary protection plan and its implementation.

\section{Summary and conclusions}

In this article we described the design of an exciting planetary mission to search for biosignatures at Jupiter's ocean moon Europa and characterize it as a potential habitat. We started from a more general question: what are the evolutional properties of a habitable moon and of its host circumplanetary system which make the development of life possible. By choosing the Jupiter system as our destination, we can build on the advanced understanding of this system which the missions preceding JEM, Juno, JUICE and Europa Clipper will provide. We propose the following overarching goals for the JEM mission: Understand Europa as a complex system responding to Jupiter system forcing, characterise the habitability of its potential biosphere, and search for life at its surface and in its sub-surface and exosphere. These goals can be addressed by a combination of five Priority Scientific Objectives providing detailed 
1086

1087

1088

1089

1090

1091

1092

1093

1094

1095

1096

1097

1098

1099

1100

1101

1102

1103

1104

1105

1106

1107

1108

1109

1110

1111

1112

1113

1114

1115

1116

constraints on the science payloads, on the platforms that will carry them and on the mission architecture.

Scientific observations will be made during three sequences: 1- on a high-latitude, low-latitude Europan orbit providing a global mapping of planetary fields (magnetic and gravity) and of the neutral and charged environment; 2- in-situ measurements at the surface, using a soft lander focusing on the search for bio-signatures at the surface and sub-surface using analytical techniques in the solid and liquid phases, and a surface geophysical station; 3- measurements of the very low exosphere in search for biomolecules originating from the surface or sub-surface during the final descent phase.

These observations will be done by two science platforms: a soft Europa lander and an orbiter. In this concept, the carrier/orbiter will carry the lander stack from Earth to a Europan orbit from which it will release the lander. It will then provide the data relay during the lander operations and perform science operations during the relay phase on a halo orbit of the Europa-Jupiter system, before moving to its final Europan science orbit for three months.

Our orbiter payload includes seven well-proven instruments to characterize planetary fields and the plasma, neutrals and dust environment. To efficiently address the radiation issue, we propose to decouple the sensor heads from the other parts of the electronics and to group these parts in a dedicated vault or a well-shielded location within the platform. Appropriate planetary protection measures corresponding to at least Planetary Protection Category IVb will be applied to all subsystems, including the payload and the spacecraft element.

Our lander science platform is composed of a geophysical station and of two complementary astrobiology facilities carrying biosignature characterization experiments operating respectively in the solid and in the liquid phases. The development of the liquid phase laboratory, called AWL for "Astrobiology Wet Laboratory", could be a specific European contribution. The two astrobiology facilities will be fed by a common articulating arm operating at the platform level that will collect the samples at the surface or sub-surface. We are proposing two alternative options for the deployment of AWL: inside the main platform, where it would benefit from all its infrastructure and services, or outside of it as an independent sub-platform, to be deployed with the help of the articulated arm.

Given their investments and experience in the space exploration of the Jupiter system, NASA and ESA are in the best position to collaborate on the implementation of JEM. To make JEM an 
1117 affordable and appealing joint exploration venture for the two agencies, we propose an

1118 innovative distribution of roles; ESA would design and provide the carrier-orbiter-relay platform

1119 while NASA would provide an SLS launcher, the lander stack and most of the mission 1120 operations. We showed in this article that this delivery is technically possible using a safe 1121 technical approach, taking advantage of a double heritage of European developments for space 1122 exploration: the Juice spacecraft for the JEM orbiter avionics, and an adaptation of the ORION

1123 ESM bus for its structure. Following this approach, we believe JEM will be a very appealing 1124 joint venture of NASA and ESA, working together towards one of the most exciting scientific 1125 endeavours of the 21 st century: search for life beyond our own planet.

1127 Acknowledgements: The authors received support from the sponsors of their home institutions 1128 during the development of their projects, particularly at the two institutes leading this effort: at 1129 IRAP, Toulouse, MB and NA acknowledge the support of CNRS, University Toulouse III - Paul 1130 Sabatier and CNES. At CAB, Madrid, OPB and JGE acknowledge the support of INTA and 1131 Spanish MINECO project ESP2014-55811-C2-1-P and ESP2017-89053-C2-1-P and the AEI 1132 project MDM-2017-0737 Unidad de Excelencia "María de Maeztu.". We would also like to 1133 extend special thanks to the PASO of CNES for its precious assistance and expertise in the 1134 design of the mission scenario. 
ANNEX I: Summarized traceability matrix for JEM / OVERARCHING GOAL: Understand Europa as a complex system responding to Jupiter system forcing, characterize the habitability of its potential biosphere, and search for life at its surface.

\section{ANNEX II: JEM orbiter system design}

1141 The main design drivers of the carrier/orbiter are:

1142 - to accommodate a 2,8 tons lander stack, to sustain the lander during cruise and to eject it with the 1143 highest accuracy and reliability,

1144 - to accommodate a very large tank capacity to provide the required delta $\mathrm{V}(\sim 3 \mathrm{~km} / \mathrm{s})$ for a $\sim 13$ 1145 tons composite,

1146 - to accommodate large appendages (large solar generator to cope with low solar flux and high 1147 radiation degradation, high gain antenna, instruments boom to support the orbiter's instruments 1148 suite),

1149 - to maintain spacecraft resources and reliability in a very harsh environment (high radiation in

1150 Europan orbit, very cold temperature at Jupiter),

1151 - to provide a sound mechanical interface with the Space Launch System (SLS).

1152 The projected mass budget and ISP of the carrier and lander stack are shown in Table A2.1.

1153 Delta and propellant budget. The launch and transfer strategy (NASA design) features a large 1154 Deep Space Maneuver (DSM) and an Earth Gravity Assist to reach Jupiter. This so-called 1155 DVEGA scenario was also used by Juno. The SLS performance (Block 1 version) for this 1156 scenario is 13,3 tons. The delta V budget during the Jupiter Tour (Table A2.2) is taken from the 1157 JPL design known as the "12-L1" Tour ("Jovian tour design for orbiter and lander missions to 1158 Europa", Campagnola et al, 2014). The total delta V budget amounts to $3050 \mathrm{~m} / \mathrm{s}$. Assuming an 1159 orbiter dry mass of $2500 \mathrm{~kg}$ and a lander stack of $2800 \mathrm{~kg}$, the propellant budget reaches 7900 $1160 \mathrm{~kg}$. The composite wet mass (13,2 tons) is compatible with the launcher capability. The 1161 maximum dry mass requirement put on the JEM orbiter is therefore $2500 \mathrm{~kg}$, including $20 \%$ 1162 system margin. Note that an additional gravity assist at Earth would allow to reduce the DSM 1163 intensity, and provide very significant additional mass margin at the cost of one additional year 1164 of transfer. 
1165 As an alternative to the SLS, use of a Falcon Heavy launcher would significantly reduce the 1166 mission cost, though likely at the expense of an additional Earth gravity assist: we did not study 1167 this option in detail but it should be kept in mind.

1168 The delta budget is consistent with the JPL mission profile (DV-EGA transfer, 12-L1 Jupiter 1169 Tour). The propellant budget fits within the Orion ESM capability (8600 kg) with margin. Based 1170 on these key figures, it has been possible to perform a rough study of the JEM orbiter. Figure 1171 A2.1 shows its baseline configuration, stacked and deployed.

1172 Radiation design: The radiation system design is a compromise between shielding mass and rad1173 hard electronics development. The radiation analysis results in a TID of 50 kraal inside a $22 \mathrm{~mm}$ $1174 \mathrm{Al}$ sphere. This $50 \mathrm{kraal}$ value is the design target considered for JUICE, and it is proposed to be 1175 considered also for JEM to maximize the reuse of the JUICE electronics. Assuming a compact $11760,5 \mathrm{~m}^{3}$ vault (half the JUICE volume), the $22 \mathrm{~mm}$ equivalent $\mathrm{Al}$ leads to $188 \mathrm{~kg}$ of lead shielding 1177 (4.5 mm of lead thickness, assuming $15 \%$ of shielding efficiency thanks to use of a high $\mathrm{Z}$ 1178 material).

1179 Power sizing: Power generation in LILT conditions $\left(50 \mathrm{~W} / \mathrm{m}^{2}-130^{\circ} \mathrm{C}\right)$ and under the very harsh 1180 radiation environment at Europa is a challenge. Displacement damage is produced in the solar 1181 cells under electrons and protons irradiation, significantly reducing the EOL power. To reduce 1182 cost, mass and complexity, the JUICE solar generator $\left(85 \mathrm{~m}^{2}\right)$ is downsized for JEM to $78 \mathrm{~m}^{2}(4$ 1183 panels of the 5-panel JUICE wings are kept). The same design approach as currently used on 1184 JUICE is proposed for JEM, with a $300 \mu \mathrm{m}$ thick cover glass protecting the solar cells. 1185 Extrapolating the JUICE solar generator's performance on the JEM mission profile demonstrates 1186 that a $78 \mathrm{~m}^{2}$ solar generator will provide around $650 \mathrm{~W}$ end of life. This value is used as power 1187 requirement for JEM orbiter design.

1188 Mechanical, propulsion and thermal control: The Orion ESM mechanical bus is reused and 1189 adapted for JEM. The primary structure is a cylindrical shape of $4 \mathrm{~m}$ in diameter and $3 \mathrm{~m}$ in 1190 height, made of aluminum-lithium alloy. All equipment specific to the Orion mission (e.g. life 1191 support systems) are removed from the central box to free space for the Lander Stack, that is 1192 accommodated on the top face of the orbiter (as the Orion Crew Vehicle), with the Solid Rocket 1193 Motor (SRM) fitted inside the inner rectangular cylinder. Guided rails are added within the inner 1194 box to ease and secure the lander's ejection. The mechanical interface between the orbiter and 1195 the lander is made with a skirt mounted on the SRM tank. A planetary protection back shell 
covers the entire lander stack to keep it clean. The lower part of the inner cylinder accommodates the $0,5 \mathrm{~m}^{3}$ lead-shielded electronics vault. The JEM bi-propellant propulsion system makes the maximum reuse of the ESM design. The $27 \mathrm{kN}$ main engine is removed, and only the 4 nominal $490 \mathrm{~N}$ (Aerojet R-4D) are kept. These 4 main engines provide a $2 \mathrm{kN}$ thrust used in the nominal case for the large Jupiter and Europa Insertion Manoeuvres (JOI, EOI). The Reaction Control System (RCS) is downgraded, replacing the $220 \mathrm{~N}$ engines by $22 \mathrm{~N}$ thrusters (MOOG DST-12, used on JUICE). 4 pods of $3 \times 22 \mathrm{~N}$ thrusters provide attitude control during main engines boost and a safe back-up in case of one $490 \mathrm{~N}$ failure. Two upper pods of $4 \times 22 \mathrm{~N}$ provide attitude control around Z. The 4 large propellant tanks (with a maximum capacity of $8600 \mathrm{~kg}$ of propellant, compatible with JEM needs of $7900 \mathrm{~kg}$ ) and the 2 pressurant tanks are kept. The Orion ESM thermal control system (designed to reject $5 \mathrm{~kW}$ of heat) is considerably simplified and downsized for a fully passive control system, using a network of surface heat pipes to transport the heat to the radiators. The same MLI blankets (with external conductive layer) are used as for JUICE, to ensure a clean EMC environment for the orbiter's plasma package. Power system: A two-wing $78 \mathrm{~m}^{2}$ solar generator provides the required $650 \mathrm{~W}$ EOL power. The JUICE PCDU is reused to condition the electrical power on a regulated $28 \mathrm{~V}$ bus. A $167 \mathrm{Ah}$ battery (JUICE battery downscaled to 3 modules) supplies the spacecraft during the 3 hours eclipses in Europan orbit, and complements the solar generator in high power phases such as insertion manoeuvres. The PCDU also provides the electronics of the Solar Array Drive Mechanism (SADM), to optimize radiation shielding.

Avionics: The JUICE avionics is reused for the JEM orbiter. The central computer, the science mass memory and the Remote Interface Unit (RIU) are packaged into a single unit to improve shielding efficiency. Attitude control is based on a gyro-stellar estimation filter, reaction wheels for fine pointing (high gain antenna, laser altimeter) and RCS thrusters. The X-band communication system is reused from JUICE and based on a Deep Space Transponder, a 2,5m high gain antenna, and two low gain antennas for communication in LEOP and emergency TC link at Jupiter. Two UHF antennas (reused from Mars Express) are used for lander TM recovery. Relay Operations: The concept of operations is driven on one side by the configuration of the antennas and on the other side by the mission needs. The HGA (High Gain Antenna) is located below the spacecraft and the large beam width UHF antenna is located on a lateral face of the spacecraft. This ensures that there is, for any orbit around Europa and out of Jupiter eclipses, a 
significant section of the orbit where pointing HGA towards Earth is compatible with having UHF antenna in visibility of the lander. The HGA allows a data rate towards earth of more than $15 \mathrm{kbps}$ for a mission need that is below $150 \mathrm{Mb}$ per day. Thus only a small fraction of the relay orbit requires pointing of HGA towards Earth.

1231 Design for payload:

1232 A $5 \mathrm{~m}$ magnetometer boom is used to provide a clean magnetic environment to the MAG sensors.

1233 The possibility to accommodate the JUICE recurrent 10.6m MAG boom will be investigated in

1234 Phase A. All design measures taken on JUICE to ensure the best EMC cleanliness performances

1235 are reused for JEM: the electronics vault provides an efficient Faraday cage to contain E-field

1236 radiation from electronics, a distributed single grounding point is implemented within the PCDU

1237 to avoid common mode perturbation, external surfaces (solar generator, MLI) are covered with

1238 an outer conductive coating to avoid charging, a magnetic shield is implemented on the most

1239 perturbating units (reaction wheels, motor drives). Two monitoring cameras will provide pictures

1240 of the lander's ejection. The overall resources allocation for the JEM orbiter is $50 \mathrm{~kg}$ and $100 \mathrm{~W}$.

1241 The launch mass budget fits within the SLS capability and includes a 20\% system margin on the 1242 carrier's dry mass. 
1246 Once the Carrier has released the Lander, it must act as a relay for the total duration of the

1247 Lander mission. Choosing a halo orbit around the Jupiter-Europa L1 Lagrangian point (JEL1)

1248 provides a great coverage of the landing site. The unstable nature of those orbits allows low-

1249 energy transfers, while the cost of orbit maintenance is very low.

1250 Halo orbits are families of unstable periodic orbits in the 3-body problem around collinear

1251 Lagrangian points [Dynamical Systems, the Three-Body Problem ad Space Mission Design

1252 (Koon et al., 2006)]. The choice of a specific halo orbit among its family is subject to a few

1253 constraints:

1254• The position of the landing site

1255• The science expected to be accomplished

1256• The $\Delta \mathrm{V}$ needed to reach and to leave this orbit

1257 The time of flight to reach and to leave this orbit.

1258 The variation of the radiation dose is negligible regarding the choice of a specific halo orbit.

1259 Because of the symmetry of the 3-body problem, the landing site is assumed to be on the 1260 northern hemisphere of Europa, and the halo orbits are chosen in the southern class for this 1261 study. The results would be the same with a landing site on the southern hemisphere and with 1262 northern halo orbits. In order to investigate the Europa-magnetosphere interaction, a halo orbit 1263 near Europa is preferred.

1264 Once a specific halo orbit is chosen, the transfer from this halo orbit to a low-altitude, near polar, 1265 circular orbit around Europa (LEO) is studied. The characteristics selected for this orbit are an 1266 inclination between $80^{\circ}$ and $90^{\circ}$, and an altitude between $100 \mathrm{~m}$ and $200 \mathrm{~km}$ [Europa Study 2012 1267 (NASA)]. First, at each position on the halo orbit, a small burn (few $\mathrm{m} / \mathrm{s}$ ) in the unstable direction 1268 toward Europa is performed.

1269 Then, when one of those trajectories features an extremum of distance to Europa, the osculating 1270 orbital elements are calculated to see if they match the requirement of the LEO. A tangent burn 1271 to circularize around Europa is then applied. A set of halo orbits [Global search for planar and 1272 three-dimensional periodic orbits near (Russell, 2006)] labelled with ID's (Figure A3.1 and 1273 Table A3.1) was investigated in order to highlight the range of possibilities for a transfer from a 1274 halo orbit to a LEO. Figure A3.4 shows a subset of these couples of halo and transfer orbits. 
1275

1276

1277

1278

1279

1280

1281

1282

1283

1284

1285

1286

1287

1288

1289

1290

1291

1292

1293

1294

1295

1296

1297

1298

1299

1300

1301

1302

1303

The results (Figures A3.2 and A3.3) indicate a $\Delta \mathrm{V}$ between $440 \mathrm{~m} / \mathrm{s}$ and $540 \mathrm{~m} / \mathrm{s}$, for a duration of 1-7 days. Some halo orbits have more possibilities of transfer than others. Some of them don't have any possibilities of transfer (ID = 275). The closer to Europa the halo orbit is, the higher the $\Delta \mathrm{V}$ is. If we take a look at the range of possibilities of LEO's for each halo orbit, choosing a more specific LEO could limit the possibilities even more. Characteristics of some of the reachable LEO orbits are shown in Table A3.2, and characteristics of the corresponding transfer orbits in Table A3.3.

If a specific LEO is necessary, one solution would be to pick the transfer to a LEO close to the desired LEO, and then perform a change of altitude and a change of inclination. A change of altitude from $200 \mathrm{~km}$ to $100 \mathrm{~km}$ is $40 \mathrm{~m} / \mathrm{s}$ while a change of inclination of $10^{\circ}$ is $240 \mathrm{~m} / \mathrm{s}$ (which is not negligible). However, we can expand the possibilities of transfer using a non-negligible burn to leave the halo orbit. To limit the degree of freedom of this problem, a simple tangent burn is used [Connecting halo orbits to science orbit at planetary moons (Bokelmann and Russell, 2017)].

The number of possibilities is largely expanded. Even if the $\Delta \mathrm{V}$ tends to be higher, a transfer with less than $530 \mathrm{~m} / \mathrm{s}$ and a reasonable time of flight can always be found (less than 3 days). Even more, the spectrum of reachable LEO is also wide. The last thing to be done is to select the transfer best suited for the mission.

\section{ANNEX IV: Square Kilometre Array as a data downlink reception station for JEM}

This annex gives a preliminary overview of the potential capabilities of the advanced radio astronomy facility, the Square Kilometre Array (SKA), and in particular its first implementation phase for medium-range frequencies, SKA1-Mid as an Earth-based receiving station for the JEM science data downlink. The primary mission of SKA is the advancement of radio astronomy. However, exploratory discussions on a potential use of some fraction of the SKA observing time enhancing science output of planetary missions are underway too. Basic parameters of the SKA1-mid used in the estimates presented below are taken from the SKA Info Sheets ${ }^{2}$ and references therein.

\footnotetext{
${ }^{2}$ https://www.skatelescope.org/technical/info-sheets/, accessed 2020.03.23.

${ }^{3} \mathrm{https}: / /$ www.sarao.ac.za/media-releases/meerkat-joins-the-ranks-of-the-worlds-great-scientific-instrumentsthrough-its-first-light-image/, accessed 2020.03.25.
} 


\section{$\underline{\text { A4.1 Description of SKA1-Mid }}$}

The SKA1-Mid instrument will be an array of 197 offset Gregorian dishes and associated signal processing equipment (figure 4.1). The dishes will provide a total collecting area of $32,700 \mathrm{~m}^{2}$. Of these, 64 dishes have been constructed as part of the MeerKAT precursor telescope, while an additional 133 dishes will be constructed for SKA1. MeerKAT is already operational and early scientific results include the discovery of more than 1200 new galaxies in its First Light image ${ }^{3}$ and the highest resolution images yet of our galactic center ${ }^{4}$. SKA1-Mid will re-use much of the existing MeerKAT infrastructure, including the shielded subterranean Karoo Array Processor Building and the electrical power system. SKA1-Mid is being designed for $24 / 7$ operation and an overall time efficiency greater than 0.9. Several critical systems (power supply, core power distribution, processor cooling, etc.) are redundant. The full SKA1-mid array will consist of a circular dense core and three spiral arms extending to a distance of approximately $90 \mathrm{~km}$ from the core (figure 4.2). The instrument will be located near Carnarvon in the Karoo region of South Africa, approximately centered on the following coordinates: $30^{\circ} 42^{\prime} 46.37^{\prime \prime} \mathrm{S}, 21^{\circ} 26^{\prime} 35.50^{\prime \prime E}$.

SKA1-Mid will cover the frequency range $0.35-13.8 \mathrm{GHz}$ in 5 bands. The cryogenically cooled Band 5 receivers of SKA1-mid will cover the frequency range from 4.6 to $13.8 \mathrm{GHz}$, and will therefore include the X-band telemetry allocation around $8.4 \mathrm{GHz}$. The SKA1-Mid construction roll-out will progress through several array releases, with all dishes (and MeerKAT) integrated and commissioned by 2027. It is likely that a series of expansions and upgrades will be implemented following 2027, as part of the future SKA2 project.

\section{A4.2 Summary of SKA1-Mid potential for the support to deep space missions}

The sensitivity of SKA1-Mid in terms of the ratio G/T (where G is the telescope gain and $\mathrm{T}$ is the system noise temperature) will be about 25 times that of a generic modern X-band $35 \mathrm{~m}$

\footnotetext{
${ }^{4}$ https://www.sarao.ac.za/south-africas-meerkat-discovers-giant-radio-bubbles-at-centre-of-milky-way/, accessed 2020.03.25.
} 
1333 Earth-based deep space data reception station. This leads to three transformational capabilities

1334 for deep space missions. In particular,

1335 SKA1-mid will be able to increase the data rate of science data downlink delivered to Earth 1336 comparing to the currently operational deep space communication assets.

1337 - SKA1-mid will be able to receive data directly from small descent and landing probes or from a 1338 mini-satellites (e.g., a JEM cubesat), without a relay spacecraft.

1339 - SKA1-mid could directly receive data from a mission spacecraft during critical phases of high

1340 scientific interest, like a descent to a planetary surface, radio occultation, etc.

1341 In many cases, the SKA1-mid facility will be the only instrument on Earth capable of providing

1342 these capabilities, and could therefore be an important resource for future deep space 1343 exploration.

1344 In order to evaluate the capacity of SKA1-mid for data reception, a model link budget has been 1345 analyzed under the following assumptions:

1346 - Spacecraft transmitter Power: $50 \mathrm{~W}$

1347 - Onboard HGA gain: $44.8 \mathrm{~dB}$

1348 - Pointing loss: $0.1 \mathrm{~dB}$

1349 In the X-band, the SKA1-mid Band 5 receiver figure of merit $(\mathrm{G} / \mathrm{T})$ has been conservatively

1350 estimated as $67.22 \mathrm{~dB}$. Assuming the following link parameters:

- $\quad$ Link margin: $3 \mathrm{~dB}$

- $\quad$ Bit error rate (BER): $10^{-5}$;

1354 Ratio of the energy per transmitted bit, $E_{b}$, to the spectral noise density, $N_{0}$,

$1355 \quad \mathrm{~Eb} / \mathrm{No}=0.3$

1356 - Modulation: QPSK;

1357 - Forward error correction: turbo code with the code rate 0.25 ;

1358 - The distance between the spacecraft and Earth: $8 \times 10^{8} \mathrm{~km}$.

1359 These parameters result in the over-the-air data rate of 1.6 Mbps when using SKA1-mid as 1360 reception station, and up to $2.3 \mathrm{Mbps}$ under ideal conditions. This calculation should be 1361 considered an initial estimation, and further study is required. The major underlying 1362 assumption is that $60 \%$ of the collecting area of the SKA1-mid array can be used for reception, 1363 due to the difficulty in correcting phase errors of the outer spiral arm dishes. Thus, a 
1364 conservative working assumption is that dishes up to a radius of approximately $1.3 \mathrm{~km}$ (i.e.

1365 most of the core) can be successfully phased up.

1366 For radio telescopes it is customary to express their instantaneous sensitivity performance in

1367 terms of effective collecting area over system temperature $\left(\mathrm{A}_{\mathrm{e}} / \mathrm{T}_{\mathrm{sys}}\right)$. This parameter for SKA1-

$1368 \mathrm{mid}$ at $8.4 \mathrm{GHz}$ is $\mathrm{A}_{\mathrm{e}} / \mathrm{T}_{\mathrm{sys}}=890 \mathrm{~m}^{2} / \mathrm{K}$. At a radius of $1.3 \mathrm{~km}$, the total available sensitivity is

1369 reduced to $60 \%$ of the total, giving $A_{e} / T_{\text {sys }}=534 \mathrm{~m}^{2} / \mathrm{K}$.

1370

1371 
1373 Baross, J.A. and S. E. Hoffman (1985). Origins of Life and Evolution of the Biosphere 15(4): $1374 \quad 327-345$.

1375 Bills, B., Ray, R. (2000). J. Geophys. Res., 105 (E12), p. 29277-29282

1376 Biele J. et al. (2011). Adv. Space Res.48, 755-763

1377 Bij de Vaate J.G. et al. (2004), 'Spacecraft Tracking Applications of the Square Kilometre 1378 Array', 3rd International Workshop on Tracking, Telemetry and Command Systems for Space 1379 Applications, TTC 2004, 93-100 (https://arxiv.org/abs/2002.10024)

1380 Bird M.K., Allison M., Asmar S.W., Atkinson D.H., Avruch I.M., Dutta-Roy R., Dzierma Y., 1381 Edenhofer P., Folkner W.M., Gurvits L.I., Johnston D.V., Plettemeier D., Pogrebenko S.V., 1382 Preston R.A., Tyler G.L., 2005, Nature 438, 800-802

1383 Blöcker A., J. Saur, and L. Roth (2016), J. Geophys. Res.., 121, doi: 10.1002/ 2016JA022479.

1384 Bocanegra Bahamón T.M., Molera Calvès G., Gurvits L.I., Duev D.A., Pogrebenko S.V., Cimò G., Dirkx 1385 D., and Rosenblatt P., 2018, AA 609, A59

1386 Bocanegra Bahamón T.M., Molera Calvés G., Gurvits L.I., Cimò G., Dirkx D., Duev D.A., Pogrebenko 1387 S.V., Rosenblatt P., Limaye S., Cui L., Li P., Kondo T., Sekido M, Mikhailov A.G., Kharinov M.A., 1388 Ipatov A.V., Wang W., Zheng W., Ma M., Lovell J.E.J., and McCallum J.N. 2019, A\&A, 624, A59

1389 Bokelmann, K.A., Russell, R.P.: Halo orbit to science orbit captures at planetary moons. Acta Astron.

1390 134, 141-151 (2017). https://doi.org/10.1016/j.actaastro.2017.01.035

1391 Brown M.E. and Hand K.P. (2013). Astronomical J. 145, 110

1392 Campagnola,S., Buffington,B. B., Petropoulos, A.E. (2014). Acta Astronautica, 100, 68-81

1393 Carlson R.W. et al. (1999). Science 286, 97-99

1394 Carlson et al., (2005). Icarus 177, 461-471 
Cassen, P., et al. (1979). Geophys. Res. Lett. 6(9): 731-734.

1396 Chen, E. M. A. et al. (2014). Icarus, Volume 229, p. 11-30

1397 Cooper, J. F., et al. (2009). Planet Space Sci., Volume 57, Issue 13, p. 1607-1620

1398 Cooper J.F. et al. (2001). Icarus 149, 133-159

1399 Coustenis et al. (2019). The COSPAR Panel on Planetary Protection Role, Structure and 1400 Activities. Space Research Today 205, 14-26

1401 Dalton et al., (2005). Icarus 177, 472-490

1402 Dalton, J. B. et al. (2010). EGU General Assembly Conference Abstracts.

1403 Dirkx D., Gurvits L.I., Lainey V., Lari G., Milani A., Cimò G., Bocanegra-Bahamon T.M., 1404 Visser P.N.A.M., 2017, PSS 147, 14-27

1405 Dirkx D., Lainey V., Gurvits L.I., Visser P.N.A.M. 2016, PSS 134, 82-95

1406 Dirkx D., Prochazka I., Bauer S., Visser P.N.A.M., Noomen R., Gurvits L.I., Vermeersen L.L.A. 1407 2018, Journal of Geodesy, p. 1-16

1408 Duev D.A., Molera Calvés G., Pogrebenko S.V., Gurvits L.I., Cimò G., Bocanegra Bahamon 1409 T.M., 2012, A\&A 541, A43

1410 Duev D.A., Pogrebenko S.V., Cimò G., Molera Calvés G., Bocanegra Bahamón T.M., Gurvits 1411 L.I., Kettenis M.M., Kania J., Tudose V., Rosenblatt P., Marty J.-C., Lainey V., de Vicente P., 1412 Quick J., Nicola M., Neidhardt A., Kronschnabl G., Ploetz G., Haas R., Lindquist M., Orlatti A., 1413 Ipatov A.V., Kharinov M.A., Mikhailov A.G., Lovell J.E.J., McCallum J.N., Stevens J., Gulyaev 1414 S.A., Natush T., Weston S., Wang W.H., Xia B., Yang W.J., Hao L.F., Kallunki J., and Witasse 1415 O. 2016, A\&A 593, A34

1416 Fridman P.A., Gurvits L.I., Pogrebenko S.V. (2010) 'The SKA as a Direct-to-Earth Data 1417 Acquisition Facility for Deep Space Science Missions', in Wide Field Science and Technology 1418 for the Square Kilometre Array, eds. S.A. Torchinsky, A. van Ardenne, T. van den Brink, A.J.J. 1419 van Es, A.J. Faulkner, ISBN 978-90-805434-5-4, p. 43-50 [PoS(SKADS 2009)006] 
Gaudin, D., ISAE master study report, 2016.

1421 Hand K.P. et al. (2007). Astrobiology 7, 1006-1022

1422 Hand K. P. and Chyba, C.F. (2007) Empirical constraints on the salinity of the Europan ocean 1423 and implications for a thin ice shell, Icarus 189, 424-438.

1424 Hand K.P., Murray, A. E., Garvin, J. B., Brinckerhoff, W. B., Christner , B.C., Edgett, K.S., 1425 Ehlmann, B.L., German, C.R., Hayes, A.G., Hoehler, T.M., Horst, S.M., Lunine, J.I., Nealson, 1426 K.H., Paranicas, C., Schmidt, B.E., Smith, D.E., Rhoden, A.R., Russell, M.J., Templeton, A.S., 1427 Willis, P.A., Yingst, R.A., Phillips, C.B., Cable, M.L., Craft, K.L., Hofmann, A.E., Nordheim, 1428 T.A., Pappalardo, R.P., and the Project Engineering Team (2017): Report of the Europa Lander 1429 Science Definition Team.

1431 Hanley, J., et al. (2014). J. Geophys. Res.-Planets 119(11): 2370-2377.

1432 Hussmann, H., Spohn, T. (2004). Icarus, 171, 391-410

1433 Hussmann, H., et al. (2010). Space Sci. Rev. 153 (1-4): 317-348.

1434 Jia, X., Kivelson, M. G., Khurana, K. , Kurth W. S. (2018), Evidence of a plume on Europa from 1435 Galileo magnetic and plasma wave signatures, Nature Astronomy, 2, 459-464.

1436 Jimenez-Jorquera C. et al., (2010). Sensors 10.

1437 Kattenhorn S.A. Prockter L.M. (2014). Nature Geoscience 7, 762-767

1438 Khurana, K.K., Kivelson M.G., Hand K.P. and Russell, C.T., Electromagnetic induction from

1439 Europa's ocean and deep interior, in Europa, Arizona University Press, 571-586 (2009).

1440 Khurana, K. K.; Jia, X.; Kivelson, M. G.; Nimmo, F.; Schubert, G.; Russell, C. T., Evidence of a

1441 Global magma Ocean in Io's Interior, Science, 332, 1186 (2011).

1442 Kiefer et al. (2006). Science 314, 1764-1766

1443 Koon, W. S., Lo, M. W., Marsden, J. E., \& Ross, S. D. (2006). Dynamical systems, the three-body

1444 problem and space mission design. California Institute of Technology, Pasadena, CA, USA.

1445 Kounaves, S.P. et al., (2003). J. Geophys. Res. 108, 10.1029/2002JE001978

1446 Lainey, V.,et al. (2006). Astronomy \& Astrophysics, 456, 783-788. 
1448 Lebreton J.-P., Witasse O., Sollazzo C., Blancquaert T., Couzin P., Schipper A.-M., Jones J.B., Matson

1449 D.L., Gurvits L.I., Atkinson D.H., Kazeminejad B., Pérez-Ayúcar M. 2005, Nature 438, 758-764

1450 Loeffler and Baragiola, (2005). Geophys. Res. Lett. 32, L17202

1451 Lunine, J. L. and Atkinson, D. J. (1985). Thermodynamics of clathrate hydrate and low and high 1452 pressures with application to the outer solar system. Ap. J. Supplement 58-3; 493-531

1453 McCord et al., (1999). J. Geophys. Res.-Planets 104, 11827-11851

1454 McCord, T. B., et al. (2001). J. Geophys. Res.-Planets 106(E2): 3311-3319.

1455 Maize, E. Europa Lander and technology Update. Presentation to the August 2019 OPAG

1456 Meeting. University of Colorado's Laboratory for Atmospheric and Space Physics (LASP)

1457 Boulder, CO

Mark D. et al., (2010). "Microfluidic lab-on-a-chip platforms: requirements, characteristics and applications." Chemical Society Reviews 39.

1461 Moore, W., (2003). J. Geophys. Res., 108, Issue E8, pp. 15-1

1462 Nimmo, F., et al. (2002). Geophys. Res. Lett. 29(7).

1463 NRC (Natl. Acad. Sci. Washington, DC). Task Group on the Forward Contamination of Europa,

1464 Space Studies Board, National Research Council (U.S.) (2000) Preventing the Forward 1465 Contamination of Europa

1466 Ojakangas, G.W., Stevenson D.J., (1986). Icarus, 66, 341-358

1467 Paganini, L., Villanueva, G. L., Roth, L., Mandell, A. M., Hurford, T., Retherford, K. D., 1468 Mumma, M. J. (2019) A measurement of water vapour amid a largely quiescent environment on 1469 Europa, Nature Astronomy 2397-3366, doi.org/10.1038/s41550-019-0933-6

1470 Pappalardo R.T., W. B. McKinnon and K. K. Khurana, Europa, University of Arizona Press, 1471 Tucson, (2009).

1472 Parro V. et al., (2005). Planet. Space Sci. 53, 729-737 
1474 Parro, V. et al., (2011). Astrobiology 11, 969-996

1475 Patterson G.W. et al. (2012). Icarus, 220, 286-290

1476 Porco C.C.et al (2006). Science, 311, 1393-1401

1477 Pogrebenko S.V., Gurvits L.I., Campbell R.M., Avruch I.M., Lebreton J.P., van't Klooster 1478 C.G.M., 2004, in Planetary Probe Atmospheric Entry and Descent Trajectory Analysis and

1479 Science, A. Wilson (ed.), ESA SP-544, 197-204

1480 Roth L. et al. (2014). Science 343, 171-174

1481 Russell, M. J. and A. J. Hall (1997). J. Geol. Soc. 154: 377-402.

1482 Russell, M. J., et al. (2014). Astrobiology 14, 308-343.

1483 Russell, R.P. (2006) Global search for planar and three-dimensional periodic orbits near europa. J. Astron.

1484 Sci. 54, 199-226. https://doi.org/10.1007/BF03256483

1485 Sakurai T. et al., (2016). Cold Regions Science and technology 121.

1486 Schilling, N., et al. (2004). J. Geophys. Res.-Planets 109(E5).

1487 Schmidt J. et al. (2008). Nature 451, 685-688

1488 Schutte, A.N., 2016, 'The Square Kilometre Array Radio Telescope: Transformational 1489 Capabilities for Deep Space Missions', 15 ${ }^{\text {th }}$ Reinventing Space Conference, 27 October 2016, 1490 London

1491 Shematovich V.I.et al. (2005). Icarus 173, 480-498

1492 Sims M.R. et al., (2012). Planet. Space Sci.72.

1493 Tobie, G., et al. (2003). J. Geophys. Res.-Planets 108(E11).

1494 Tobie, G., et al (2005). Icarus, Volume 177, Issue 2, p. 534-549 
1495 Truscott, P. et al. (2011). IEEE TRANS. NUCL. Sci., 58(6), 2776 - 2784.

1496 Tyler R., (2008). Nature, 456, 770-772

1497 Ulamec S. et al., (2007). Rev. Environ Sci. Biotechnol. 6

1498 Weiss P. et al. (2011). Adv. Space Res. 48

1499 Westall, F, Brack, A. (2018) The Importance of Water for Life, Space Science Reviews 214(2). DOI:

$1500 \quad \underline{10.1007 / \mathrm{s} 11214-018-0476-7}$

1501 Wisdom J., (2004). Astronom. J. 128, 484-491.

1502 Witasse, O., Altobelli, N., Barabash, S., Bruzzone, L., Dougherty, M., Erd, C., Fletcher, L.,

1503 Gladstone, R., Grasset, O., Gurvits, L., Hartogh, P., Hussmann, H., Iess, L., Langevin, Y., 1504 Palumbo, P., Piccioni, G., Sarri, G., Titov, D., and Wahlund, J.E. 2015, JUICE: A European 1505 Mission to Jupiter and its Icy Moons, in European Planetary Science Congress, pp. EPSC20151506564.

1507 Zahnle K. et al. (2008). Icarus 194, 660-674 
Table 1: Proposed list of orbiter platform instruments and their contribution to the different Priority Science Objectives (PSO's) presented in section 2.

\begin{tabular}{|c|c|c|}
\hline & \multicolumn{2}{|c|}{ Orbiter Science Platform - JEM (Orbiter-Carrier) ESA/NASA } \\
\hline & Facility/Instrument & Reference PSO \\
\hline \multirow[t]{6}{*}{ Core Payload } & $\begin{array}{l}\text { Gravity Science } \\
\text { Investigation (GSI) }\end{array}$ & PSO\#2, PSO\#4 \\
\hline & Magnetometer (MAG) & PSO\#1, PSO\#3, PSO\#4 \\
\hline & Laser Altimeter (LA) & PSO\#2, PSO\#4 \\
\hline & $\begin{array}{l}\text { Ion Mass Spectrometer + } \\
\text { Electron Spectrometer } \\
\text { (IMS/ELS) }\end{array}$ & PSO\#1, PSO\#3, PSO\#5 \\
\hline & $\begin{array}{l}\text { Ion and Neutral Mass } \\
\text { Spectrometer (INMS) }\end{array}$ & PSO\#3, PSO\#5 \\
\hline & Dust Analyser (DA) & PSO\#1, PSO\#3, PSO\#5 \\
\hline Augmentation & Langmuir Probe (LP) & PSO\#1, PSO\#3 \\
\hline
\end{tabular}


Table 2: Projected resource requirements for the different orbiter platform instruments.

\begin{tabular}{|c|c|c|c|c|c|c|}
\hline \multicolumn{6}{|c|}{ Orbital Science Platform projected required resources } & \multirow[b]{3}{*}{ TRL } \\
\hline Facility/Instrument & Outside the vault & Insid & the vault & & & \\
\hline & & Mass (kg) & Volume $\left(\mathrm{m}^{3}\right)$ & Total (kg) & Power $(\mathrm{W})$ & \\
\hline GSI & - & 3.4 & 0.006 & 3.4 & 22 & 5 \\
\hline$\underline{\mathrm{MAG}}$ & $\underline{0.1}$ & $\underline{0.1}$ & 0.001 & $\underline{0.2}$ & $\underline{0.4}$ & $\underline{8 / 9}$ \\
\hline LA & 11 & 9 & 0.08 & 20 & 40 & $5-6$ \\
\hline IMS/ELS & 7 & 3 & 0.006 & 10 & 11 & 5 \\
\hline$\underline{\text { INMS }}$ & 3.2 & 3 & 0.006 & 6.2 & 16 & $5-6$ \\
\hline$\underline{\mathrm{DA}}$ & $\underline{7.5}$ & $\underline{2.6}$ & $\underline{0.003}$ & $\underline{10.1}$ & $\underline{9.7}$ & $\underline{5-6}$ \\
\hline Total for core payload & 28.8 & 21.1 & 0.102 & 49,9 & 99.1 & \\
\hline Augmentation: LP & $\underline{1.6}$ & $\underline{3}$ & $\underline{0.004}$ & 4.6 & $\underline{6}$ & $5-6$ \\
\hline
\end{tabular}


Table 3: Proposed list of surface science platform instruments and their contribution to the different Priority Science Objectives (PSO's) presented in section 2.

\begin{tabular}{|l|c|}
\hline \multicolumn{2}{|c|}{ Surface Science Platform - JEM (Lander) NASA } \\
\hline Facility/Instrument & Reference PSO \\
\hline 1. Solid Sample Analysis & \\
\hline Organic compound analyzer & \\
\hline Vibrational Spectrometer & \\
\hline Microscope & \\
\hline PanCam & \\
\hline $\begin{array}{l}\text { 2. Liquid Sample Analysis } \\
\text { Astrobiological Wet Laboratory }\end{array}$ & \\
\hline Multiprobe Array Sensors (MPAS) & PSO\#5 \\
\hline Multiparametric Probes (MPP) & PSO\#5 \\
\hline 3. Geophysical Science & PSO\#2 \\
\hline Geophone & PSO\#2, PSO\#4 \\
\hline Magnetometer & PSO\#1 \\
\hline Laser reflector & \\
\hline
\end{tabular}


Table 4: Projected resource requirements for the different instruments of the surface science platform.

\begin{tabular}{|c|c|c|c|}
\hline \multicolumn{5}{|c|}{ Surface Science Platform projected required resources } \\
\hline Facility/Instrument & Mass (kg) & Power (W) & TRL \\
\hline $\begin{array}{c}\text { AWL sensors MPAS } \\
\text { AWL sensors MPP } \\
\text { AWL sensors VISTA }\end{array}$ & 0.15 & 1.4 & $3-4$ \\
\cline { 2 - 5 } & 0.1 & 1 & $3-4$ \\
\cline { 2 - 5 } & 0.09 & 0.24 & $5-6$ \\
\hline Total for AWL (cf. 4.3.3.2) & 11 (incl. 7 for shielding) & 17.4 Whr & $8 / 9$ \\
\hline MAG & 0.6 & 0.8 & - \\
\hline Laser Reflector & 0.0025 & - & \\
\hline
\end{tabular}

Table 5: approximate flight time $\Delta V$ and TID (behind 2,5 $\mathrm{mm}$ finite Al slab shell)

\begin{tabular}{|l|l|l|l|l|l|}
\hline Sequence & $\begin{array}{l}\text { Sequence } \\
\text { name }\end{array}$ & Flight time & $\Delta \mathbf{V}(\mathbf{m} / \mathbf{s})$ & TID @ 2.5mm Al \\
\hline S-1 & $\begin{array}{l}\text { Launch + } \\
\text { cruise }\end{array}$ & Reach Jupiter System & 4,9 years & 800 & $\sim$ \\
\hline S-2 & $\begin{array}{l}\text { JOI + PRM } \\
\text { maneuver }\end{array}$ & $\begin{array}{l}\text { Insert into the Jovian } \\
\text { system }\end{array}$ & 6,5 months & 1000 & $\sim$ \\
\hline S-3 & $\begin{array}{l}\text { Jovian tour to } \\
\text { Europa } \\
\text { vicinity }\end{array}$ & $\begin{array}{l}\text { Phase the spacecraft } \\
\text { with Europa }\end{array}$ & 9,5 months & 100 & $125 \mathrm{krad}$ \\
\hline S-4 & EOI + & Insert into Europa, & & 700 & $\sim$ \\
\hline
\end{tabular}




\begin{tabular}{|c|c|c|c|c|c|}
\hline & $\begin{array}{l}\text { Ejection to } \\
\text { relay orbit }\end{array}$ & $\begin{array}{l}\text { release the lander, } \\
\text { reach relay orbit }\end{array}$ & & & \\
\hline S-5 & Lander relay & $\begin{array}{l}\text { Relay and downlink } \\
\text { lander data }\end{array}$ & 35 days & $\sim$ & $370 \mathrm{krad}$ \\
\hline S-6 & Relay to LEO & $\begin{array}{l}\text { Reach low-altitude } \\
\text { quasi-polar orbit }\end{array}$ & 1-3 days & 400 (ТBC) & $12 \mathrm{krad} /$ day \\
\hline S-7 & $\begin{array}{l}\text { LEO } \\
\text { operations }\end{array}$ & $\begin{array}{l}\text { Support orbiter science } \\
\text { mission }\end{array}$ & 3 months & & $930 \mathrm{krad}$ \\
\hline S-8 & $\begin{array}{l}\text { Descent to } \\
\text { surface }\end{array}$ & & & & \\
\hline S-9 & Impact & End of mission & & & \\
\hline$\underline{\text { Total }}$ & & & 6,6 years & $\underline{3,05 \mathrm{~km} / \mathrm{s}}$ & 1,5 Mrad \\
\hline
\end{tabular}

Table 6: Total Ionizing Dose (TID, in krad) versus Aluminium thickness (in mm) for the relay phase, the transfer to Low-Europa Orbit (LEO), the science orbit as well as the total for these three phases. For the relay and transfer phases, the second column corresponds to the worst case scenario with a radiation design factor of 2; for the LEO the second column corresponds to the case where the reduced radiation environment at low-altitude around Europa is taken into account (factor 3 reduction), and the third column to the worst case scenario with a radiation design factor of 2. The values obtained are very similar to those reported in the 2012 NASA Europa Orbiter report. 


\begin{tabular}{|c|c|c|c|c|c|c|c|c|c|c|}
\hline \multirow{2}{*}{$\begin{array}{c}\text { Al } \\
\text { absorb } \\
\text { er } \\
\text { thickne } \\
\text { ss } \\
(\mathrm{mm})\end{array}$} & \multicolumn{2}{|c|}{$\begin{array}{l}\text { S5 - Lander } \\
\text { relay } \\
\text { TID (krad) }\end{array}$} & \multicolumn{2}{|c|}{$\begin{array}{l}\text { S6 - Relay to } \\
\text { LEO } \\
\text { TID (krad) }\end{array}$} & \multicolumn{3}{|c|}{ S7 - LEO operations TID (krad) } & \multicolumn{3}{|c|}{ S5 to S7 - Total TID (krad) } \\
\hline & $\begin{array}{c}\text { no } \\
\text { margi } \\
n\end{array}$ & $\begin{array}{c}\text { margi } \\
n \times 2\end{array}$ & $\begin{array}{c}\text { no } \\
\text { margi } \\
n\end{array}$ & $\begin{array}{c}\text { margi } \\
n \times 2\end{array}$ & $\begin{array}{c}\text { no } \\
\text { margi } \\
n\end{array}$ & $\begin{array}{l}\text { Europa } \\
\text { shield. }\end{array}$ & $\begin{array}{c}\operatorname{margi} \\
n \times 2\end{array}$ & $\begin{array}{c}\text { no } \\
\text { margi } \\
n\end{array}$ & $\begin{array}{c}\text { Shield/no } \\
\text { marg }\end{array}$ & margin $x 2$ \\
\hline 2,5 & 369 & 738 & 12,3 & 24,6 & 930 & 310 & 620 & 1311 & 691 & 1382 \\
\hline 3 & 299 & 598 & 9,98 & 20,0 & 753 & 251 & 502 & 1062 & 560 & 1120 \\
\hline 4 & 207 & 414 & 6,91 & 13,8 & 521 & 174 & 347 & 735 & 388 & 775 \\
\hline 5 & 152 & 304 & 5,07 & 10,1 & 382 & 127 & 254 & 539 & 284 & 568 \\
\hline 6 & 117 & 233 & 3,89 & 7,77 & 293 & 97,6 & 195 & 413 & 218 & 436 \\
\hline 7 & 92,61 & 185 & 3,09 & 6,18 & 233 & 77,5 & 155 & 328 & 173 & 346 \\
\hline 8 & 75,6 & 151 & 2,52 & 5,04 & 190 & 63,2 & 126 & 268 & 141 & 283 \\
\hline 9 & 62,9 & 126 & 2,10 & 4,19 & 158 & 52,6 & 105 & 223 & 118 & 235 \\
\hline 10 & 53,2 & 106 & 1,77 & 3,54 & 133 & 44,5 & 88,9 & 188 & 99,4 & 199 \\
\hline 11 & 45,5 & 91,0 & 1,52 & 3,03 & 114 & 38,0 & 76,1 & 161 & 85,1 & 170 \\
\hline 12 & 39,3 & 78,6 & 1,31 & 2,62 & 98,6 & 32,9 & 65,8 & 139 & 73,5 & 147 \\
\hline 13 & 34,2 & 68,5 & 1,14 & 2,28 & 85,9 & 28,6 & 57,2 & 121 & 64,0 & 128 \\
\hline 14 & 30,0 & 60,0 & 1,00 & 2,00 & 75,3 & 25,1 & 50,2 & 106 & 56,1 & 112 \\
\hline 15 & 26,5 & 53,0 & 0,88 & 1,76 & 66,4 & 22,1 & 44,3 & 93,8 & 49,5 & 99,0 \\
\hline 16 & 23,5 & 46,9 & 0,78 & 1,56 & 58,8 & 19,6 & 39,2 & 83,1 & 43,9 & 87,7 \\
\hline 17 & 20,9 & 41,8 & 0,70 & 1,39 & 52,4 & 17,5 & 34,9 & 74,0 & 39,1 & 78,1 \\
\hline 18 & 18,7 & 37,4 & 0,62 & 1,24 & 46,8 & 15,6 & 31,2 & 66,1 & 34,9 & 69,8 \\
\hline 19 & 16,7 & 33,5 & 0,56 & 1,12 & 42,0 & 14,0 & 28,0 & 59,3 & 31,3 & 62,6 \\
\hline 20 & 15,1 & 30,1 & 0,50 & 1,00 & 37,7 & 12,6 & 25,2 & 53,3 & 28,1 & 56,3 \\
\hline
\end{tabular}




\begin{tabular}{|c|c|c|c|c|c|c|c|c|c|c|}
22 & 12,3 & 24,6 & 0,41 & 0,82 & 30,8 & 10,3 & 20,5 & 43,5 & 23,0 & 45,9 \\
\hline 25 & 9,23 & 18,5 & 0,31 & 0,61 & 23,1 & 7,70 & 15,4 & 32,6 & 17,2 & 34,5 \\
\hline
\end{tabular}

Table 7: summarized characteristics of the Sample Analysis Module (SAM)

\begin{tabular}{|l|}
\hline MAIN TECHNICAL CHARACTERISTICS OF SAM \\
\hline Drilling activities consumption $10 \mathrm{~W}$ for 1 hour. \\
\hline Additional sample processing $2.5 \mathrm{~W}$ for 3 hour. \\
\hline Data processing \& control core consumptions $5 \mathrm{~W}$. \\
\hline Orbiter has the capacity to charge and monitor the battery (req. 85 \\
W.hr) \\
\hline Battery should be maintained warmed to T $>-20^{\circ} \mathrm{C}$ \\
\hline No redundancy \\
\hline Standard flight EEE components \\
\hline Control based on a FPGA running a low frequency \\
\hline S/W in coded C and small program size < 64 KB \\
\hline Power conditioning based on COTS converter \\
\hline Orbiter has the capacity to charge and monitor the battery (req. 145 \\
\hline including AWL self heating). \\
\hline \\
\hline
\end{tabular}

Table A2.1: JEM projected mass budget and ISP. 


\begin{tabular}{|l|r|l|}
\hline Carrier dry mass & $2485 \mathrm{~kg}$ & \\
\hline Lander Stack mass & $2800 \mathrm{~kg}$ & \\
\hline ISP & $315 \mathrm{~s}$ & $\begin{array}{c}\text { R-4D } \\
490 \mathrm{~N}\end{array}$ \\
\hline
\end{tabular}

Table A2.2: JEM deltaV and propellant budget

\begin{tabular}{|c|c|c|c|c|}
\hline & $\begin{array}{c}\text { Delta V } \\
(\mathbf{m} / \mathbf{s})\end{array}$ & Propellant (kg) & Wet mass (kg) & Comment \\
\hline Cruise (DSM / EGA) & 800 & 3002 & 13163 & $\begin{array}{l}\text { 4,9 years transfer } \\
\text { (DVEGA) }\end{array}$ \\
\hline JOI + PRM & 1000 & 2809 & 10160 & $840 \mathrm{JOI}+160 \mathrm{PRM}$ \\
\hline Jupiter Tour & 100 & 234 & 7351 & Europa 2012 study \\
\hline EOI & 600 & 1256 & 7117 & $\begin{array}{l}\text { elliptical orbit } \\
200 \times 7000 \mathrm{~km}\end{array}$ \\
\hline Ejection to relay & 100 & 187 & 5861 & allocation \\
\hline Relay to science & 400 & 349 & 2875 & $200 \times 200 \mathrm{~km}$ \\
\hline Orbit maintenance & 50 & 41 & 2526 & 3 months in orbit \\
\hline Total & 3050 & 7878 & 13163 & \\
\hline & & & & \\
\hline
\end{tabular}

Table A3.1: Characteristics of the range of the reachable LEO 


\begin{tabular}{|c|c|c|c|c|}
\hline \multirow{2}{*}{ ID } & \multicolumn{2}{|c|}{ Inclination $\left(^{\circ}\right)$} & \multicolumn{2}{c|}{ Altitude (km) } \\
\cline { 2 - 5 } & $\min$ & $\max$ & $\min$ & $\max$ \\
\hline 100 & 82,8 & 89,8 & 116 & 198 \\
\hline 150 & 83,4 & 89,8 & 103 & 200 \\
\hline 200 & 80,2 & 82,9 & 104 & 199 \\
\hline 225 & 88,1 & 89,7 & 109 & 196 \\
\hline 250 & 80,5 & 87,8 & 101 & 199 \\
\hline 275 & - & - & - & - \\
\hline 284 & 81,1 & 88,7 & 102 & 185 \\
\hline
\end{tabular}

Table A3.2: Characteristics of some of the reachable LEO

\begin{tabular}{|l|l|l|l|l|}
\hline \multirow{2}{*}{ ID } & \multicolumn{2}{|l|}{ Inclination $\left(^{\circ}\right)$} & \multicolumn{2}{l|}{ Altitude $(\mathrm{km})$} \\
\cline { 2 - 5 } & $\min$ & $\max$ & $\min$ & $\max$ \\
\hline 100 & 80,0 & 89,9 & 100 & 190 \\
\hline 150 & 80,2 & 90,0 & 102 & 199 \\
\hline 200 & 80,1 & 90,0 & 103 & 199 \\
\hline 225 & 80,1 & 89,9 & 102 & 199 \\
\hline 250 & 80,0 & 90,0 & 101 & 200 \\
\hline 275 & 80,0 & 89,9 & 100 & 200 \\
\hline 284 & 80,0 & 90,0 & 100 & 200 \\
\hline
\end{tabular}


Table A3.3: Characteristics associated to the set of transfers

\begin{tabular}{|l|c|c|c|c|c|}
\hline & $\begin{array}{c}\text { Halo } \\
\text { orbit ID }\end{array}$ & $\Delta \mathrm{V}_{\text {total }}(\mathrm{m} / \mathrm{s})$ & $\begin{array}{c}\text { Duration } \\
(\text { days })\end{array}$ & $\begin{array}{c}\text { Altitude } \\
(\mathrm{km})\end{array}$ & $\begin{array}{c}\text { Inclination } \\
\left({ }^{\circ}\right)\end{array}$ \\
\hline a) & 100 & 488 & 1,6 & 118 & 84,8 \\
\hline b) & 150 & 491 & 1,2 & 110 & 85,5 \\
\hline c) & 200 & 512 & 1,3 & 104 & 82,6 \\
\hline d) & 225 & 539 & 1,3 & 108 & 84,0 \\
\hline e) & 250 & 534 & 3,7 & 104 & 87,6 \\
\hline f) & 275 & 541 & 2,1 & 115 & 82,4 \\
\hline g) & 284 & 551 & 1,8 & 119 & 84,3 \\
\hline h) & 284 & 515 & 1,2 & 199 & 80,8 \\
\hline
\end{tabular}




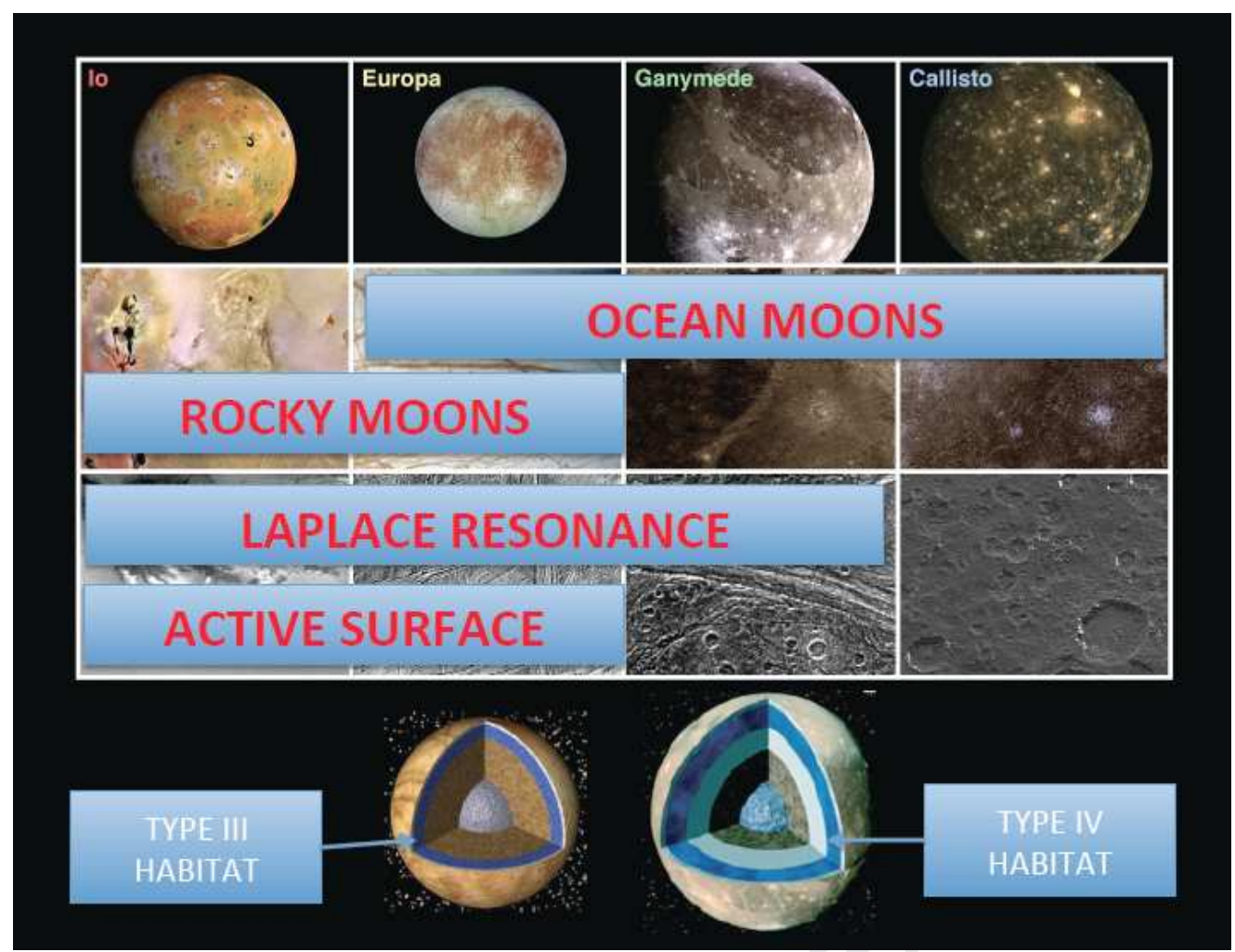

Figure 1: when the four Galilean moons are broadly characterized by the four properties shown, Europa stands out as the best possible candidate "habitable moon" (see text)

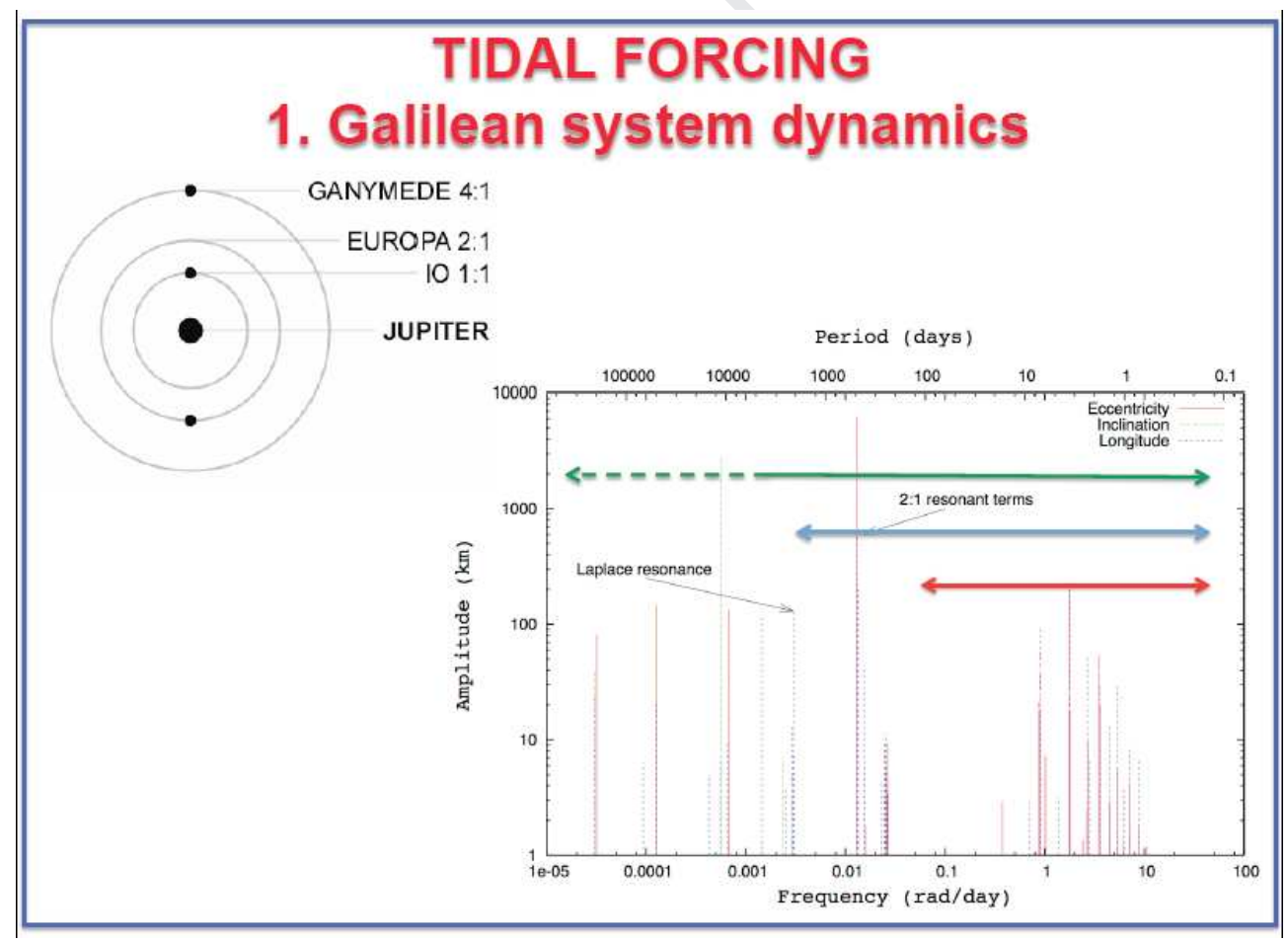

Figure 2: Tidal coupling of Europa to the Jupiter System is controlled by the dynamics of the Galilean system and its Laplace resonance (left). The figure shows the very broad spectrum of gravitational perturbations exerted on Europa's motion in its reference frame. The short periods, to the right, correspond to the orbital motions of the different satellites and their beats, which induce the most important tidal stresses. The long periods to the left correspond to all long-period oscillations of the system, and include the pendular motions in the Laplace resonance. The ranges of periods accessible respectively to JEM alone (red line), to the succession of missions to Jupiter (blue) and to the combinations of long series of astrometric measurements from the ground and from space (green) are also indicated (derived from Layné et al., 2006) 


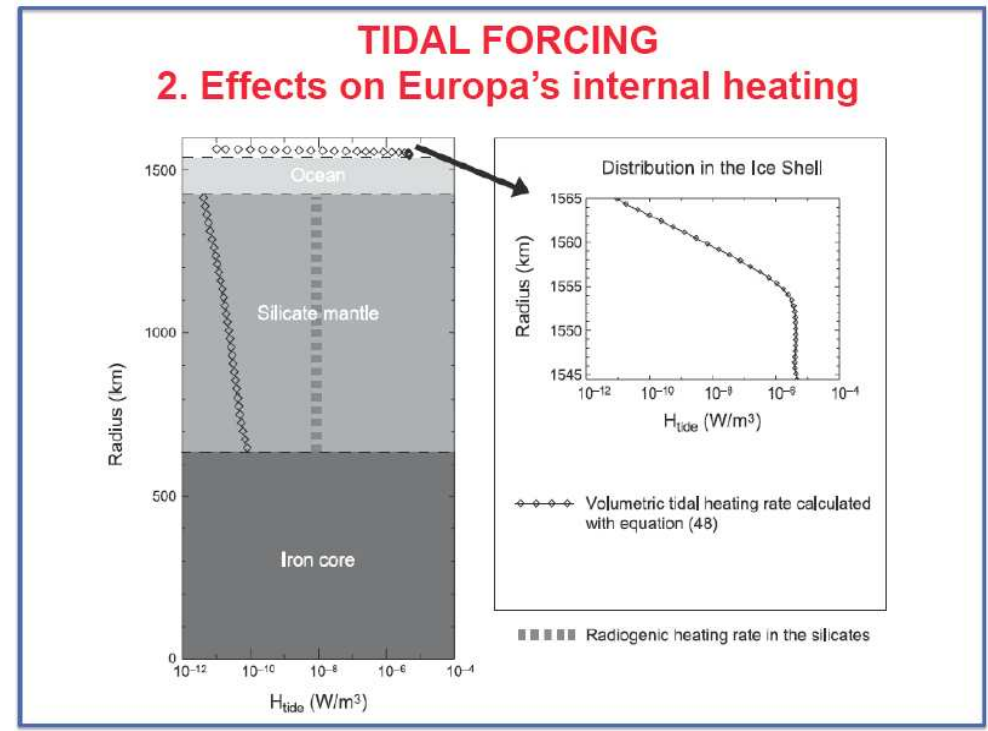

Figure 3: Tidal coupling between Io, Europa, Ganymede and Jupiter is responsible for a continuous transfer of angular momentum and energy between Jupiter and the three moons resulting in continuous heating of their interiors, ice shells, and oceans. The model of Tobie et al. (2003) shown here predicts that most of this heating goes to the ice shell in the case of Europa. Observations from an orbiter will be critical to solve this open question.

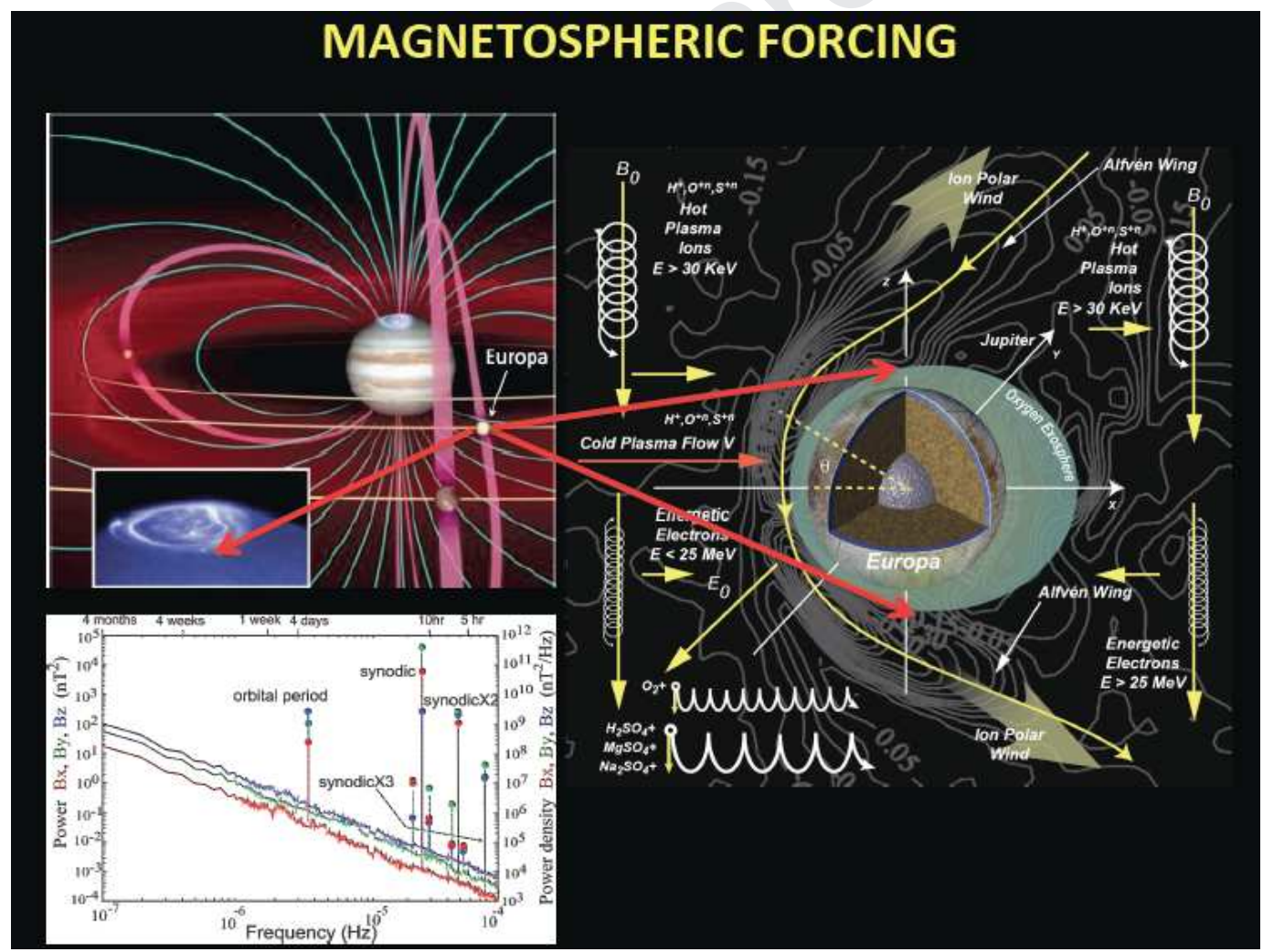

Figure 4: A simplified representation of Europa's interaction with the Jovian magnetosphere, which involves two obstacles: Europa's surface, and its subsurface ocean. This interaction generates effects from the planetary scale (a giant electrical current system coupling Europa's ionosphere to the Jovian ionosphere) to the very local Europan scales (the space weathering of Europa's icy surface by magnetospheric thermal and radiation belt particles). The broad-band spectrum of magnetic fluctuations associated with this interaction, seen in the Europan frame, allows an accurate magnetic sounding of Europa's ocean (diagram in white insert, courtesy K. Khurana). 


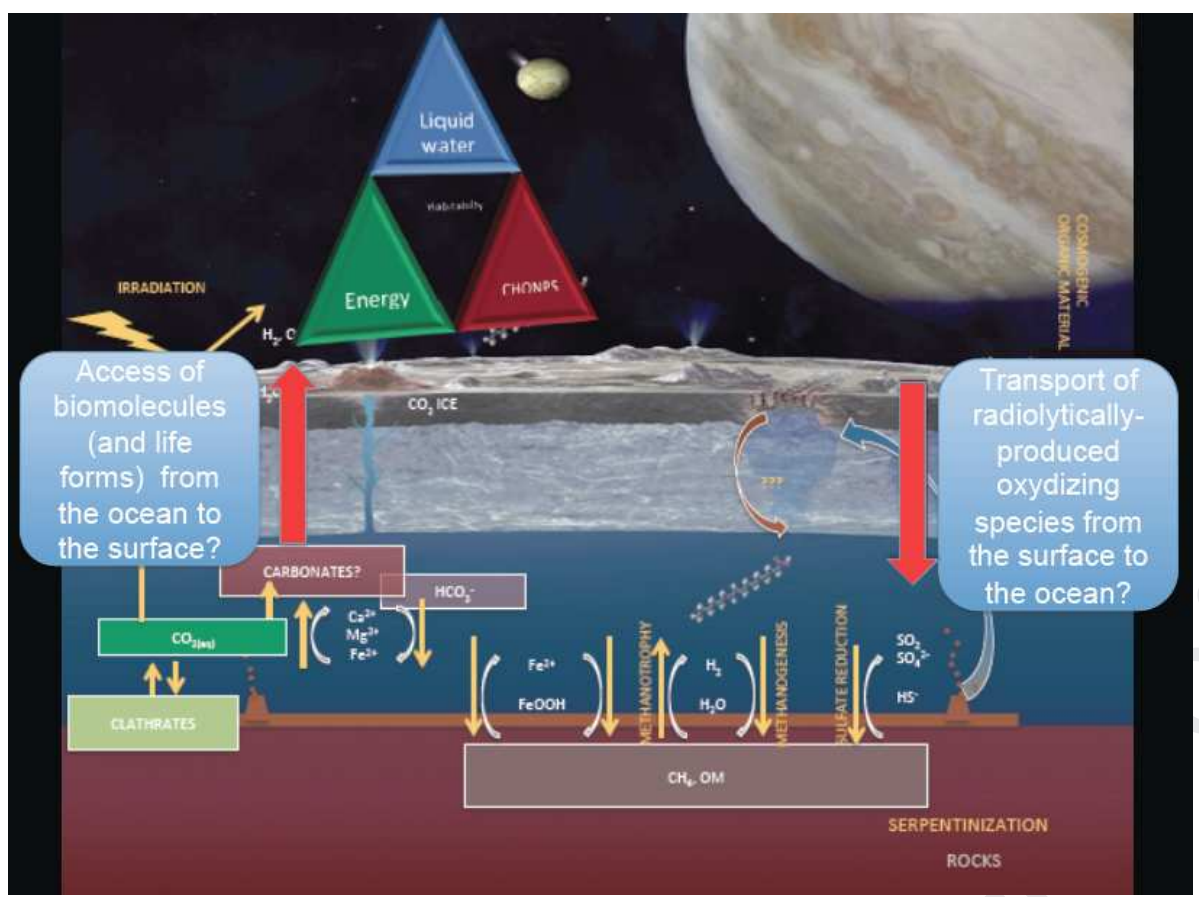

Figure 5: An examination of the properties of the layers of Europa extending from the silicate sea-floor to the ice shell surface and near-surface exosphere in the light of the "triangle of habitability" leads to the important conclusion that this aqueous internal region of Europa may be considered as a potential "dark biosphere" (see text).

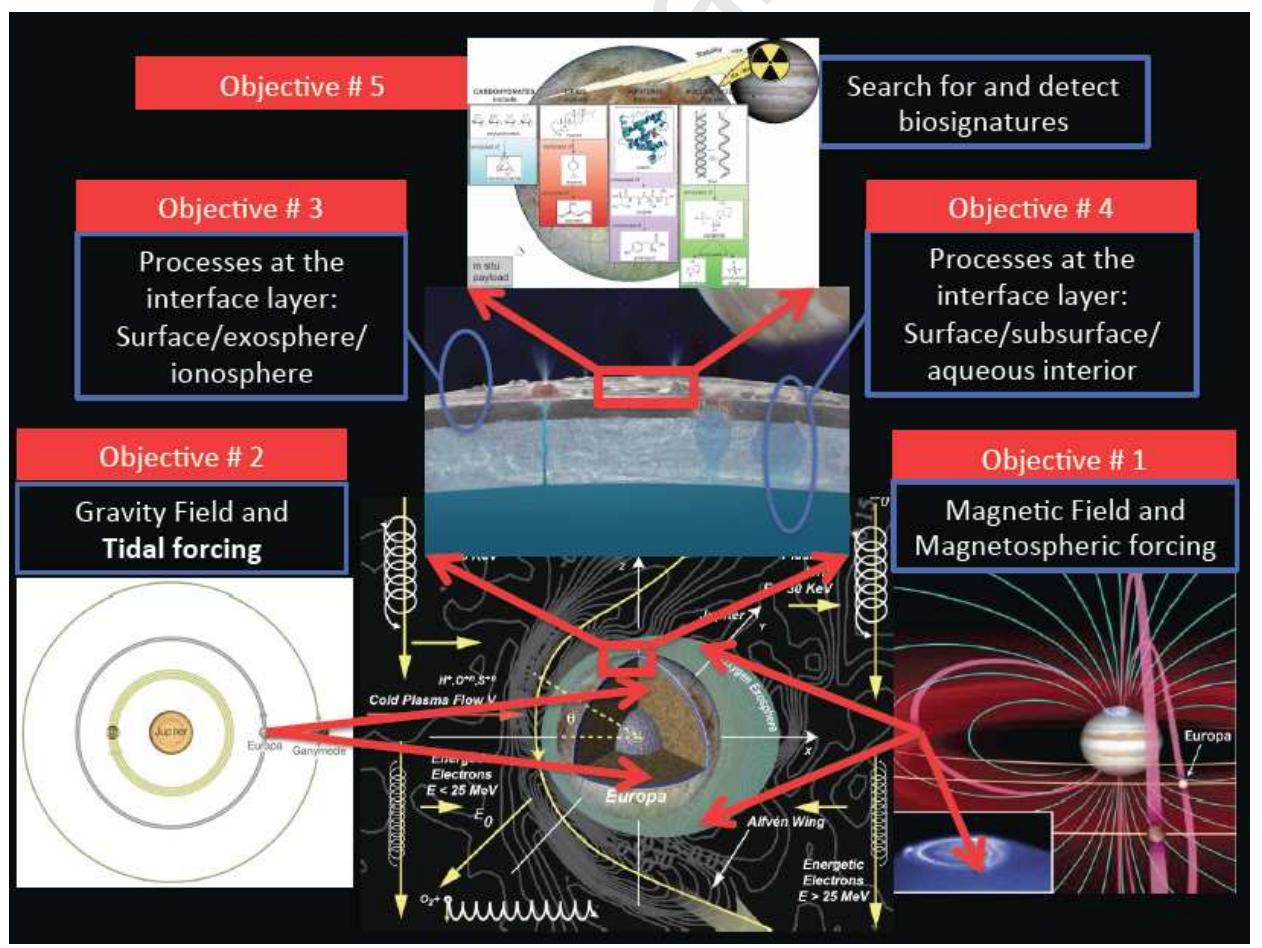


Figure 6: This logical chart of our Science Plan shows the three successive scales investigated by JEM, from bottom upwards: (1) the global Europa, a complex system responding to the two main types of Jovian forcing; (2) the scale of Europa's potential biosphere (median figure) and (3) finally the local scale at which we will perform life detection experiments.

The JEM science plan successively articulates five "Priority Science Objectives", culminating with PSO \#5, the search for biosignatures of life at the surface, sub-surface and eventually in the exosphere, to reach its Overarching Goals.
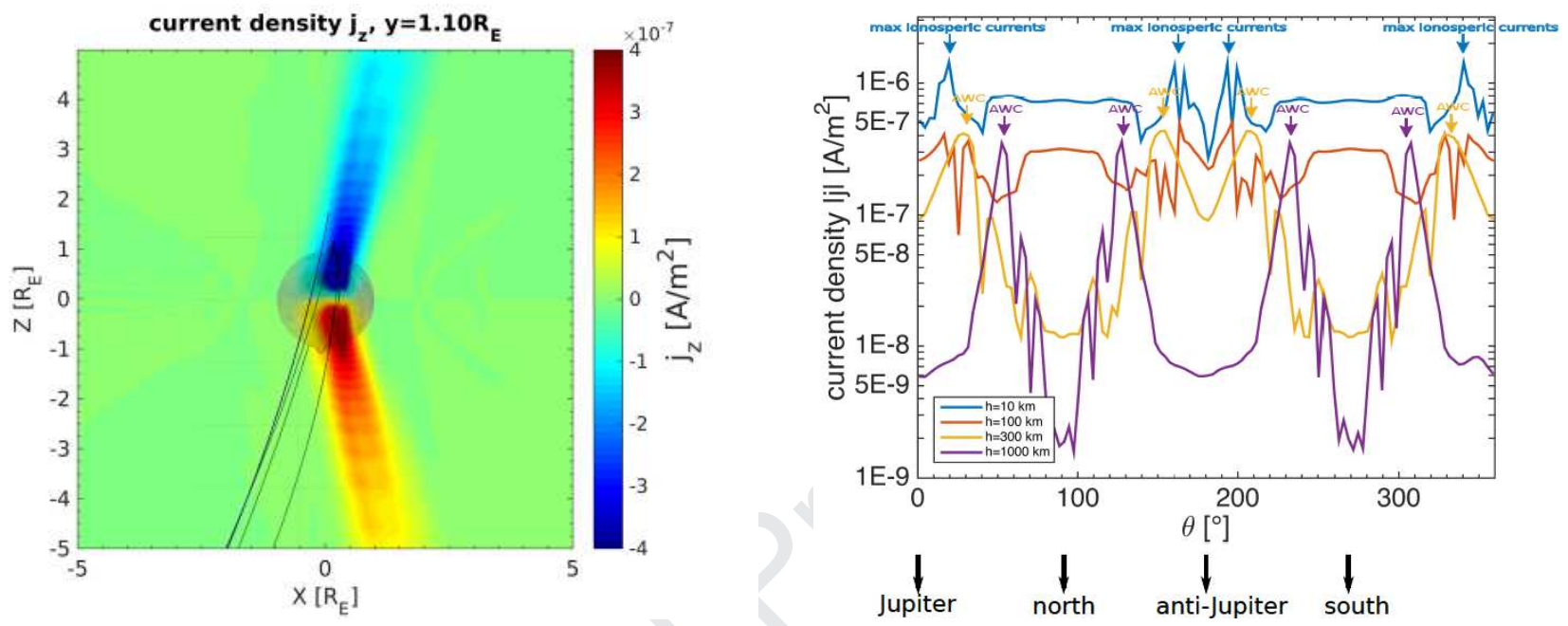

Figure 7: Ionospheric current density (left) in the XZ plane; Ionospheric current density and Alfven wave currents $(A W C)$ in the northern and southern hemispheres towards and away from Jupiter plotted for various altitudes along circular polar orbits. Adapted from Blöcker et al. (2016).

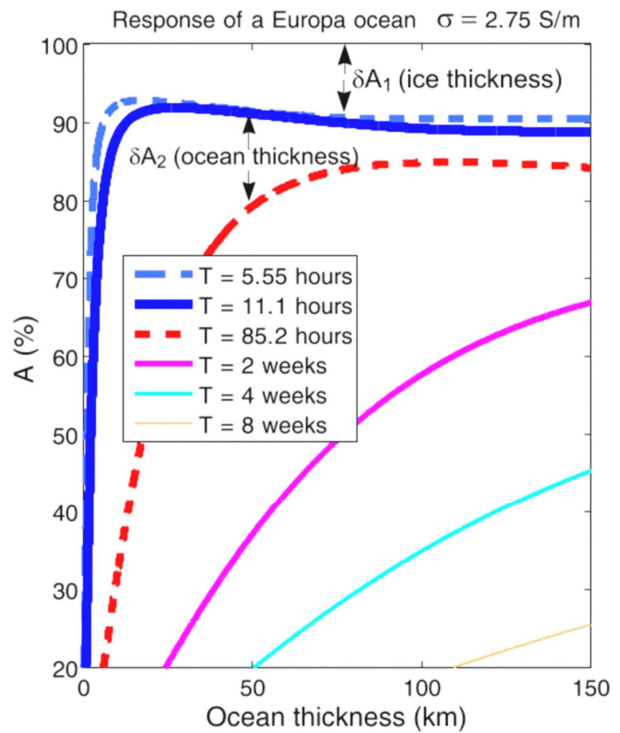


Figure 8: Response (surface induced field at pole/inducing field) of a Europa ocean with conductivity similar to that of the Earth's at six different periods. An ice thickness of $30 \mathrm{~km}$ was assumed for results shown in both of these figures. Figure adapted from Khurana et al. (2009)

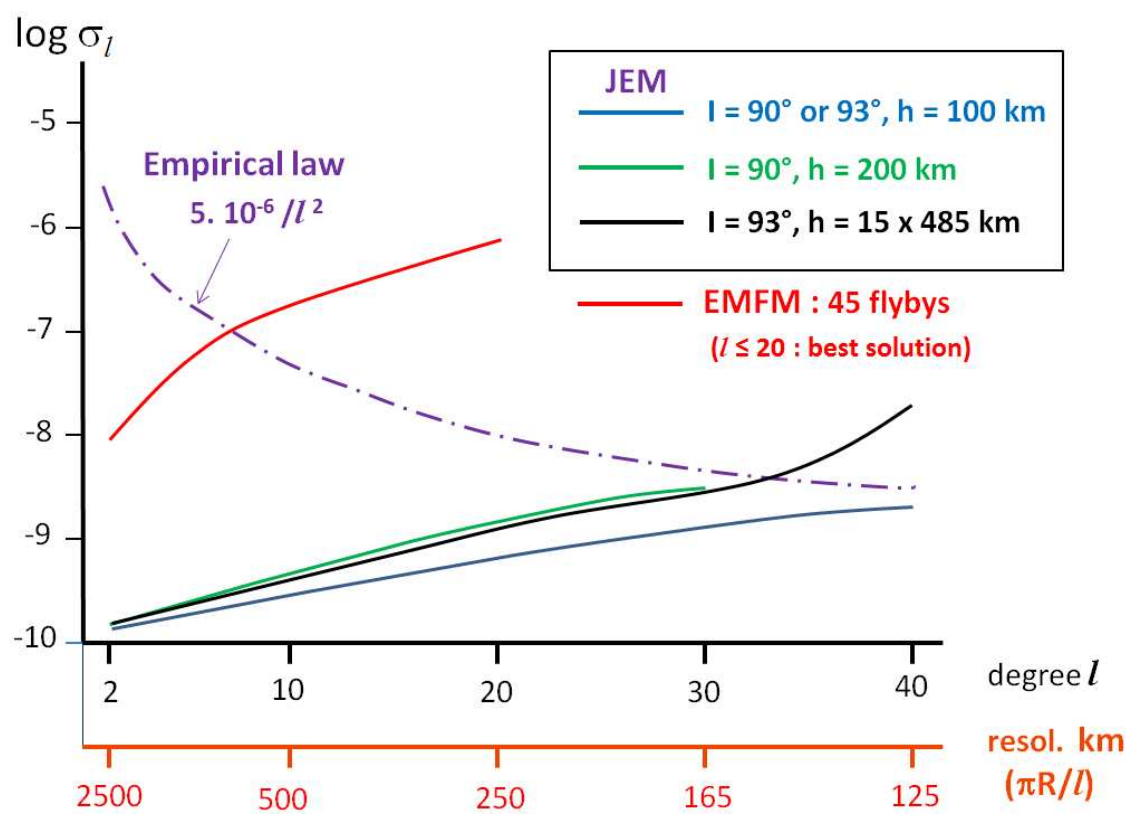

Figure 9: Determination of Europa's gravity field from two possible mission scenarios.

$\sigma_{l}$ (dimensionless) measures the uncertainty in all harmonic coefficients of degree $l$, corresponding to the resolution shown on the second abscissa scale. An empirical law (same shape as for other terrestrial bodies) is shown for comparison.

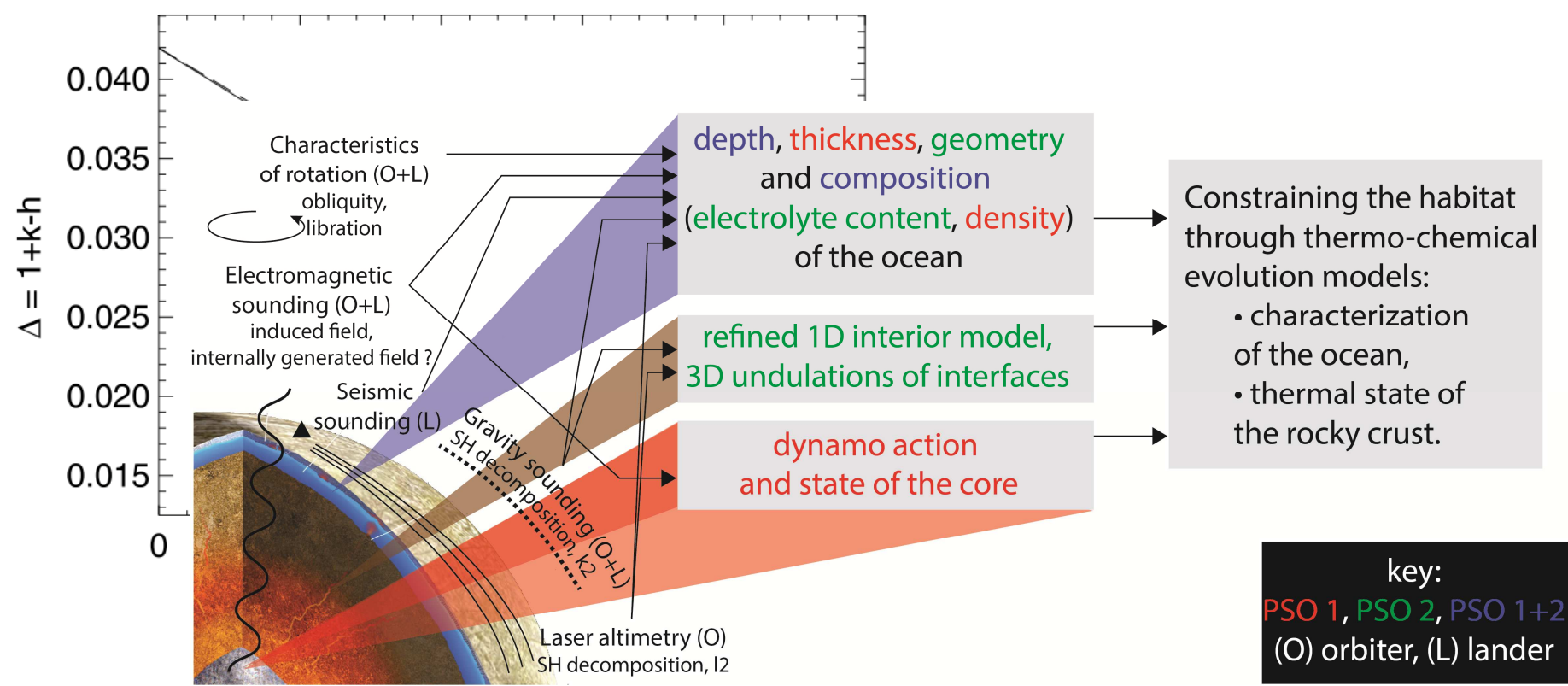

Figure 10: Synergetic orbiter / lander investigation of Europa's response to Jupiter's magnetic and gravitational forcing 

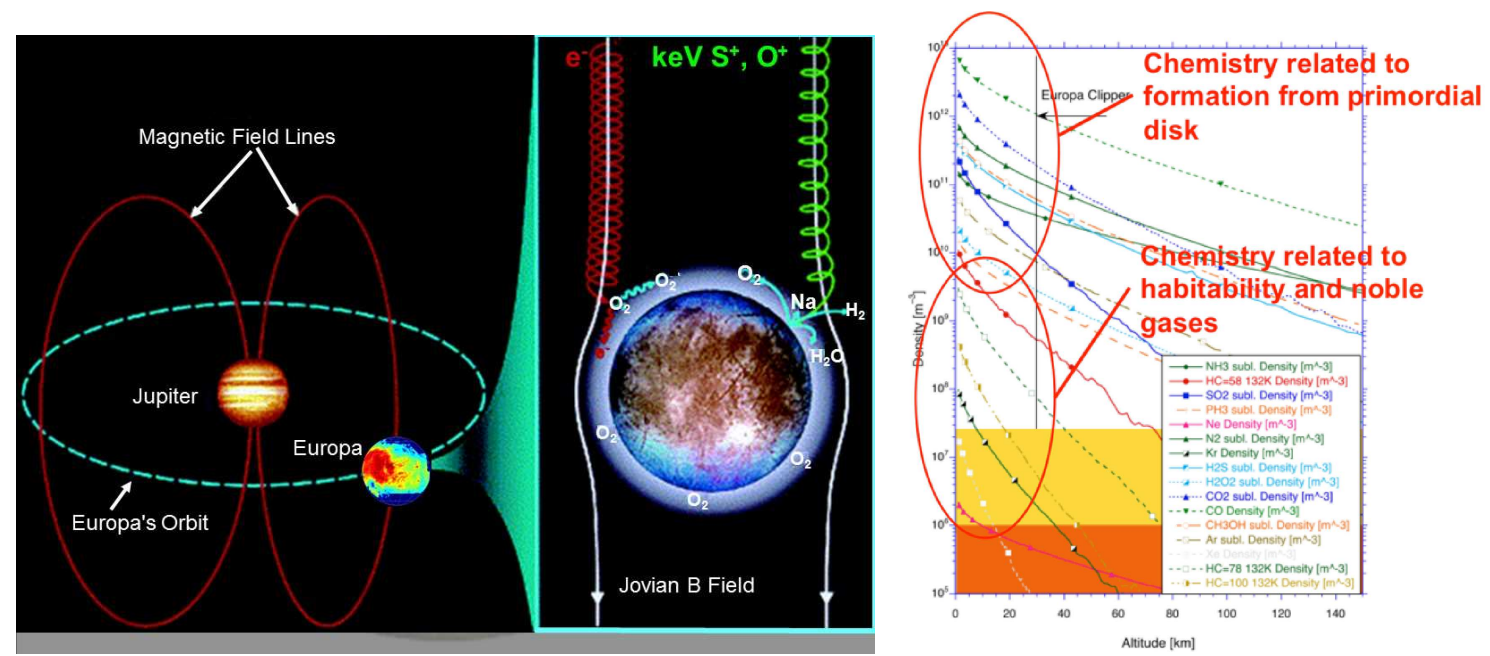

Figure 11: Cartoon of Europan interaction with Jupiter's magnetosphere showing how the Jovian plasma moving with Jupiter magnetospheric lines induces a trailing/leading asymmetry in the interaction. Neutral species produced by sputtering of Europa's icy surface form Europa's exosphere, which is composed essentially of $\mathrm{O}_{2}$ and of trace species (left); calculated exospheric density profiles calculated by Shematovich et al. (2005) for species expected to be present based on the formation model (right). "SP" stands for sputtering, and "subl." stands for "released together with sublimation" water. HC are hydrocarbon molecules with the indicated mass
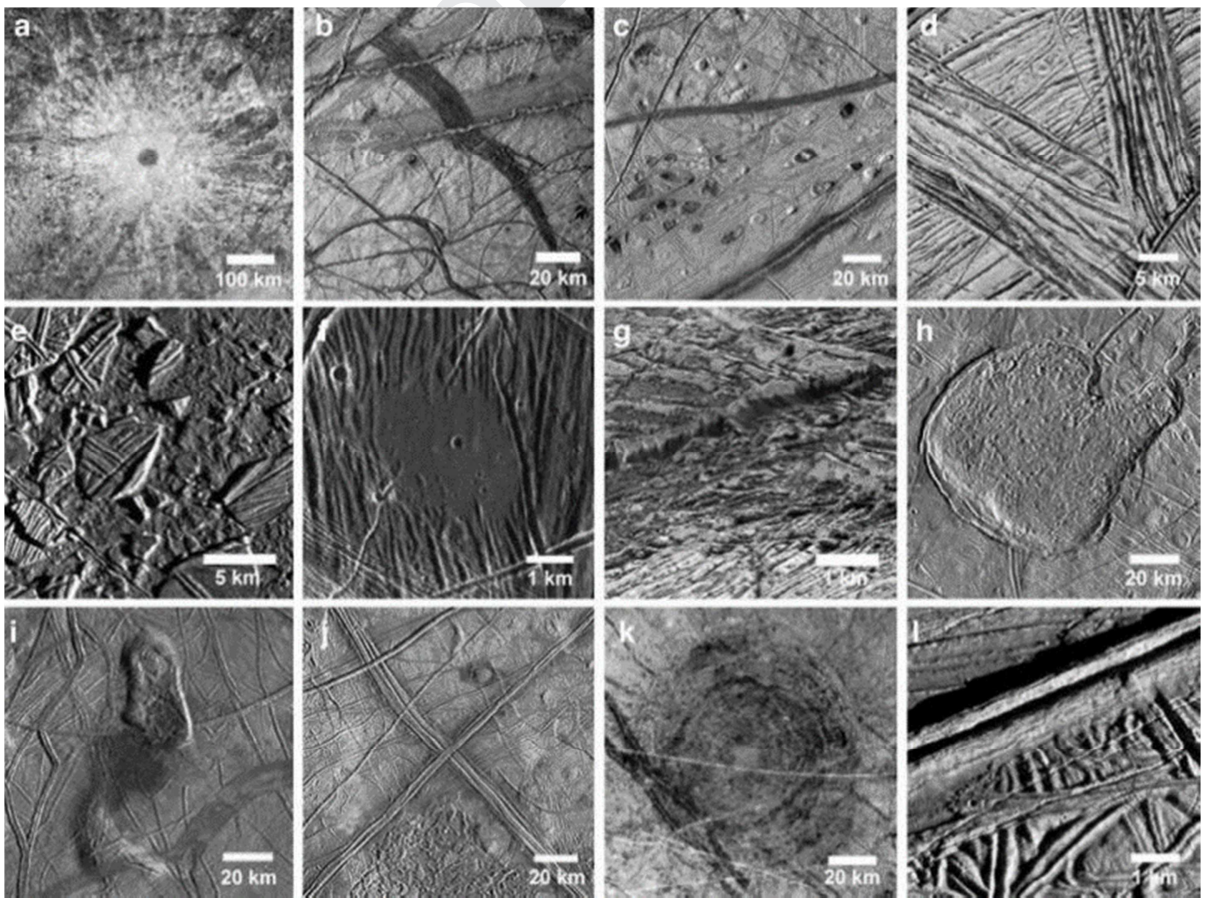

Figure 12: Variety of surface features on Europa: (a) the impact crater Pwyll; (b) pull-apart bands; (c) lenticulae; (d) ridge complexes at high resolution; (e) Conamara Chaos; $(f)$ dark plains material in a 
topographic low; $(g)$ very high-resolution image of a cliff, showing evidence of mass wasting; $(h)$ Murias Chaos, a cryovolcanic feature; ( $i$ ) the Castalia Macula region; $(j)$ double 7 complex ridges; $(k)$ Tyre impact feature; and (l) one of Europa's ubiquitous ridges. (Credit: NASA/JPL/Caltech).

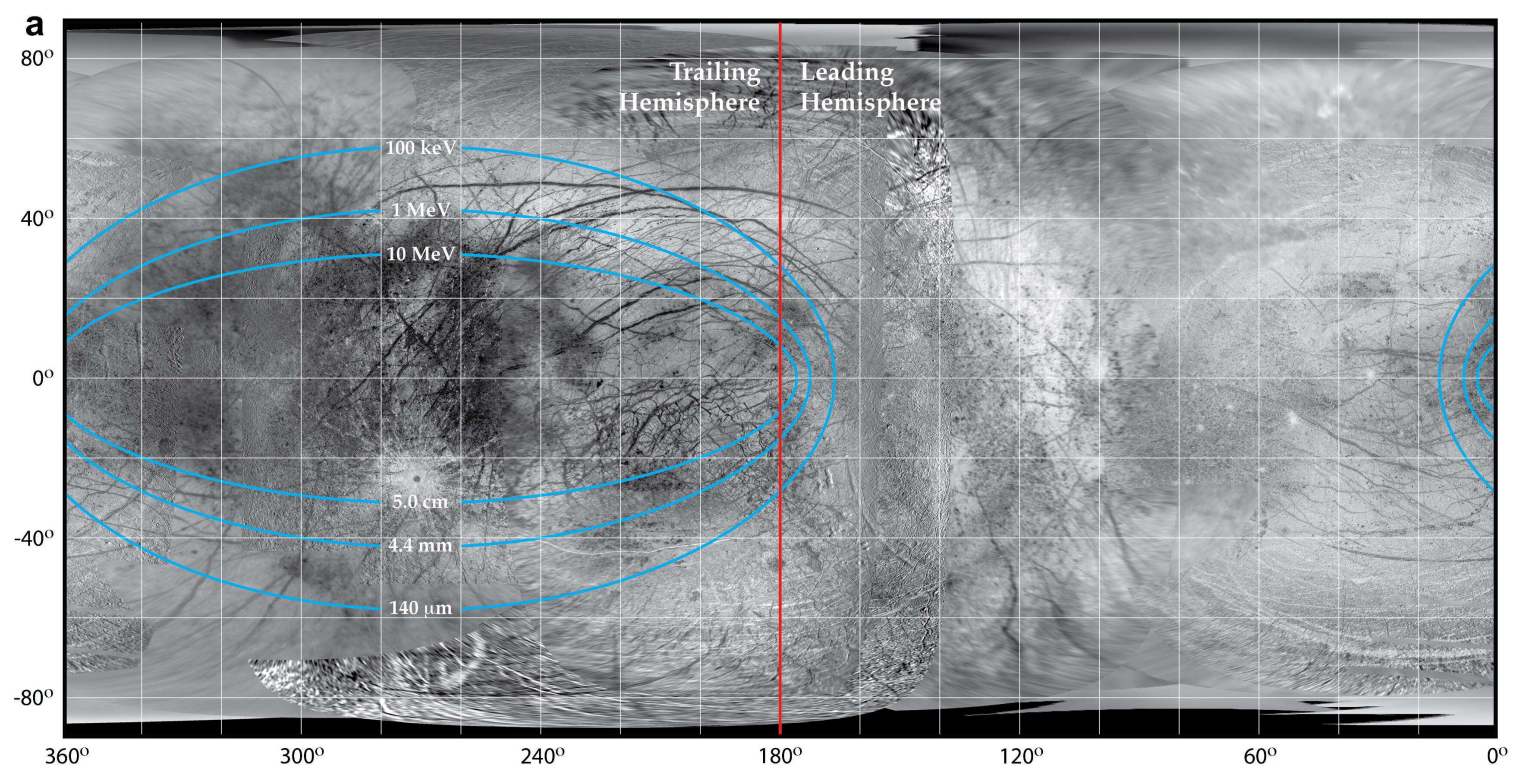

Figure 13: Contour plot of electron bombardment of Europa where energies and penetration depths are indicated from Patterson et al. 2012)

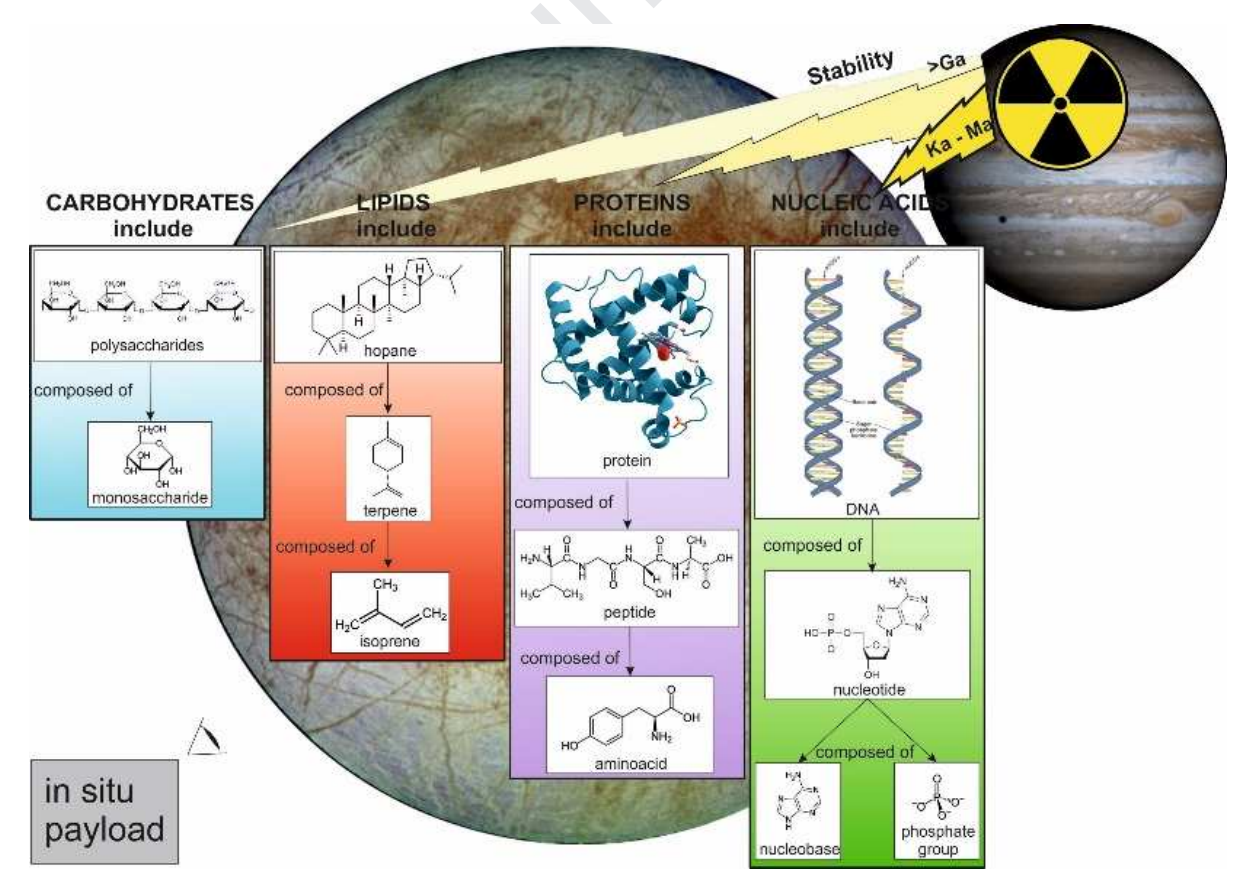

Figure 14: Types of biomolecules, from their monomers to the more complex polymers. Their higher stability under radiation is marked by the lower intensity of the yellow colour of the ray. 


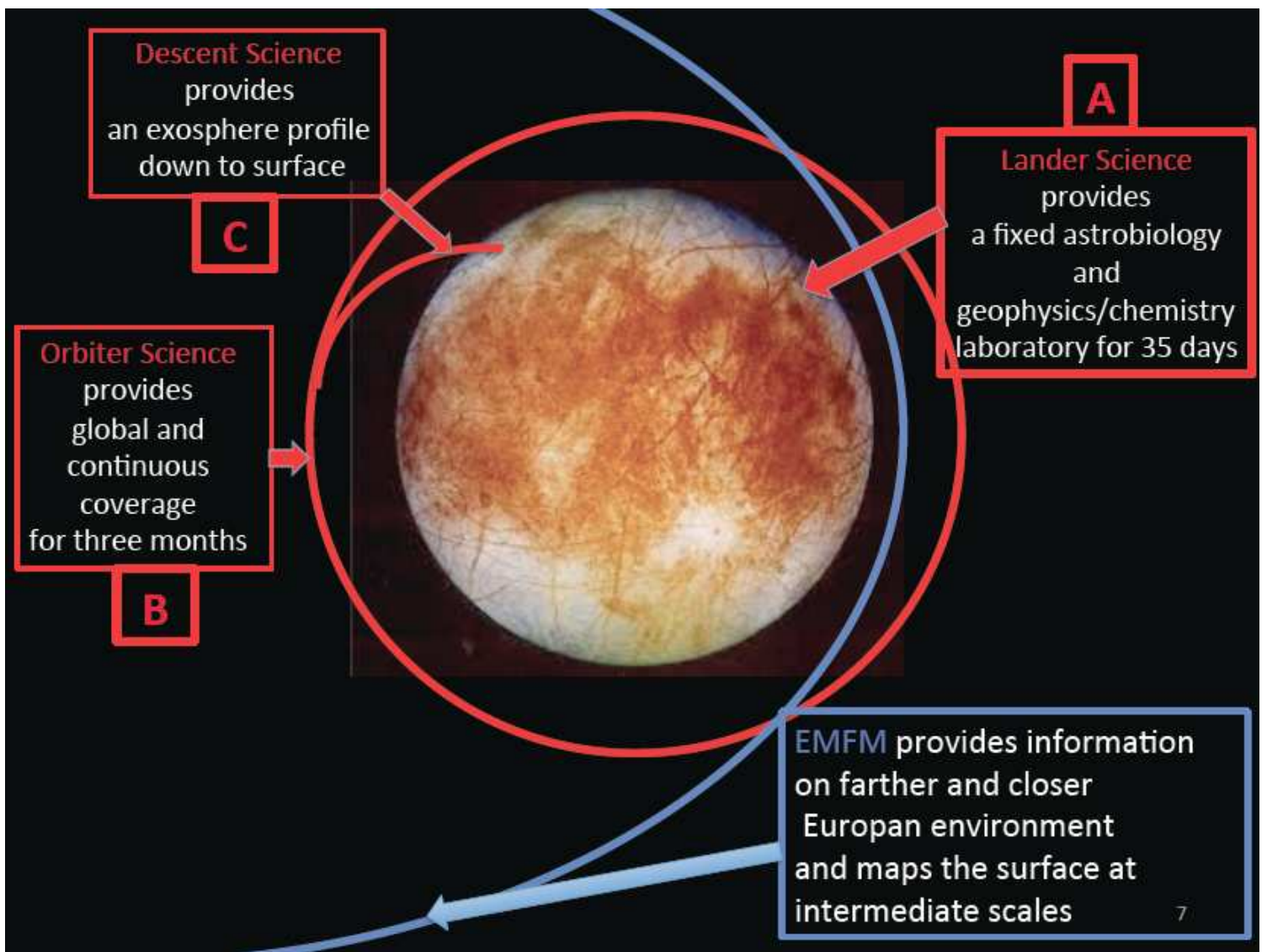

Figure15: the JEM Observing system, with its two main platforms, will provide three main science sequence, complemented by VLBI astrometry measurements from Earth.

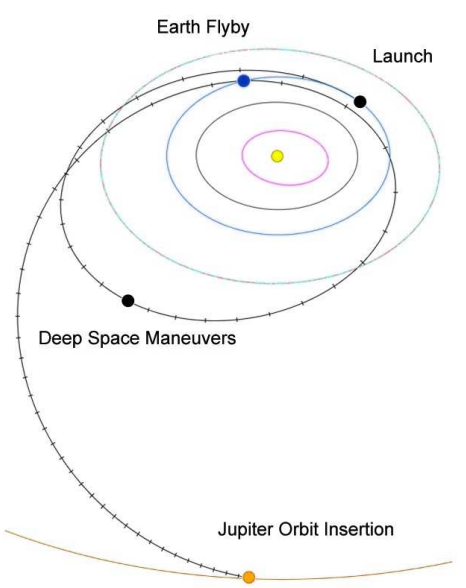

Figure 16: S1 - Interplanetary cruise 

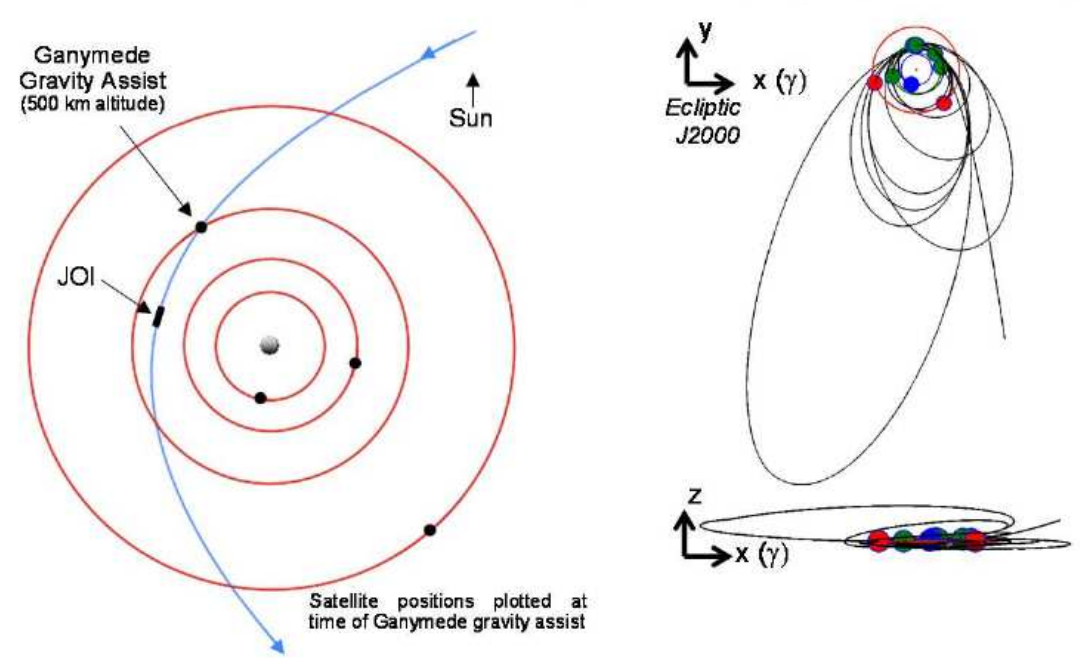

Callisto to Ganymede 3:2, 1:1

resonances to Europs

Figure 17: S2 - Jupiter orbit insertion (left)hand figure) \& S3 - Jovian tour. This tour starts with a series of eccentric orbits whose apojove and inclination are progressively reduced (center figures, projections in the $Y X$ (top) and XZ (bottom) planes, and continues with a set of low-eccentricy orbits in the equatorial plane to progressively approach Europa (blue spot), using its mean motion resonance with Callisto (red spot).

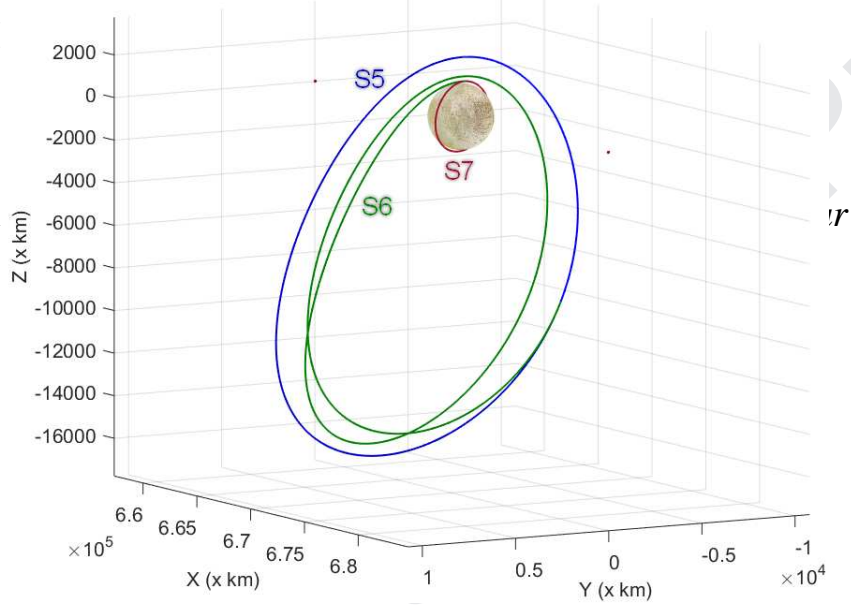

Figure 18: configuration of the Europa science orbits: halo orbit about the L1 Lagrangian point (blue, S5); transfer to Low Europa Orbit (green, S6) and finally low quasi-polar Europa orbit (red, S7).

Electron flux

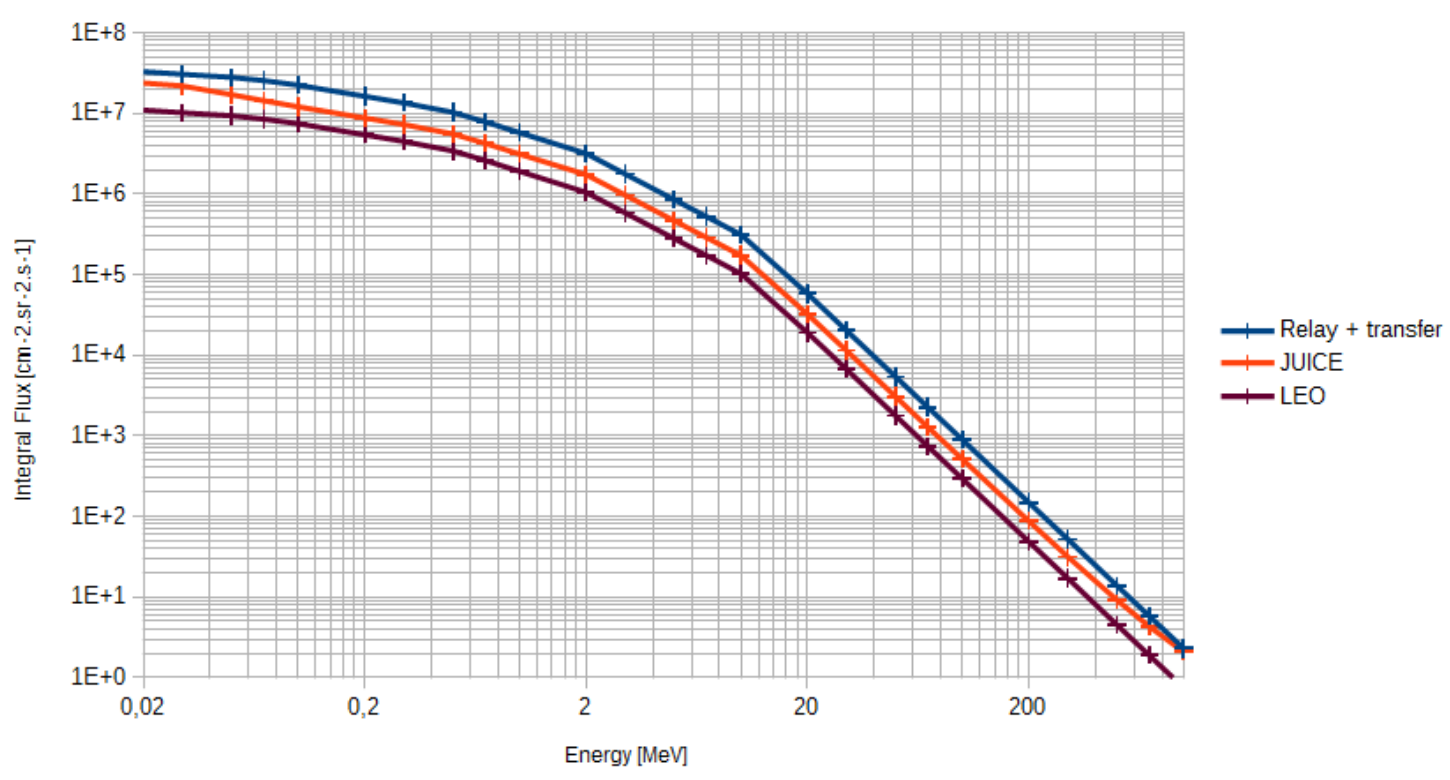


Figure 19: Integral electron flux vs. energy from SPENVIS, displayed for various phases of the JEM and compared

to

JUICE

worst-case.

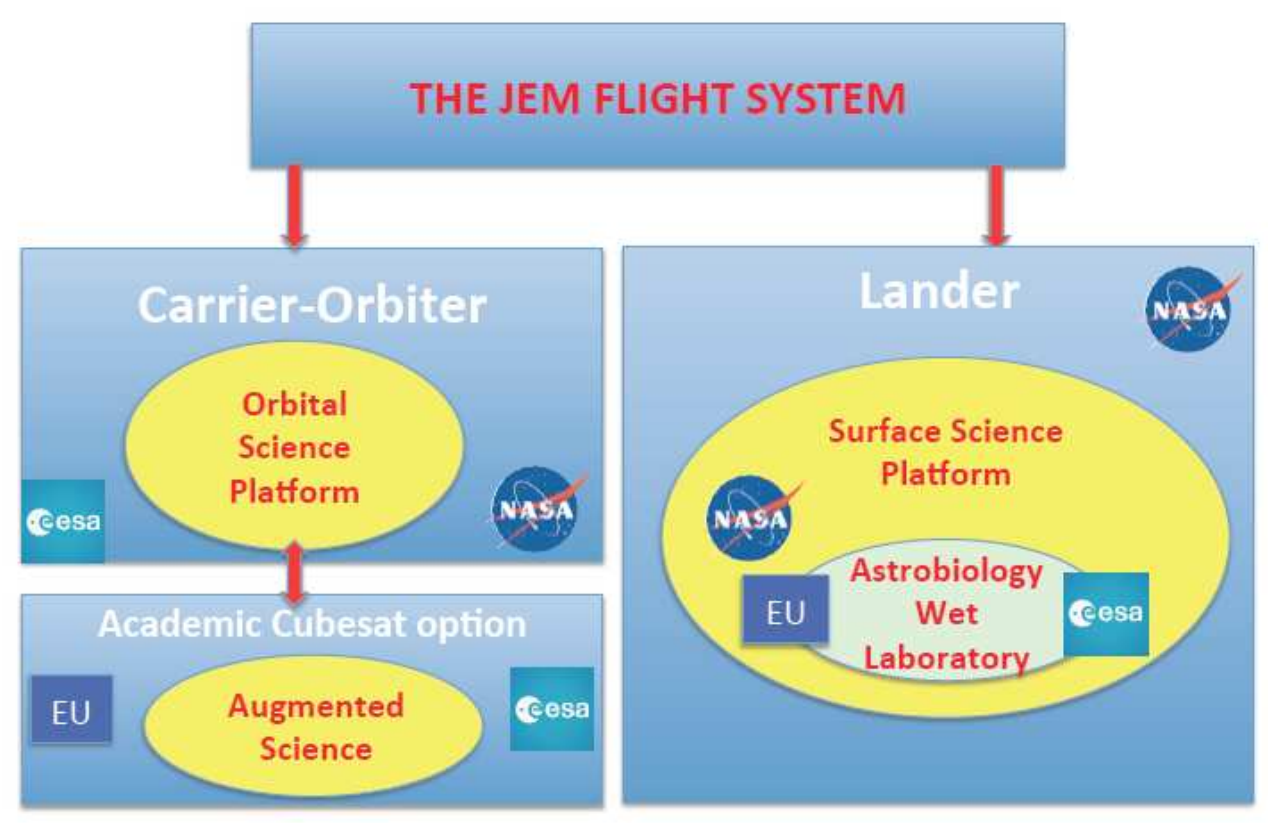

Figure 20: Overall architecture of the proposed JEM flight system, with its different flight elements.

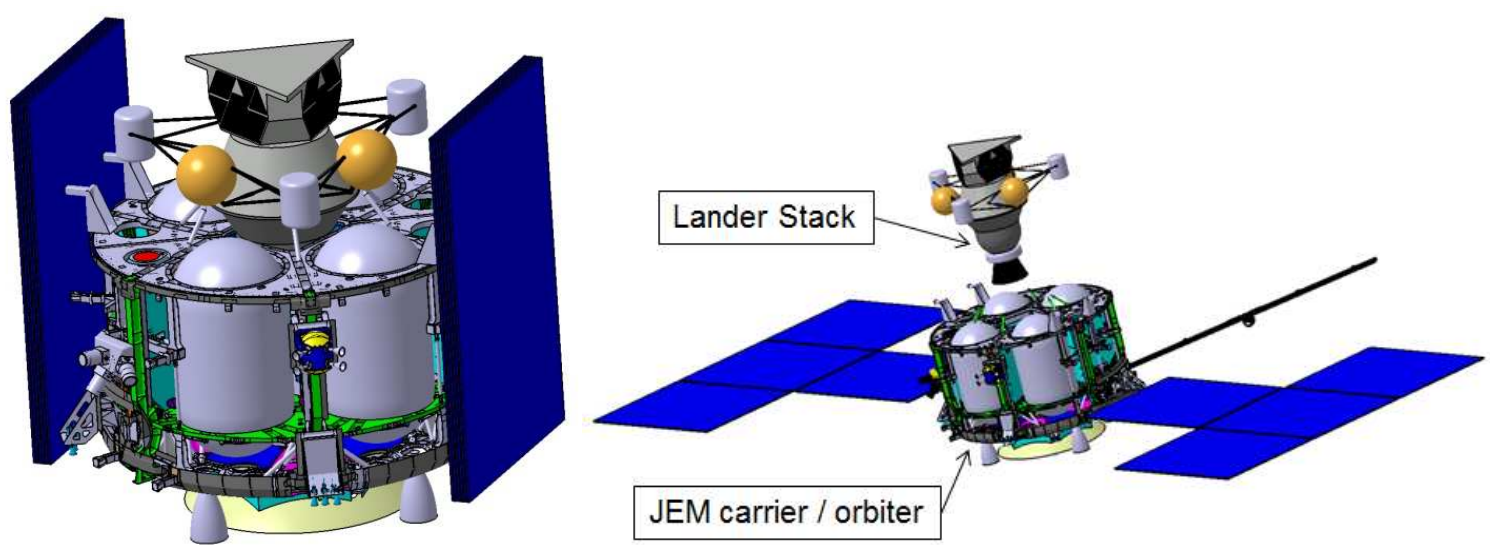

Figure 21: JEM carrier and lander interface 


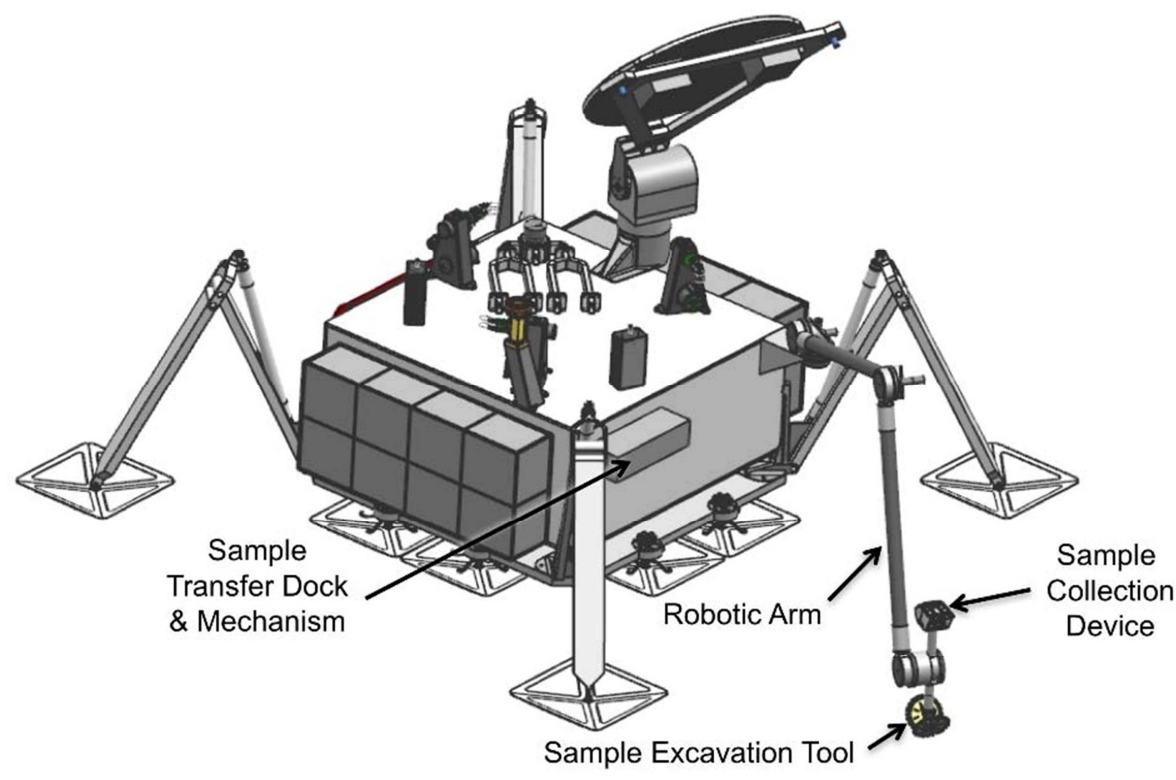

Figure 22: The NASA Europa lander concept presented in the Europa Lander Science Definition Team report (K. Hand et al., 2017).

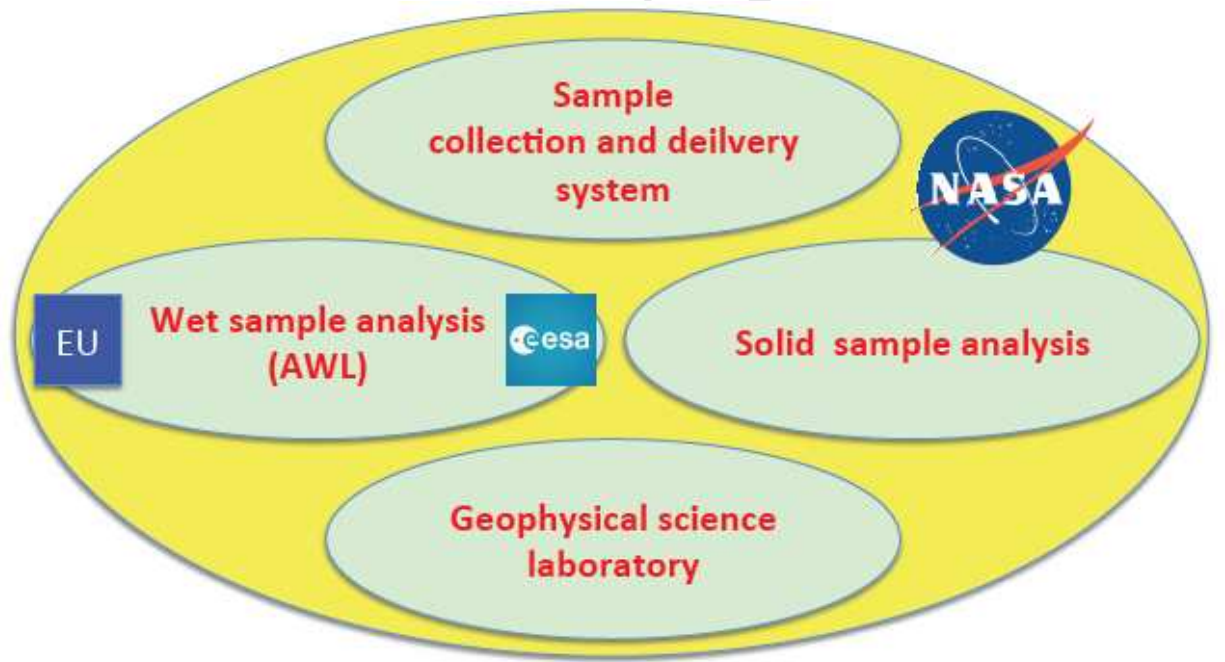

Figure 23: Proposed functional structure of the surface science platform on board the soft lander. 

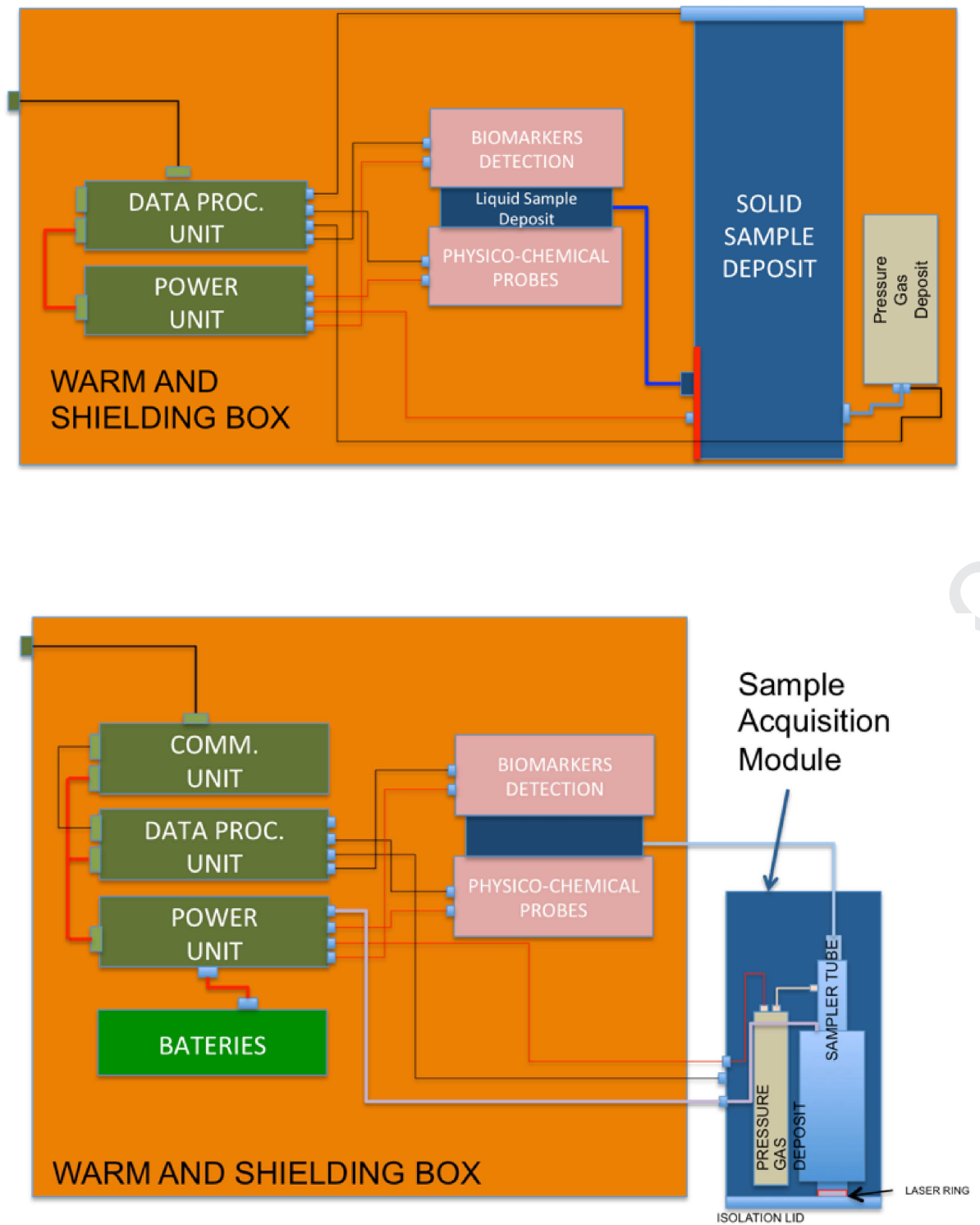

Figure 24: AWL/L (top) Block Diagram in case it is accommodated inside the lander and AWS/S in case it is deployed at the surface

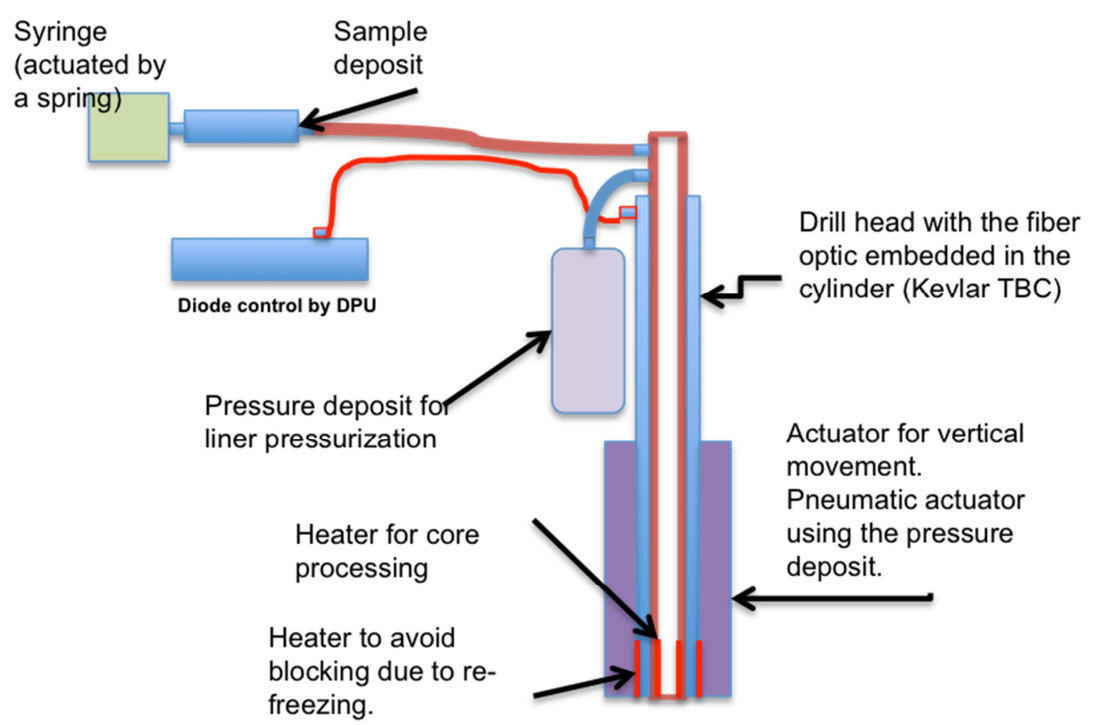


Figure 25: Sample acquisition concept.

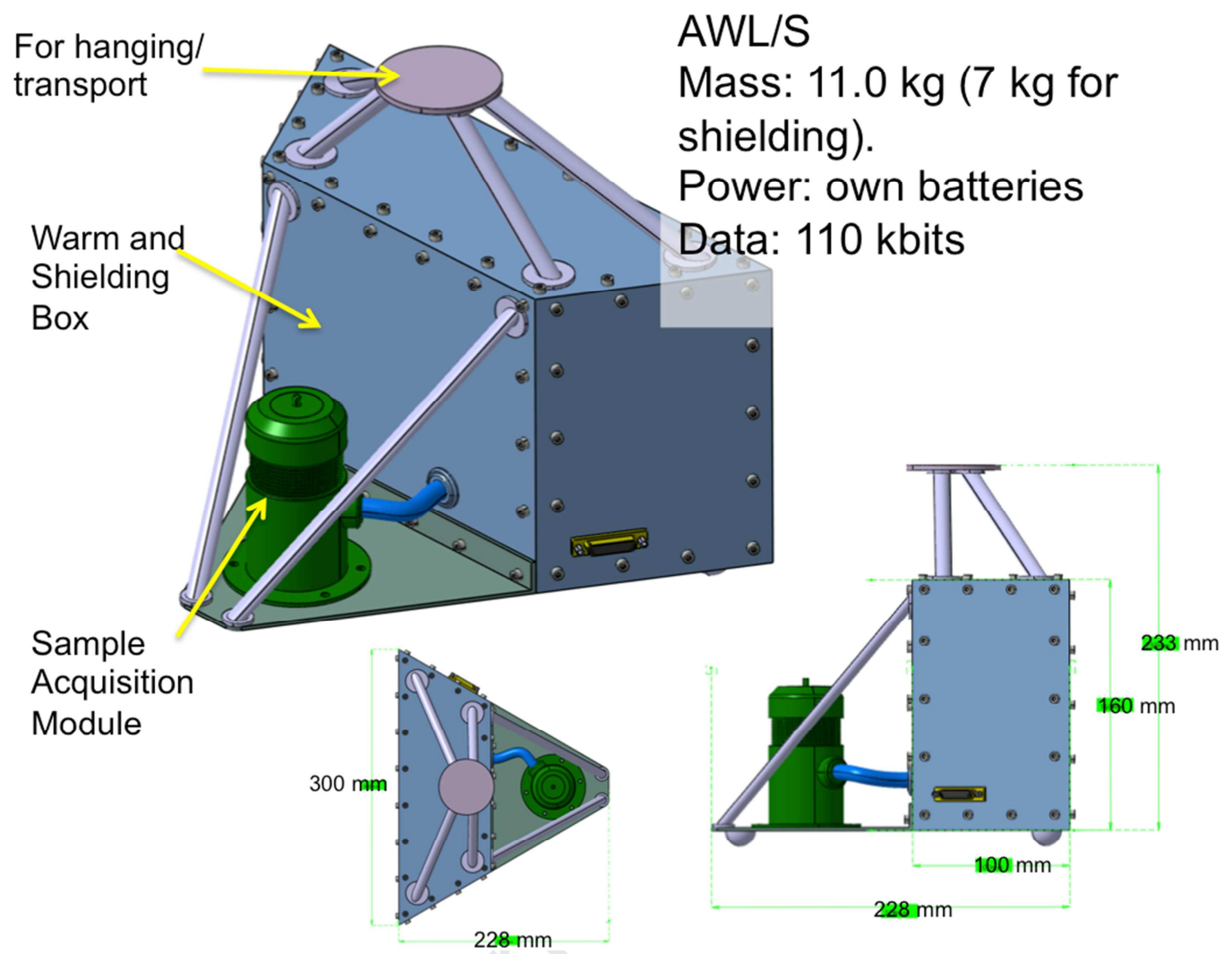

Figure 26: AWL/S mechanical configuration concept. A support structure allows it to be handled by the lander arm. A box protects the electronics, MAP and MPP. The isolation lid, below SAM, has a lateral movement to be open.

\section{Annex II: JEM orbiter system design}
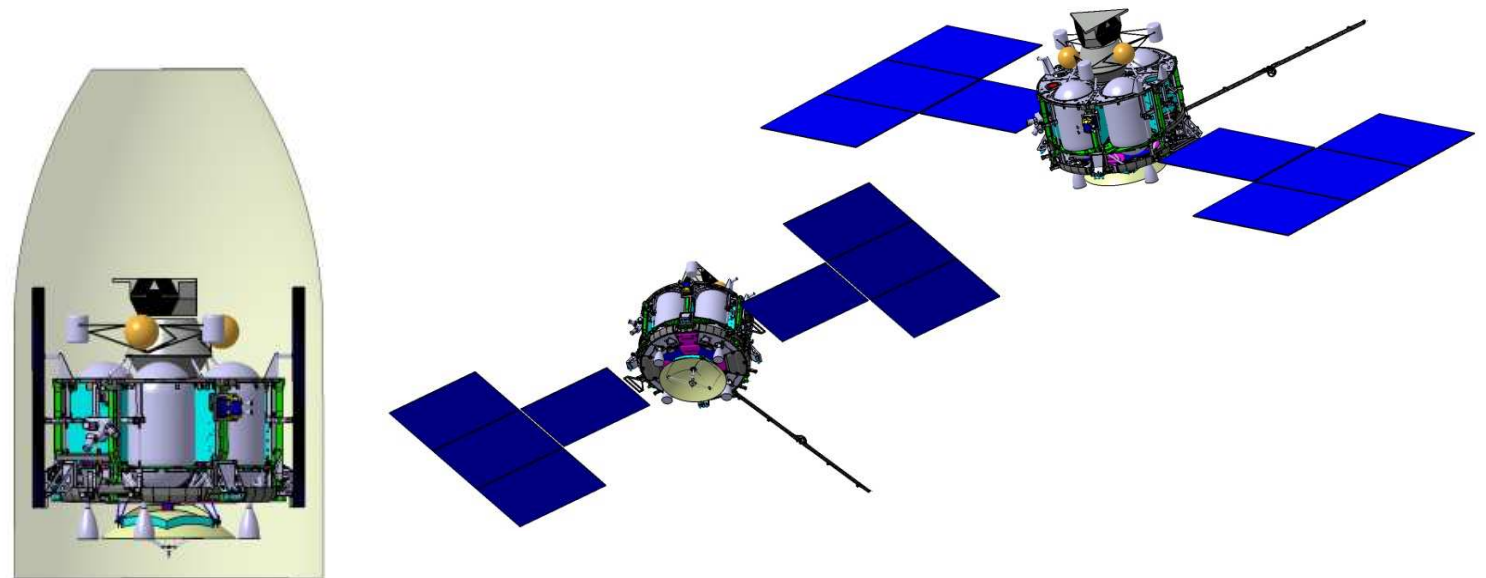

Figure A2.1: Spacecraft configuration (stacked and deployed) 


\section{ANNEX III: Orbitography for the JEM mission}

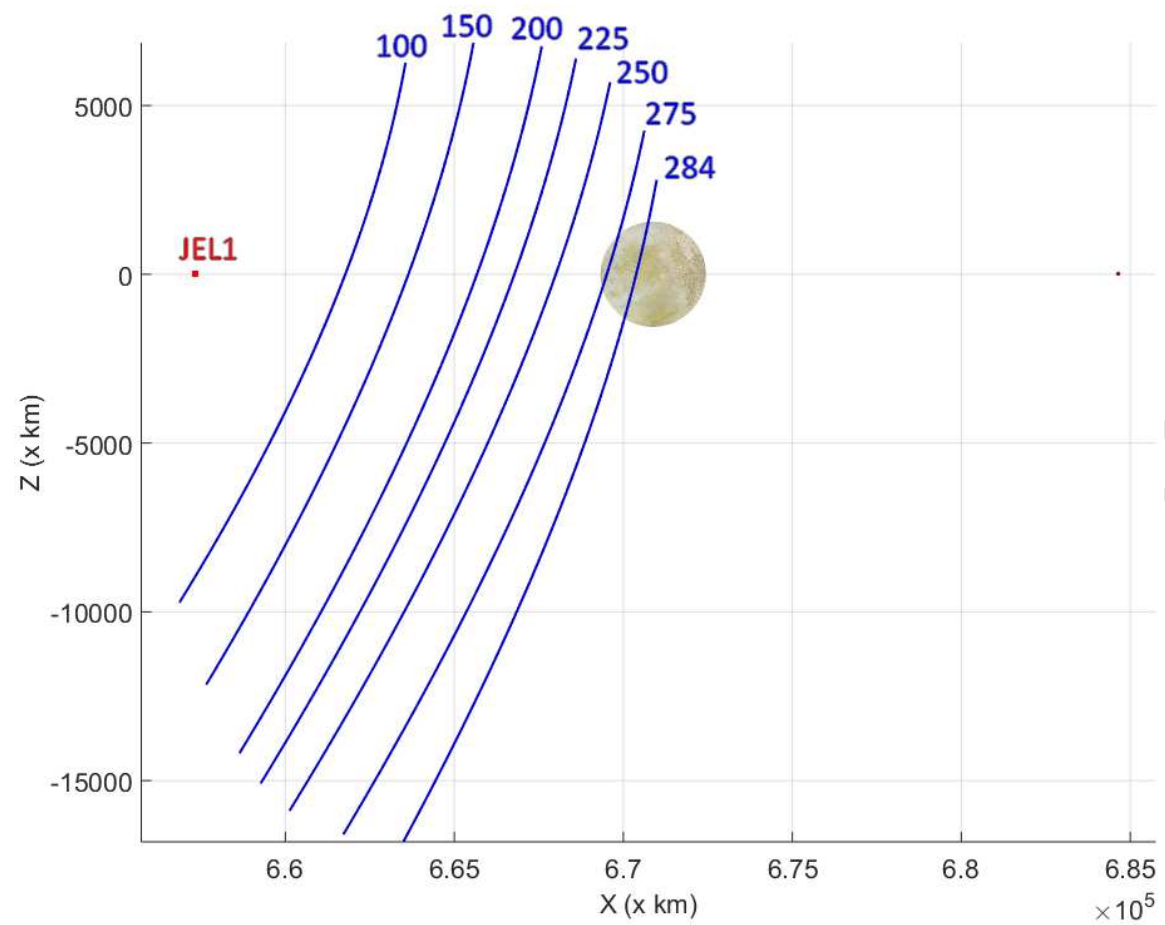

Figure A3.1: A set of JEL1 southern halo orbit in Jupiter-Europa rotating frame

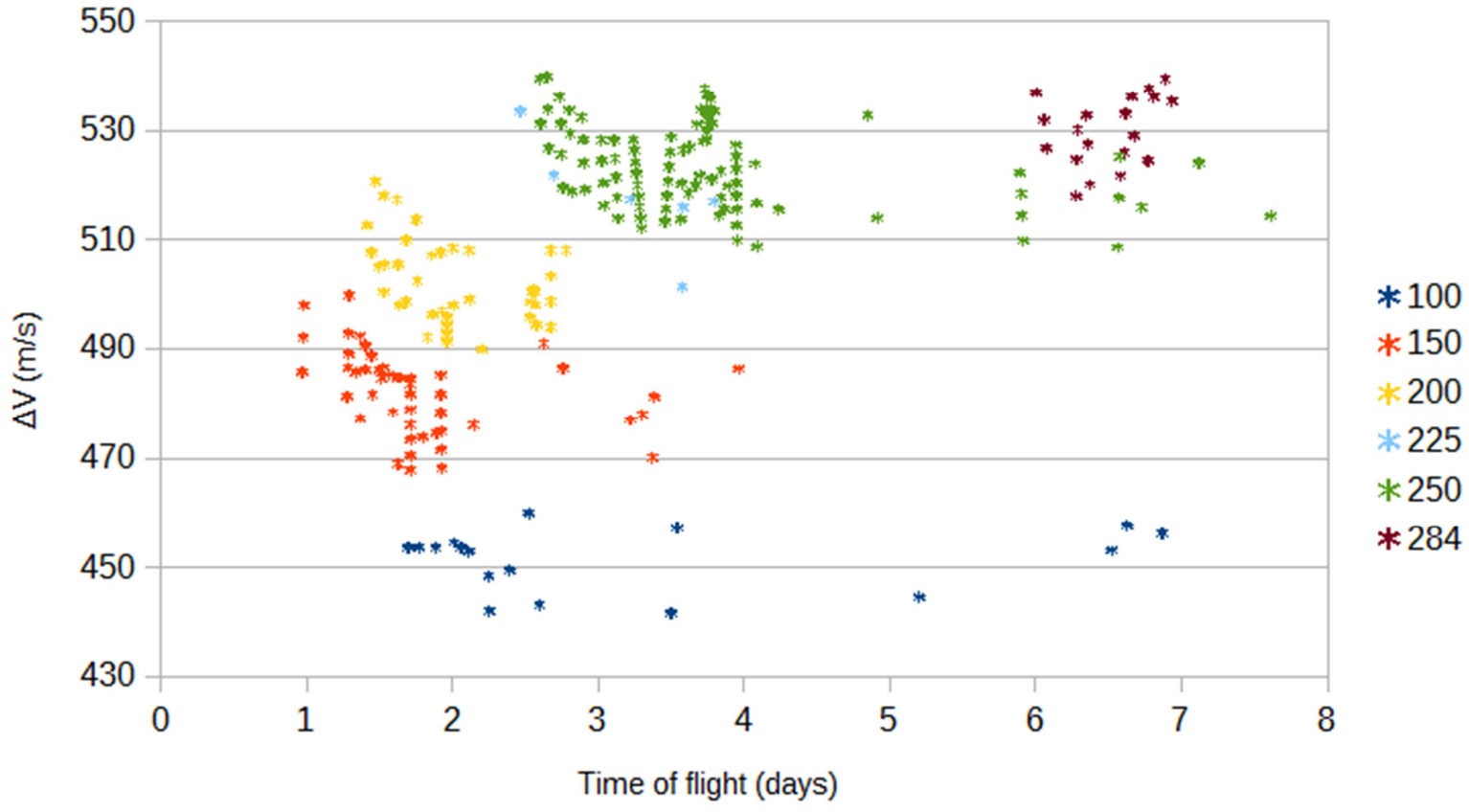

Figure A3.2: $\Delta V$ vs Time of flight for all the possible transfers of a set of halo orbits 


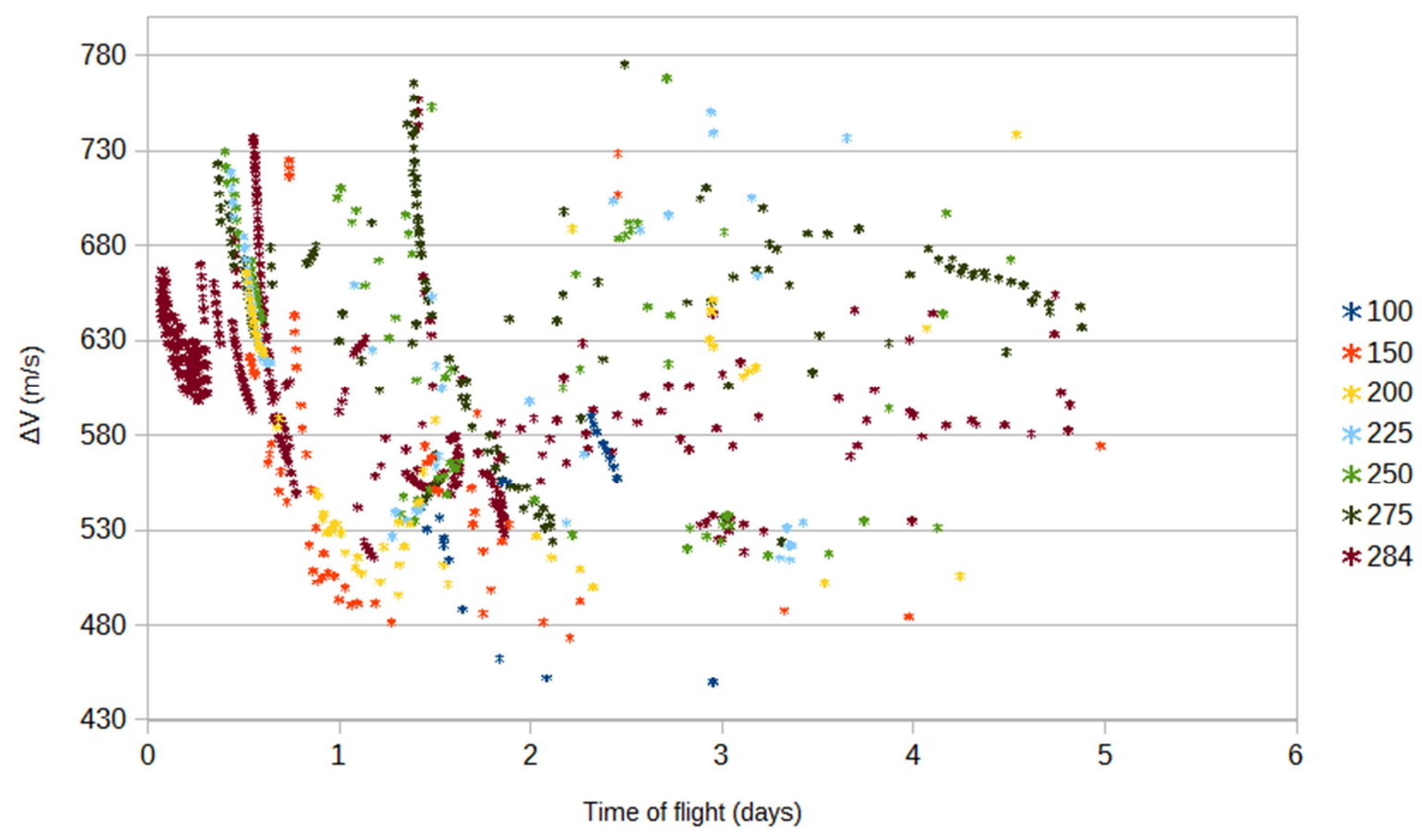

Figure A3.3: $\Delta V v$ s Time of flight for all the possible transfers with a tangent burn to leave a set of halo orbits

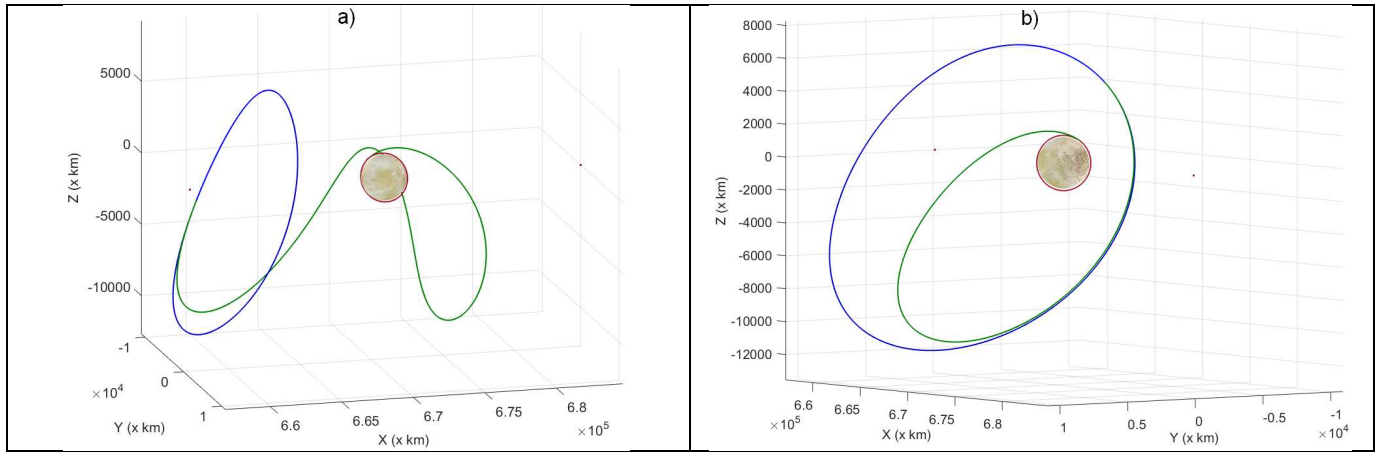


Journal Pre-proof

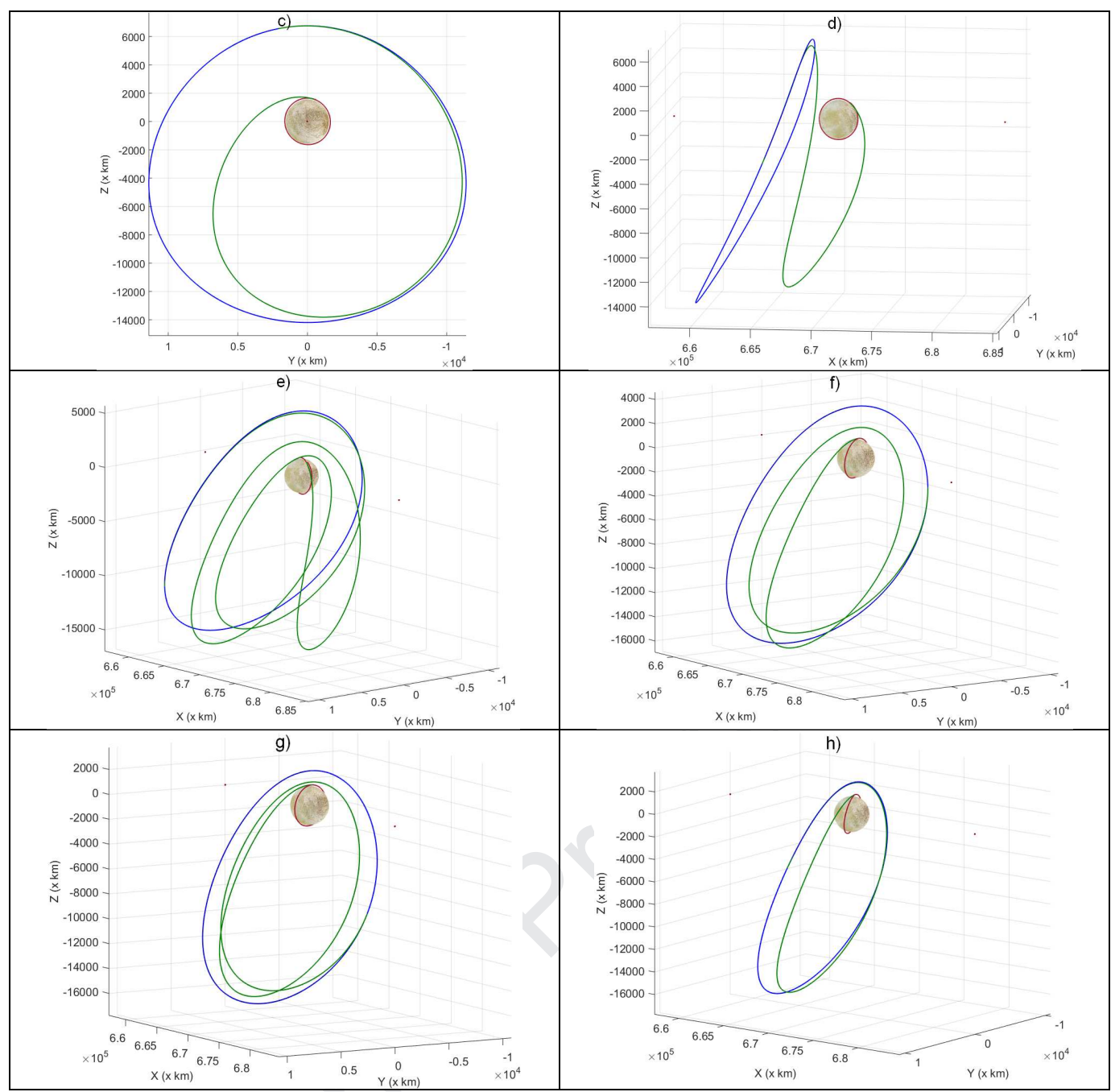

Figure A3.4: Set of transfers using different halo orbits 

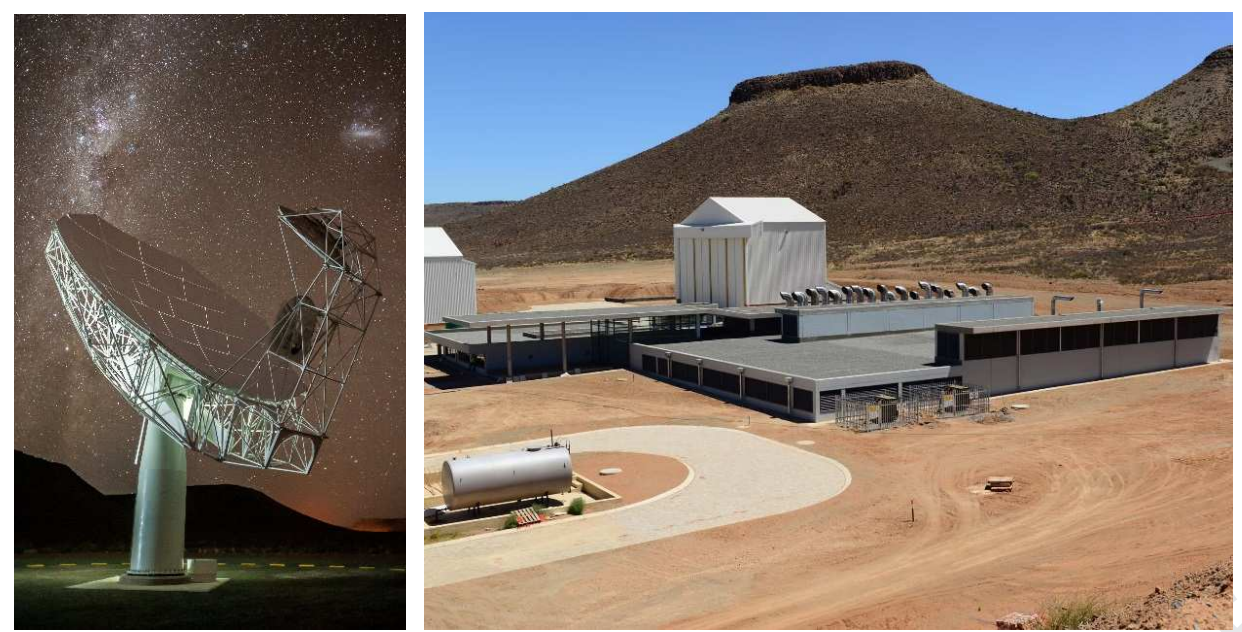

Figure A4.1: MeerKAT Dish (Left) and Karoo Array Processor Building (Right)
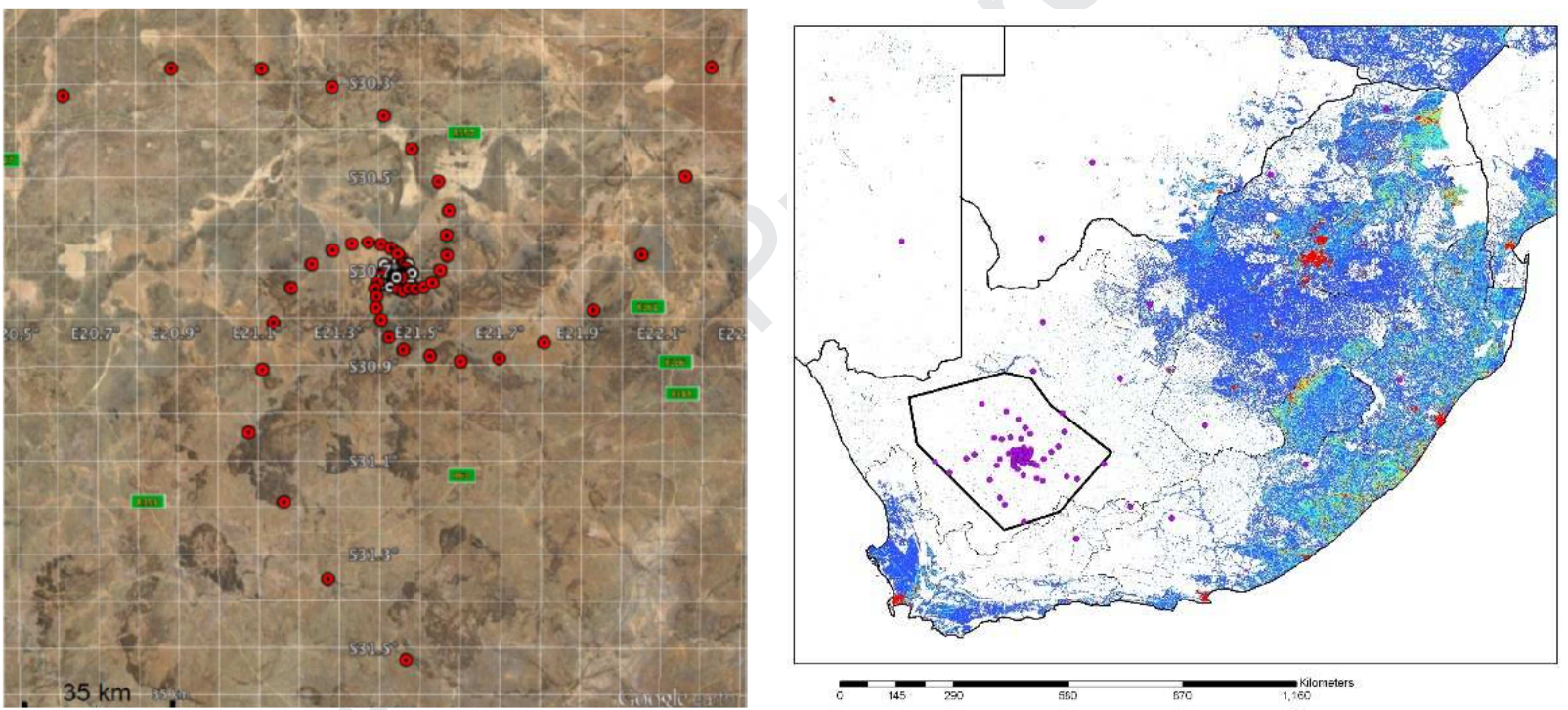

Figure A4.2: SKA1-Mid Array Configuration (Left) and SKA1-Mid Array Location in South Africa (Right, Showing Population Density and an Older Array Config) 


\section{Highlights}

In this article we are proposing that ESA collaborates with NASA to design and fly jointly an ambitious and exciting planetary mission, which we call the Joint Europa Mission (JEM), to reach two objectives: perform a full characterization of Jupiter Moon Europa's habitability with the capabilities of a Europa orbiter, and search for bio-signatures in the environment of Europa (surface, subsurface and exosphere) by the combination of an orbiter and a lander. JEM can build on the advanced understanding of this system which the missions preceding JEM will provide: Juno, JUICE and Europa Clipper, and on the Europa lander concept currently designed by NASA (Maize, report to OPAG, 2019).

We propose the following overarching goals for our proposed Joint Europa Mission (JEM): Understand Europa as a complex system responding to Jupiter system forcing, characterize the habitability of its potential biosphere, and search for life at its surface and in its sub-surface and exosphere.

The JEM observation strategy will combine three types of scientific measurement sequences: measurements on a high-latitude, low-altitude Europan orbit; in-situ measurements to be performed at the surface, using a soft lander; and measurements during the final descent to Europa's surface.

The implementation of these three observation sequences will rest on the combination of two science platforms: a soft lander to perform all scientific measurements at the surface and sub-surface at a selected landing site, and an orbiter to perform the orbital survey and descent sequences.

We describe a science payload for the lander and orbiter that will meet our science objectives.

We propose an innovative distribution of roles for NASA and ESA; while NASA would provide an SLS launcher, the lander stack and most of the mission operations, ESA would provide the carrierorbiter-relay platform and a stand-alone astrobiology module for the characterization of life at Europa's surface: the Astrobiology Wet Laboratory (AWL). 
ANNEX I: Summarized traceability matrix for JEM / OVERARCHING GOAL: Understand Europa as a complex system responding to Jupiter system forcing, characterize the habitability of its potential biosphere, and search for life at its surface

\begin{tabular}{|c|c|c|c|c|}
\hline \multirow{2}{*}{ Priority Science Objectives (PSO) } & \multicolumn{2}{|c|}{ Carrier-Orbiter } & \multicolumn{2}{|c|}{ Lander } \\
\hline & Required measurements & $\begin{array}{l}\text { Constraints on mission } \\
\text { and platform }\end{array}$ & Required measurements & $\begin{array}{l}\text { Constraints on mission } \\
\text { and platform }\end{array}$ \\
\hline $\begin{array}{l}\text { PSO \#1: Determine the global structure of the } \\
\text { Europan magnetic field and plasma } \\
\text { environment including potential plume } \\
\text { characterization, and the associated response } \\
\text { of Europa, including its ocean, to Jupiter } \\
\text { System magnetospheric forcing. }\end{array}$ & $\begin{array}{l}\text { Magnetometer } \\
\text { Ion Mass Spectrometer/ } \\
\text { Electron Mass Spectrometer } \\
\text { (Langmuir Probe) } \\
\text { Radiation Monitor } \\
\text { Ion and Neutral Mass Spectrometer } \\
\text { Dust analyzer }\end{array}$ & $\begin{array}{l}\text {-3D Coverage of the Europan } \\
\text { environment including crossing of the } \\
\text { Alfven wings } \\
\text {-Low-altitude }(100-200 \mathrm{~km}) \text { near-polar, } \\
\text { circular orbit for at least } 30 \text { days } \\
\text {-Low-altitude crossing of plumes }(<160 \\
\mathrm{km} \text { ) for orbiter }\end{array}$ & Magnetometer & $\begin{array}{l}\text { Lander lifetime of at } \\
\text { least } 7 \text { days ( } 2 \text { Europa } \\
\text { rotations) }\end{array}$ \\
\hline $\begin{array}{l}\text { PSO \#2: Determine the global structure of the } \\
\text { solid body and potential biosphere of Europa, } \\
\text { and their response to Jupiter System tidal } \\
\text { forcing. }\end{array}$ & $\begin{array}{l}\text { Radio Science Instrument } \\
\text { Laser Altimeter }\end{array}$ & & $\begin{array}{l}\text { Geophone } \\
\text { Laser Reflector }\end{array}$ & \\
\hline $\begin{array}{l}\text { PSO \#3: Understand the exchange and } \\
\text { transformation processes at the interface } \\
\text { between the ice-shell surface/subsurface and } \\
\text { the exosphere/ionosphere including potential } \\
\text { plume characterization. }\end{array}$ & $\begin{array}{l}\text { Ion and neutral MS } \\
\text { Ion MS + electron Spectrometer } \\
\text { Dust Analyzer }\end{array}$ & $\begin{array}{l}\text {-Spatial resolution of few 10's km } \\
\text { horizontally and few km in altitude up to } \\
1 \text { Europa radius from the surface; of } \\
100 \text { 's km horizontally and 10's km in } \\
\text { altitude for major species } \\
\text {-Full latitudinal and longitudinal } \\
\text { coverage at few phase angles with a } \\
\text { temporal resolution from one hour to few } \\
\text { 10s of hours } \\
\text {-Coverage of Europa's exosphere during } \\
\text { eclipse }\end{array}$ & & \\
\hline $\begin{array}{l}\text { PSO \#4: Understand the exchange processes } \\
\text { between the ice-shell surface/subsurface and } \\
\text { the aqueous interior environments, focusing } \\
\text { on the hydrochemistry and physical state of } \\
\text { the ice crust. }\end{array}$ & Laser altimeter & $\begin{array}{l}\text { Altimetry from the orbiter combined } \\
\text { with in situ measurements }\end{array}$ & $\begin{array}{l}\text { Imaging camera, } \\
\text { Microscope, GCMS, } \\
\text { Raman, Geophone } \\
\text { Thermogravimeter, } \\
\text { Electrochemical sensors, } \\
\text { Magnetometer }\end{array}$ & $\begin{array}{l}\text { In situ analysis from the } \\
\text { landing site. Sampling } \\
\text { and analysis in solid and } \\
\text { liquid state }\end{array}$ \\
\hline $\begin{array}{l}\text { PSO \#5: Search for biosignatures at the } \\
\text { surface/subsurface. }\end{array}$ & Ion and neutral MS & & $\begin{array}{l}\text { GCMS, Raman } \\
\text { Microarray immunoassay } \\
\text { detector, Imaging camera } \\
\text { Microscope } \\
\text { Thermogravimeter } \\
\text { Geophone } \\
\text { Magnetometer }\end{array}$ & $\begin{array}{l}\text { In situ analysis from the } \\
\text { landing site. Sampling } \\
\text { and analysis in solid and } \\
\text { liquid state } \\
\text { Characterize potential } \\
\text { plumes if there is some } \\
\text { activity }\end{array}$ \\
\hline
\end{tabular}


\begin{tabular}{l|ll} 
JEM & OVERARCHING GOAL
\end{tabular}

\begin{tabular}{|c|c|c|c|c|c|}
\hline & \multicolumn{5}{|c|}{$\begin{array}{l}\text { Understand Europa as a complex system responding to Jupiter system forcing, characterize the habitability of its potential biosphere, and search for life at } \\
\text { its surface }\end{array}$} \\
\hline & \multicolumn{2}{|c|}{ 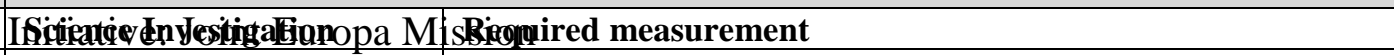 } & \multirow[b]{2}{*}{$\begin{array}{l}\text { Instrumentation } \\
\text { Magnetometer } \\
\text { Ion Mass } \\
\text { Spectrometer/ } \\
\text { Electron Mass } \\
\text { Spectrometer } \\
\text { Langmuir Probe } \\
\text { Radiation Monitor }\end{array}$} & \multirow{2}{*}{$\begin{array}{l}\text { Platform } \\
\begin{array}{l}\text { Orbiter } \\
\text { +Lander }\end{array}\end{array}$} & \multirow[b]{2}{*}{$\begin{array}{l}\text { Constraints onfightforn } \\
\text {-3D Coverage of the } \\
\text { Europan environment } \\
\text { including crossing of the } \\
\text { Alfven wings } \\
-5-\mathrm{m} \text { boom for MAG to be } \\
\text { accommodated on orbiter } \\
\text {-Small boom for LP to be } \\
\text { accommodated on orbiter } \\
\text {-Engineering payload for } \\
\text { RM to be accommodated } \\
\text { on orbiter }\end{array}$} \\
\hline \multirow{4}{*}{ 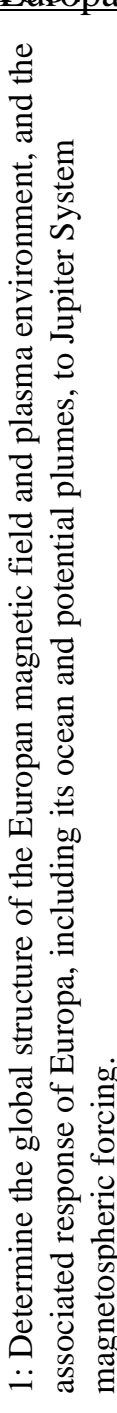 } & $\begin{array}{l}\text { Determine the global } \\
\text { structure of magnetic fields, } \\
\text { electric currents, and plasma } \\
\text { and energetic populations in } \\
\text { the Europan environment }\end{array}$ & $\begin{array}{l}\text {-Energy, flux, angular distributions, direction, and composition of } \\
\text { corotating magnetospheric particle populations from } 10 \mathrm{eV} \text { up to a } \\
\text { few } \mathrm{MeV} \text { with } 10 \mathrm{~s} \text { time resolution } \\
\text {-Energy, flux, angular distributions, direction, and composition of } \\
\text { thermal Europan exospheric and surface particle populations from } \\
<1 \mathrm{eV} \text { to } 30 \mathrm{keV} \text { with } 10 \mathrm{~s} \text { time resolution }\end{array}$ & & & \\
\hline & $\begin{array}{l}\text { Separate the four } \\
\text { contributions to Europan } \\
\text { magnetic fields and current } \\
\text { systems }\end{array}$ & $\begin{array}{l}\text { Mass resolved 3D velocity distributions functions (VDFs) of } \\
\text { plasma (ions \& electrons from < } 1 \mathrm{eV} \text { to } 30 \mathrm{keV} \text { ) and pickup ions } \\
\text { in Europa's vicinity with } 10 \mathrm{~s} \text { time resolution } \\
\text { Ion and electron flow direction, speed temperature, number and } \\
\text { charge } \\
\text { densities (currents), thermal and ram pressure; thermal and pickup } \\
\text { ion mass densities; local Alfven and sound speeds with 60s time } \\
\text { resolution Electric field vectors, electron and ion density, electron } \\
\text { temperature for local conductivity and electrical current } \\
\text { determination }\end{array}$ & $\begin{array}{l}\text { Magnetometer } \\
\text { Ion Mass } \\
\text { Spectrometer/ } \\
\text { Electron Mass } \\
\text { Spectrometer } \\
\text { Langmuir Probe }\end{array}$ & $\begin{array}{l}\text { Orbiter + } \\
\text { Lander } \\
\text { Orbiter }\end{array}$ & \\
\hline & $\begin{array}{l}\text { Perform a broad-band } \\
\text { magnetic sounding of the } \\
\text { Europan sub-surface ocean } \\
\text { and uniquely determine its } \\
\text { depth, thickness }\end{array}$ & $\begin{array}{l}\text { Measure three-axis magnetic field components at } 8 \text { vectors/s, and } \\
\text { a sensitivity of } 0.1 \mathrm{nT} \text {, near continuously to determine the } \\
\text { induction response at multiple frequencies to an accuracy of } 0.1 \\
\text { nT. }\end{array}$ & Magnetometer & $\begin{array}{l}\text { Orbiter + } \\
\text { Lander }\end{array}$ & $\begin{array}{l}\text {-Low-altitude (100-200 } \\
\mathrm{km}) \text { near-polar, circular } \\
\text { orbit for at least } 30 \text { days } \\
\text {-Lander lifetime of at least } \\
7 \text { days (2 Europa rotations) }\end{array}$ \\
\hline & $\begin{array}{l}\text { Determine the composition } \\
\text { and flux of plume material } \\
\text { to characterize properties of } \\
\text { any subsurface water }\end{array}$ & $\begin{array}{l}\text {-Composition, energy spectra, and flux of pick-up ions in plumes } \\
\text { Electron energy spectra and density inside and outside Europa's } \\
\text { flux tube } \\
\text {-Composition of ion and neutral populations in plumes } \\
\text {-Composition of dust populations in plumes }\end{array}$ & $\begin{array}{l}\text { Ion Mass } \\
\text { Spectrometer/Electr } \\
\text { on Mass } \\
\text { Spectrometer } \\
\text { Ion and Neutral } \\
\text { Mass Spectrometer } \\
\text { Dust analyzer }\end{array}$ & Orbiter & $\begin{array}{l}\text { Low-altitude crossing of } \\
\text { plumes }(<160 \mathrm{~km}) \text { for } \\
\text { orbiter }\end{array}$ \\
\hline 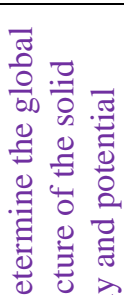 & $\begin{array}{l}\text { Determine the amplitude } \\
\text { and phase of the tidal effect } \\
\text { on the external gravitational } \\
\text { potential of Europa }\end{array}$ & $\begin{array}{l}\text { Perform range-rate measurements with an accuracy } \sim 0.01 \mathrm{~mm} / \mathrm{s} \text { at } \\
60 \mathrm{sec} \text { integration time to determine the spacecraft orbital motion } \\
\text { to better than } 1 \text {-meter ( } \mathrm{rms} \text { ) over several tidal cycles. Estimate the } \\
\text { time-dependent part of the } 2 \text { nd degree gravitational field of } \\
\text { Europa and determine the Love number } \mathrm{k} 2 \text { at the orbital } \\
\text { frequency of Europa with an absolute accuracy of better than } 0.01 \\
\text { and the phase with a precision below } 1 \text { degree }\end{array}$ & $\begin{array}{l}\text { Radio Science } \\
\text { Instrument } \\
\text { Laser Altimeter }\end{array}$ & orbiter & $\begin{array}{l}\text { quasi-polar orbit, } \\
\text { pericenter altitude } 200 \mathrm{~km} \\
\text { or less, tracking for two } \\
\text { months }\end{array}$ \\
\hline & & $\begin{array}{l}\text { Measure topographic differences from globally distributed repeat } \\
\text { ranging measurements, to recover spacecraft altitude at crossover }\end{array}$ & & & \\
\hline
\end{tabular}




\begin{tabular}{|c|c|c|c|c|}
\hline & $\begin{array}{l}\text { points to } 1-\text { meter vertical accuracy by contiguous global ranging } \\
\text { to the surface with } 10-\mathrm{cm} \text { accuracy. }\end{array}$ & & & \\
\hline \multirow[t]{3}{*}{$\begin{array}{l}\text { Characterise the tidal } \\
\text { surface displacement as a } \\
\text { function of tidal cycle. }\end{array}$} & $\begin{array}{l}\text { Measure topographic differences from globally distributed repeat } \\
\text { measurements at varying orbital phase, with better than or equal to } \\
1 \text {-meter vertical accuracy, to recover the Love number h } 2 \text { at the } \\
\text { orbital frequency with an absolute accuracy of } 0.01 \text { and the phase } \\
\text { with a precision below } 1 \text { degree by contiguous global ranging to } \\
\text { the surface with } 10-\mathrm{cm} \text { accuracy. }\end{array}$ & \multirow[t]{3}{*}{$\begin{array}{l}\text { Laser Altimeter } \\
\text { Radio Science } \\
\text { Instrument } \\
\text { radio transponder }\end{array}$} & \multirow[t]{3}{*}{$\begin{array}{l}\text { Orbiter } \\
\text { Lander }\end{array}$} & \multirow{3}{*}{$\begin{array}{l}\text { quasi-polar orbit, } \\
\text { pericenter altitude } 200 \mathrm{~km} \\
\text { or less, tracking for two } \\
\text { months } \\
\text { frequent tracking during } \\
\text { several orbital cycles from } \\
\text { Earth or an orbiter }\end{array}$} \\
\hline & $\begin{array}{l}\text { Measure spacecraft orbital motion to resolve the position of the } \\
\text { spacecraft to better than 1-meter (rms) by performing range-rate } \\
\text { measurements with an accuracy } \sim 0.01 \mathrm{~mm} / \mathrm{s} \text { at } 60 \mathrm{sec} \text { integration } \\
\text { time }\end{array}$ & & & \\
\hline & $\begin{array}{l}\text { Perform range-rate measurements with an accuracy } \sim 0.01 \mathrm{~mm} / \mathrm{s} \text { at } \\
60 \mathrm{sec} \text { integration time to determine the changes in the lander } \\
\text { position related to tidal surface displacements. }\end{array}$ & & & \\
\hline $\begin{array}{l}\text { Determine the tidal surface } \\
\text { acceleration }\end{array}$ & $\begin{array}{l}\text { Measure the surface acceleration with an absolute accuracy of } \\
0.01 \mathrm{mGal} \text {. }\end{array}$ & gravimeter & lander & $\begin{array}{l}\text { lifetime of at least one tidal } \\
\text { cycle (one orbital period). } \\
\text { Lander in equatorial region } \\
\left( \pm 30^{\circ}\right) \text { and near to sub- or } \\
\text { anti-Jovian point }\left( \pm 50^{\circ}\right)\end{array}$ \\
\hline \multirow[t]{3}{*}{$\begin{array}{l}\text { Determine the rotation state } \\
\text { of Europa }\end{array}$} & $\begin{array}{l}\text { Determine the mean spin pole direction (obliquity) to better than } \\
10 \text { meters from the static external gravitational field and by } \\
\text { developing an altimetry-corrected geodetic control network ( } \sim 100 \\
\text { points) at a resolution better than } 100 \text { meter/pixel. }\end{array}$ & \multirow{3}{*}{$\begin{array}{l}\text { Laser Altimeter, } \\
\text { Radio Science } \\
\text { Instrument } \\
\text { Radio Science } \\
\text { Instrument } \\
\text { Radio transponder }\end{array}$} & \multirow[t]{3}{*}{$\begin{array}{l}\text { Orbiter } \\
\text { lander }\end{array}$} & \multirow[t]{3}{*}{$\begin{array}{l}\text { quasi-polar orbit, } \\
\text { pericenter altitude } 200 \mathrm{~km} \\
\text { or less, tracking for two } \\
\text { months }\end{array}$} \\
\hline & $\begin{array}{l}\text { Characterise the forced nutation of the spin pole and determine the } \\
\text { amplitude of the forced libration at the orbital period to better than } \\
\text { a few meters from variations in the external gravitational field and } \\
\text { by developing an altimetry corrected geodetic control network at a } \\
\text { resolution better than } 10 \text { meter/pixel }\end{array}$ & & & \\
\hline & $\begin{array}{l}\text { Perform range-rate measurements with an accuracy } \sim 0.01 \mathrm{~mm} / \mathrm{s} \text { at } \\
60 \mathrm{sec} \text { integration time to determine the position of the lander in } \\
\text { time. Determine the obliquity and libration at orbital period to } \\
\text { better than a few meters from tracking the lander. }\end{array}$ & & & \\
\hline \multirow[t]{2}{*}{$\begin{array}{l}\text { Determine the orbital } \\
\text { characteristics of Europa } \\
\text { and its long-term evolution }\end{array}$} & $\begin{array}{l}\text { Determine the position of Europa's center of mass relative to } \\
\text { Jupiter during the lifetime of the mission to better than } 10 \text { meters, } \\
\text { by performing range measurements with an accuracy of } 30 \mathrm{~cm} \\
\text { end-to -end and range-rate measurements with an accuracy } \sim 0.01 \\
\mathrm{~mm} / \mathrm{s} \text { at } 60 \mathrm{sec} \text { integration time to determine spacecraft orbit to } \\
\text { better than 1-meter (rms) throughout the lifetime of the orbiter. }\end{array}$ & \multirow[t]{2}{*}{$\begin{array}{l}\text { Radio Science } \\
\text { Instrument } \\
\text { Radio Science } \\
\text { Instrument, Laser } \\
\text { Altimeter }\end{array}$} & \multirow[t]{2}{*}{ orbiter } & \multirow[t]{2}{*}{$\begin{array}{l}\text { quasi-polar orbit, } \\
\text { pericenter altitude } 200 \mathrm{~km} \\
\text { or less, tracking for two } \\
\text { months }\end{array}$} \\
\hline & $\begin{array}{l}\text { Determine the tidal dissipation in Europa from measurements of } \\
\text { the phase of the tidal Love numbers } \mathrm{h} 2 \text { and } \mathrm{k} 2 \text { with a precision } \\
\text { below } 1 \text { degree. }\end{array}$ & & & \\
\hline Determine locally the depth & Determine the local ice shell thickness from Europan-diurnal & Seismometer/geoph & lander & Range : $0.1-10 \mathrm{~Hz}$, \\
\hline
\end{tabular}




\begin{tabular}{|c|c|c|c|c|c|}
\hline & of Europa's ocean & $\begin{array}{l}\text { cycle seismic activity }(85.2 \mathrm{~h}) \text { with an expected power spectral } \\
\text { density of }-140 /-160 \mathrm{~dB}\end{array}$ & one & & $\begin{array}{l}\text { PSD }<-170 \mathrm{~dB} \\
\text { operating for one month. }\end{array}$ \\
\hline & $\begin{array}{l}\text { Determine the structure and } \\
\text { elastic properties of the ice } \\
\text { shell and the possible } \\
\text { occurrence of water close to } \\
\text { the lander site }\end{array}$ & $\begin{array}{l}\text { Measure Europan-diurnal cycle seismic activity ( } 85.2 \mathrm{~h}) \text { with an } \\
\text { expected power spectral density of }-140 /-160 \mathrm{~dB}\end{array}$ & $\begin{array}{l}\text { Seismometer/geoph } \\
\text { one }\end{array}$ & lander & $\begin{array}{l}\text { Range : } 0.1-10 \mathrm{~Hz} \\
\text { PSD }<-170 \mathrm{~dB} \\
\text { operating for one month. }\end{array}$ \\
\hline & $\begin{array}{l}\text { Determine the structure of } \\
\text { the crust and deeper interior }\end{array}$ & $\begin{array}{l}\text { Determine the gravity field to degree and order } 30 \text { or better by } \\
\text { performing range-rate measurements with an accuracy better than } \\
0.01 \mathrm{~mm} / \mathrm{s} \text { at } 60 \mathrm{sec} \text { integration time. }\end{array}$ & $\begin{array}{l}\text { Radio Science } \\
\text { Instrument } \\
\text { Laser Altimeter }\end{array}$ & orbiter & $\begin{array}{l}\text { quasi-polar orbit, } \\
\text { pericenter altitude } 200 \mathrm{~km} \\
\text { or less, tracking for two }\end{array}$ \\
\hline & & Determine the global topography to degree and order 30 or better & & & months \\
\hline & & $\begin{array}{l}\text { Measure locally (10s of } \mathrm{km}) \text { the surface roughness on footprint } \\
\text { scale between } 1^{\circ} \text { and } 40^{\circ}(50 \mathrm{~m}) \text { with an accuracy better than } 20 \% \\
\text { (TBC) for different geological terrain type }\end{array}$ & & & \\
\hline & & $\begin{array}{l}\text { Test the hypothesis of hydrostatic equilibrium by measuring the } \\
\text { degree } 2 \text { coefficients of the gravity field and topography }\end{array}$ & & & \\
\hline & $\begin{array}{l}\text { Characterize local } \\
\text { subsurface thermo-physical } \\
\text { properties }\end{array}$ & $\begin{array}{l}\text { Measure the thermal inertia of the shallow subsurface, as well as } \\
\text { the roughness and emissivity of the surface. }\end{array}$ & radiometer & lander & $\begin{array}{l}\text { measurements during } \\
\text { several diurnal cycles } \\
(85.2 \mathrm{hrs})\end{array}$ \\
\hline 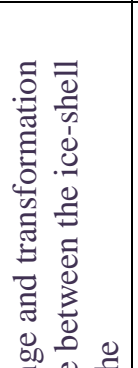 & $\begin{array}{l}\text { Nature of Europa's } \\
\text { exosphere today }\end{array}$ & $\begin{array}{l}\text { Composition (major and trace species). } \\
\text {-Density of the main neutral exospheric species } \\
\text { From few to } 108 \mathrm{~cm}-3 \text { up to } 100 \mathrm{amu} \text { with } \mathrm{M} / \Delta \mathrm{M} \sim 100 \text { and an } \\
\text { energy range of less than few } \mathrm{eV} \\
\text {-Density of the main ion exospheric species } \\
\text { From few } 10-2 \text { to } 104 \mathrm{~cm}-3 \text { up to } 50 \mathrm{amu} \text { with } \mathrm{M} / \Delta \mathrm{M} \sim 50 \text {, and an } \\
\text { energy range from eV to few tens of eV }\end{array}$ & Ion and neutral MS & orbiter & $\begin{array}{l}\text {-Spatial resolution of few } \\
\text { tens of km horizontally } \\
\text { and few km in altitude } \\
\text { from Europa's surface up } \\
\text { to } 1 \text { Europa radius from } \\
\text { the surface } \\
\text {-Full latitudinal and } \\
\text { longitudinal coverage at } \\
\text { few phase angles }\end{array}$ \\
\hline 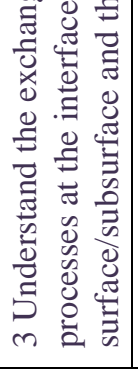 & & 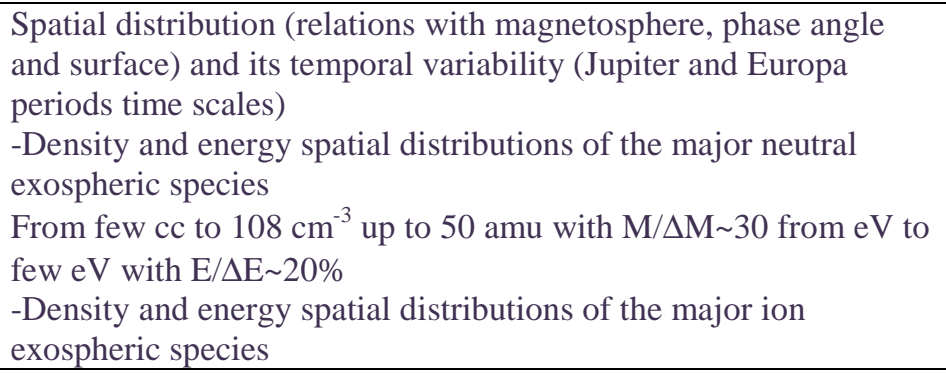 & & & $\begin{array}{l}\text {-Spatial resolution of few } \\
10 \text { 's km horizontally and } \\
\text { few km in altitude from } \\
\text { Europa's surface up to } 1 \\
\text { Europa radius from the } \\
\text { surface } \\
\text {-Full latitudinal and } \\
\text { longitudinal coverage at } \\
\text { few phase angles with a }\end{array}$ \\
\hline
\end{tabular}




\begin{tabular}{|c|c|c|c|c|c|}
\hline & & $\begin{array}{l}\text { From few } 10-2 \text { to } 104 \mathrm{~cm}-3 \text { up to } 50 \text { amu with } \mathrm{M} / \Delta \mathrm{M} \sim 30 \text { from } \mathrm{eV} \\
\text { to one } \mathrm{keV} \text { with } \mathrm{E} / \square \mathrm{E} \sim 20 \%\end{array}$ & & & $\begin{array}{l}\text { temporal resolution from } \\
\text { one hour to few 10s of } \\
\text { hours } \\
\text {-Coverage of Europa's } \\
\text { exosphere during eclipse }\end{array}$ \\
\hline & $\begin{array}{l}\text { What are the main drivers of } \\
\text { exosphere formation? Role } \\
\text { of the magnetosphere /dust. }\end{array}$ & $\begin{array}{l}\text { Ion and electron densities } \\
\text { - From few } 10-2 \text { to } 104 \mathrm{~cm}-3 \text { with } \mathrm{M} / \Delta \mathrm{M} \sim 30 \text { from } \mathrm{keV} \text { to few } \\
\text { tens of } \mathrm{keV} \text { with } \mathrm{E} / \Delta \mathrm{E} \sim 20 \% \\
\text { - Dust density and composition }\end{array}$ & $\begin{array}{l}\text { Ion MS + electron } \\
\text { Spectrometer }\end{array}$ & orbiter & $\begin{array}{l}\text {-Spatial resolution of few } \\
10 \text { 's km horizontally and } \\
\text { few km in altitude for trace } \\
\text { species; of } 100 \text { 's km }\end{array}$ \\
\hline & $\begin{array}{l}\text { What are the main drivers of } \\
\text { exosphere formation? Role } \\
\text { of the Surface /subsurface }\end{array}$ & $\begin{array}{l}\text { Density spatial distributions of the neutral exospheric species } \\
\text { From few to } 108 \mathrm{~cm}-3 \text { up to } 100 \text { amu with } \mathrm{M} / \Delta \mathrm{M} \sim 100 \text { and an } \\
\text { energy range of less than few eV }\end{array}$ & & & $\begin{array}{l}\text { horizontally and } 10 \text { 's km } \\
\text { in altitude for major } \\
\text { species } \\
\text {-Full latitudinal and } \\
\text { longitudinal coverage at } \\
\text { few phase angles with a } \\
\text { temporal resolution of one } \\
\text { hour }\end{array}$ \\
\hline & $\begin{array}{l}\text { Determine the composition } \\
\text { of ejecting compounds from } \\
\text { potential plumes }\end{array}$ & $\begin{array}{l}\text { Measure major volatiles and key organic and inorganic } \\
\text { compounds and compare with the surrounding exosphere to look } \\
\text { for anomalies }\end{array}$ & $\begin{array}{l}\text { Ion and neutral MS } \\
\text { Dust analyzer }\end{array}$ & Orbiter & \\
\hline 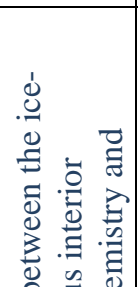 & $\begin{array}{l}\text { Detect any geological } \\
\text { feature which involves } \\
\text { exchange processes between } \\
\text { surface/interior at the } \\
\text { landing site and determine } \\
\text { whether any activity exists } \\
\text { today }\end{array}$ & $\begin{array}{l}\text { Correlation between feature topography, morphology and } \\
\text { materials } \\
\text { Mapping key materials } \\
\text { Measure isotopic relationships to determine the age of materials }\end{array}$ & $\begin{array}{l}\text { Imaging camera } \\
\text { Geophone } \\
\text { GCMS } \\
\text { Laser altimeter }\end{array}$ & $\begin{array}{l}\text { Lander/ } \\
\text { orbiter }\end{array}$ & $\begin{array}{l}\text { Altimetry from the orbiter } \\
\text { Images from the local site }\end{array}$ \\
\hline 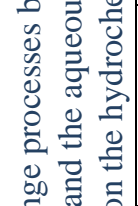 & $\begin{array}{l}\text { Characterize the } \\
\text { biosignature preservation } \\
\text { potential (BPP) of } \\
\text { accessible surface materials } \\
\text { at the landing site }\end{array}$ & $\begin{array}{l}\text { Measure the radiation dose and magnetic field intensity that affect } \\
\text { the compounds at the landing site }\end{array}$ & $\begin{array}{l}\text { Magnetometer } \\
\text { Radiometer }\end{array}$ & Lander & $\begin{array}{l}\text { In situ analysis on landing } \\
\text { spot }\end{array}$ \\
\hline 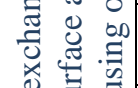 & $\begin{array}{l}\text { Characterize the physical } \\
\text { properties at the landing site }\end{array}$ & $\begin{array}{l}\text { Determine the grain size, porosity and mineral crystallinity of the } \\
\text { regolith and the fresh materials underneath }\end{array}$ & $\begin{array}{l}\text { Microscope, } \\
\text { Imaging camera }\end{array}$ & Lander & $\begin{array}{l}\text { In situ analysis on landing } \\
\text { spot }\end{array}$ \\
\hline 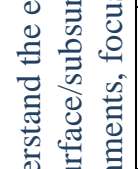 & $\begin{array}{l}\text { Characterize the habitability } \\
\text { key compounds of the near } \\
\text { surface }\end{array}$ & $\begin{array}{l}\text { Identify phase minerals (e.g. salt hydrates, phyllosilicates, } \\
\text { clathrate hydrates, oxides), organics, volatiles }\end{array}$ & $\begin{array}{l}\text { Raman } \\
\text { spectrometer, } \\
\text { GCMS, } \\
\text { thermogravimeter }\end{array}$ & Lander & $\begin{array}{l}\text { Near-surface sampling } \\
\text { /analysis (solid state) }\end{array}$ \\
\hline 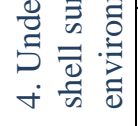 & $\begin{array}{l}\text { Characterize the wet context } \\
\text { of exchanging materials }\end{array}$ & $\begin{array}{l}\text { Measure physical chemical parameters of the melt ice: } \mathrm{pH} \text {, redox, } \\
\text { conductivity, ions, volatiles }\end{array}$ & $\begin{array}{l}\text { Electrochemical } \\
\text { sensors }\end{array}$ & Lander & $\begin{array}{l}\text { Sampling/analysis in liquid } \\
\text { state of the } \\
\text { surface/subsurface material }\end{array}$ \\
\hline
\end{tabular}




\begin{tabular}{|c|c|c|c|c|c|}
\hline \multirow{6}{*}{ 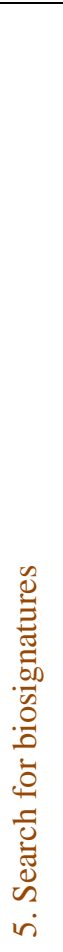 } & Identify general biomarkers & $\begin{array}{l}\text { Identify D/L aa, PAHs, Short peptides, Anti-freezing peptides and } \\
\text { sugars, EPS from psychrophilic microbes, Cold shock proteins } \\
\text { (Concentration < 10ppb) }\end{array}$ & $\begin{array}{l}\text { Microarray } \\
\text { immunoassay } \\
\text { detector }\end{array}$ & lander & $\begin{array}{l}\text { Sampling/analysis in liquid } \\
\text { state of the } \\
\text { surface/subsurface } \\
\text { material. }\end{array}$ \\
\hline & $\begin{array}{l}\text { Detect and characterize any } \\
\text { organic indicator of past or } \\
\text { present life }\end{array}$ & $\begin{array}{l}\text { Identify organics, including some monomers of biomolecules } \\
\text { (amu TBC, e.g. hydrocarbons, aa) in the near surface and in the } \\
\text { potential plumes }\end{array}$ & $\begin{array}{l}\text { GCMS } \\
\text { Raman spec. } \\
\text { thermogravimeter } \\
\text { (only for } \\
\text { hydrocarbons) } \\
\text { Ion and neutral MS }\end{array}$ & $\begin{array}{l}\text { Lander/ } \\
\text { orbiter }\end{array}$ & $\begin{array}{l}\text { Near-surface } \\
\text { sampling/analysis (solid } \\
\text { state) } \\
\text { Get face to the potential } \\
\text { plumes }\end{array}$ \\
\hline & $\begin{array}{l}\text { Identify and characterize } \\
\text { morphological and textural } \\
\text { indicators of life }\end{array}$ & $\begin{array}{l}\text { Identify cellular structures and biogenic fabrics on near-surface } \\
\text { minerals }\end{array}$ & $\begin{array}{l}\text { Microscope } \\
\text { Raman } \\
\text { spectrometer }\end{array}$ & lander & $\begin{array}{l}\text { In situ analysis on landing } \\
\text { spot (solid state) }\end{array}$ \\
\hline & $\begin{array}{l}\text { Detect and characterize any } \\
\text { inorganic indicator of past } \\
\text { and present life }\end{array}$ & $\begin{array}{l}\text { Measure isotopic ratios, biominerals, decomposition temperature } \\
\text { of minerals }\end{array}$ & $\begin{array}{l}\text { GCMS, Raman } \\
\text { spectrometer } \\
\text { thermogravimet } \\
\text { er }\end{array}$ & lander & $\begin{array}{l}\text { Near-surface } \\
\text { sampling/analysis (solid } \\
\text { state) }\end{array}$ \\
\hline & $\begin{array}{l}\text { Determine the provenance } \\
\text { of sampled material }\end{array}$ & Isotopic ratios, association with geological features & $\begin{array}{l}\text { Imaging camera, } \\
\text { GCMS, Raman } \\
\text { spectrometer }\end{array}$ & lander & $\begin{array}{l}\text { Near-surface } \\
\text { sampling/analysis (solid } \\
\text { state) }\end{array}$ \\
\hline & $\begin{array}{l}\text { Determine if living } \\
\text { organisms persist in } \\
\text { sampled materials }\end{array}$ & $\begin{array}{l}\text { Measure the release of metabolic products from features in the } \\
\text { near surface }\end{array}$ & $\begin{array}{l}\text { GCMS, Raman } \\
\text { spectrometer }\end{array}$ & lander & $\begin{array}{l}\text { Near-surface } \\
\text { sampling/analysis(solid or } \\
\text { liquid) }\end{array}$ \\
\hline
\end{tabular}




\section{No conflict of interest statement}

The authors declare that they have no known competing financial interests or personal relationships that could have appeared to influence the work reported in this paper. 